IZA DP No. 7464

Trust, Growth and Well-being: New Evidence and Policy Implications

Yann Algan

Pierre Cahuc

June 2013 


\title{
Trust, Growth and Well-being: New Evidence and Policy Implications
}

\author{
Yann Algan \\ Sciences Po \\ and IZA \\ Pierre Cahuc \\ ENSAE-CREST, Ecole Polytechnique, \\ IZA and CEPR \\ Discussion Paper No. 7464 \\ June 2013 \\ IZA \\ P.O. Box 7240 \\ 53072 Bonn \\ Germany \\ Phone: +49-228-3894-0 \\ Fax: +49-228-3894-180 \\ E-mail: iza@iza.org
}

\begin{abstract}
Any opinions expressed here are those of the author(s) and not those of IZA. Research published in this series may include views on policy, but the institute itself takes no institutional policy positions. The IZA research network is committed to the IZA Guiding Principles of Research Integrity.

The Institute for the Study of Labor (IZA) in Bonn is a local and virtual international research center and a place of communication between science, politics and business. IZA is an independent nonprofit organization supported by Deutsche Post Foundation. The center is associated with the University of Bonn and offers a stimulating research environment through its international network, workshops and conferences, data service, project support, research visits and doctoral program. IZA engages in (i) original and internationally competitive research in all fields of labor economics, (ii) development of policy concepts, and (iii) dissemination of research results and concepts to the interested public.
\end{abstract}

IZA Discussion Papers often represent preliminary work and are circulated to encourage discussion. Citation of such a paper should account for its provisional character. A revised version may be available directly from the author. 


\section{ABSTRACT \\ Trust, Growth and Well-being: New Evidence and Policy Implications*}

This survey reviews the recent research on trust, institutions and growth. It discusses the various measures of trust and documents the substantial heterogeneity of trust across space and time. The conceptual mechanisms and the methods employed to identify the causal impact of trust on economic performance are reviewed. We document the mechanisms of interactions between trust and economic development in the realms of finance, innovation, the organization of firms, the labor market and the product market. The last part reviews recent progress to identify how institutions and policies can affect trust and well-being.

JEL Classification: O11, O43, Z13

Keywords: $\quad$ trust, growth, institutions, well-being

Corresponding author:

Pierre Cahuc

Laboratoire de Macroéconomie

CREST

15 Boulevard Gabriel Péri

92245 Malakoff Cedex

France

E-mail: pierre.cahuc@gmail.com

\footnotetext{
* This paper is forthcoming in the Handbook of Economic Growth, edited by Philippe Aghion and Steven Durlauf, Elsevier, 2013.

We thank Ernst Fehr, Paola Guiliano, John Helliwell, Andrei Shleifer and Mathias Thoenig for their helpful comments. We also thank Johannes Buggle for his outstanding work as a research assistant for this article. Yann Algan acknowledges financial support from the ERC Starting Grant 240923 under the European Community Seventh Framework Programme (FP7/2007-2013).
} 
There are countries in Europe ... where the most serious impediment to conducting business concerns on a large scale, is the rarity of persons who are supposed fit to be trusted with the receipt and expenditure of large sums of money. Stuart Mill, 1848, p. 132

\section{Introduction}

The debate about the roots of economic development and the origins of income inequality across the globe has deeply evolved over time. Early researches focused on the proximate factors of growth, stressing the role of technological progress and the accumulation of human and physical capital. A decade ago, the focus shifted to the role of formal institutions, considered as the endogenous incentives to accumulate and innovate (Acemoglu et al., 2001); and to what extent those institutions could be distinguished from factors like human capital (Glaeser et al., 2005). More recently, the attention has been gradually evolving towards deeper factors, ingrained in culture or long-term history.

This survey reviews some strands of the recent research on the role of cultural values in economic development (see Nunn, 2009; and Spolaore and Wacziarg, 2013 for surveys on longterm history). In particular, we investigate the role of one the most fundamental cultural value that could explain economic development: trust. Since the path breaking work of Banfield (1957), Coleman (1974) and Putnam (2000), trust, broadly defined as cooperative attitude outside the family circle, was considered as a key element of many economic and social outcomes by social scientists. Yet, while praised in other social sciences, the role of trust in the mainstream economic literature has long been disputed.

The potential role of trust in economic development had naturally attracted some interest decades ago, no doubt for the reason stated by Arrow (1972): "virtually every commercial transaction has within itself an element of trust, certainly any transaction conducted over a period of time. It can be plausibly argued that much of the economic backwardness in the world can be explained by the lack of mutual confidence." Arrow's intuition was straightforward. In a complex society, it is impossible to write down and enforce detailed contracts that encompass all the state of natures for economic exchanges. Ultimately, in absence of informal rules like trusting behavior, markets are missing, gains from economic exchanges are forgone and resources are misallocated. To that respect, trust and the informal rules shaping cooperation could explain differences in economic development.

But the theoretical and empirical foundations of the relationship between trust and 
growth has long been considered as weak, at best. A good illustration of the state of the art one decade ago is given by the former issue of the Handbook of Economic Growth in 2005. In the chapter devoted to social capital, Durlauf and Fafchamps outlined powerfully all the conceptual and statistical flaws raised by the notion of trust in the economic literature. The concept of social capital, a buzzword according to Solow, raised a lot of ambiguity by encompassing vague concepts as norms, networks or cooperation. Besides, the authors documented forcefully the identification issued raised by the few cross-country or cross-regional correlation between social capital and growth (see also Durlauf for a critical assessment of the empirical literature on social capital, 2002).

In this chapter, we show that decisive and large progress have been made on those different dimensions to give a central role to trust in mainstream economics, and more particularly for explaining economic development. This chapter has five main goals. First we outline a unified conceptual framework for thinking about how trust and cooperation can increase economic efficiency. We distinguish the specific role of trust, relative to reputation incentives, to overcome market failures. Second, we review the various methods to measure trust and cooperation empirically. The recent development of experimental economics, combined with an increasing number of social surveys, has helped to clarify what trust is and how it differs from other beliefs and preferences. Third, we document the empirical relationship between trust, income per capita and growth. We review the recent advances to identify a causal impact of trust on economic outcomes. Recent empirical work confirms what Arrow posited: trust does indeed appear to constitute a decisive determinant of growth. This observation is buttressed at present by a range of contributions that not only have shed light on the correlations between these two variables, but have also elaborated strategies for detecting the ways in which trust may affect growth. Fourth, we review the burgeoning literature that focuses on the channels of influence of trust: from financial, product and labor markets to innovation and the organization of firms. Fifth, we document more recent research looking at how institutions and trust co-evolve, and how public policy could boost pro-social behaviors.

Several surveys to date have analyzed the role of social capital and trust in economics (see Guiso et al., 2008c and 2011; Tabellini, 2008a; Fehr, 2009 and Bowles and Polania-Reyes, 2012, among others). The present addition to the literature is specific in three ways. First, we focus on the relations between trust, growth, and institutions and we utilize the most recent assemblages of data on values, which allow us to cover more than $90 \%$ of the world population. Second, we take full account of the progress made during the last decade in identifying the impact of trust, or inherited trust, by deploying as instruments events of an essentially historical kind. Recent 
research allows us to pinpoint more closely the mechanisms by which transmission of trust affects the economy, and to distinguish its various channels. Lastly, we present a synthesis of research on how political and economic institutions interact with trust. We also review the various factors and policies that have been found to affect trust, such as the transparency of institutions, the extent of inequality or education and early childhood intervention.

The remainder of the chapter is organized as follows. The first part outlines the theoretical mechanisms that explain the influence of trust on economic performance. The second part discusses the various measures of trust and documents the international and interregional heterogeneity of trust, using surveys that furnish rich sets of data going back to the start of the 1980s. The third part is a presentation of the dynamics of trust, stressing that in general it evolves slowly from one generation to the next. This inertia, which may nevertheless be perturbed by major historical events such as wars, is observable both at the individual level and at the macrosocial level. Part four presents the methods employed to identify the causal impact of trust and provides an empirical illustration of the relation between trust and economic development. Part five describes the mechanisms by which trust has an impact on growth. Part six analyzes the interaction of trust with formal institutions and policies and discusses how trust can be built. Eventually, part seven concludes this chapter by discussing the new perspectives provided by recent research showing that well-being depends not only on income but also, and foremost, on the quality of social relationships.

\section{1/ Theoretical foundations}

We begin by providing a conceptual framework that rationalizes the relationship between trust and economic performance. We then document the theoretical channels through which trust interacts with the institutional environment and can emerge as a stable equilibrium.

For trust to have an economic impact and to improve efficiency, one has first to consider the reasons why the economy would depart from the first-best allocation in absence of trust. In his analysis of the limits of organization, Arrow (1972) considers trust as co-substantial to economic exchange in presence of transactions costs that impede information and contracts. Fundamentally, the economic efficiency of trust flows from the fact that it favors cooperative behavior and thus facilitates mutually advantageous exchanges in presence of incomplete contracts and imperfect information. In Arrow's term, trust would act as a lubricant to economic exchange in a second-best allocation.

This remark raises various questions. How can we rationalize the impact of trust on 
economic exchange? How can trust emerge and be sustained in economic exchanges? Why shall we expect trust rather than institutions to overcome these market imperfections?

To address those issues, we start from a simple example inspired from the trust game of Berg et al. (1995), where each participant is an investor. We show that cooperation cannot emerge in absence of reputation, which is at odds with the insights of behavioral economics which documents that individuals do often cooperate with anonymous other in one-shot exchange. It is thus necessary to include trust as an additional characteristic to rationalize cooperation. We then discuss how trust evolves and is transmitted to become a stable equilibrium. We also document the interaction between trust and institutions to explain economic exchanges.

\subsection{Cooperation and Reputation}

Let us consider two individuals, both of whom are free to invest-or not—an irrecoverable sum I $>0$ that will enable them to produce jointly. Only by mutual agreement do they invest. Once they do, the incompleteness of contracts, arising out of the complexity of the association which makes it impossible for a third party to verify that everything promised is performed, gives each player the chance to profit from the association at the expense of the other. Hence each player has the option of investing or not at the outset, and of cooperating or defecting subsequently. Production is positive only if the two individuals invest. If the two players cooperate, their investment yields production amounting to $2(\mathrm{Y}+\mathrm{I})>0$, divided into equal shares such that each obtains a gain, net of the cost of the investment, amounting to $Y>0$. If neither cooperates, production is zero and the sum each invested is entirely forfeited. Finally, if one cooperates while the other defects, the one who defects preempts the production to his advantage and obtains a net gain of $2 \mathrm{Y}+\mathrm{I}$, while the one who cooperated forfeits his initial investment entirely. The gains are represented in Table 1. The Nash equilibrium of this game is an absence of cooperation entailing that the players have no interest in participating, since the anticipated gains are systematically negative. This model illustrates the fact that the absence of cooperation may prevent mutually advantageous exchanges from coming about.

The possibilities of cooperation arising between individuals interacting in this type of game have been explored through random matching games based on purely rational individuals encountering one another at random (Kandori, 1992, Ellison, 1994). The horizon of these random matching games is infinite: in each interval each player takes part in a prisoner's dilemma game with a fresh partner drawn at random from the population. Anonymity is retained to the 
horizon of the game. It is demonstrable that cooperative solutions can emerge as subgame perfect equilibria if the population and the players' preference for the present are sufficiently small. Equilibrium strategies consist of no longer cooperating, or of cooperating less often, in all future encounters, once a player has participated in a game in which cooperation was chosen by neither partner. It is the threat of a future surge of non-cooperative behavior that may act as an incentive to cooperation at each interval. These results tell us that the spontaneous emergence of cooperative behavior in populations of large size is improbable if each individual is a pure homo economicus and they all interact anonymously.

In this setting, cooperation can only emerge as a reputation devise and in presence of punishment. Greif (1993, 1994), in his analysis of the Maghribi and Geneose traders, or Dixit (2004), have shown that the transmission of information, and the coordinated implementation of strategies intended to punish those caught defecting, might facilitate cooperation. Cooperation may exist in the absence of any formal institution defining legal rules if the size of the population and the preference for the present are sufficiently small. If these conditions are unmet, however, formal institutions explicitly laying down legal rules and sanctions are needed in order to sustain cooperation.

The value of such analyses is that they illuminate the role of coordination and of formal institutions. But they cannot account for the cooperative behavior often experimentally observed to arise in anonymous, non-repetitive games. In particular, Bowles et al. (2005) show that individuals from various societies display cooperation in games absent any reputational considerations (see the synthesis of Fehr, 2009; and Bowles and Gintis, 2007).

\subsection{Cooperation and Other-regarding preferences}

To rationalize the existence of cooperation in absence of reputation, the economic literature has incorporated the insights from research in psychology, social science and behavioral economics showing the existence of an intrinsic motivation linked to cooperation (see the synthesis by Bowles and Polania-Reyes, 2012; Kahneman and Tversky, 2011). Individuals are motivated by more than material payoffs and value the act of cooperating per se. They have "warm glow preferences" or concerns for reciprocity that favor cooperation.

To modelize this behavior, François and Zabojnick (2005), Tabellini, (2008b), Algan and Cahuc (2009), Bidner and Francois (2011), Michau (2012), and others, suppose that from non cooperation there may flow psychological costs. A variant consists of supposing a preference for reciprocity: individuals are altruistic with others who display cooperative behavior, but may sanction those who do not respect cooperative norms (Fehr and Schmidt, 1999; Fehr and 
Gaetcher, 2000; Gintis et al, 2005; Hoff et al., 2011). In all these setting, individuals are assumed to have other-regarding preferences, and not just self-regarding preferences, which allow cooperation to emerge in groups of anonymous and with substantial size (see Bowles and Gintis for a synthesis, 2007)

On the assumption that there do exist psychological costs from non cooperation, we can modify the payoffs of the trust game described above by adding a cost from non cooperation. In this setting, cooperation becomes a Nash equilibrium in the previous game described by the payoff matrix above, if the costs from non cooperating, denoted $\mathrm{C}$, is superior to the net individual gain from non cooperation $Y+I$. The term $C$ may be influenced by social and cultural norms, by education, or by the social distance between individuals. For example, Tabellini (2008b) assumes that the psychological costs from non cooperation decreases with social distance: all those sufficiently close cooperate among themselves, but they adopt non-cooperative strategies with those more distant. This assumption is consistent with evidence that individuals tend to distrust more those who are more dissimilar than themselves (see Alesina and La Ferrara, 2002).

In this setting, to trust another individual at any one iteration is to embrace the belief that the others taking part in the game are choosing cooperation, that they are, in other words, trustworthy. It is possible to analyze the role of trust in a random matching game where a portion of the population is trustworthy. The trustworthy persons cooperate systematically. Each person knows whether he himself is trustworthy or untrustworthy, but this private information is not available to the others. When two persons meet up, they may decide to go ahead and invest, or pass on the opportunity, in which case they get a payoff equal to zero. If they do go ahead, the trustworthy partners systematically cooperate since not to do so is too costly for them. Conversely the untrustworthy and purely opportunistic persons always choose to defect.

This modified game can rationalize the existence of cooperation, that is trust, as a Nashequilibrium. To show it, let us denote by $s$ the portion of trustworthy persons in the population. The expected gain of a trustworthy person who invests amounts to $s Y-(1-s) I$, which implies that such persons invest if the trustworthy portion of the population is superior to $s>I /(Y+I)$. If this condition is unmet, no one has a reason to invest, as all persons who do want to go ahead and invest are necessarily untrustworthy. There are in consequence two possible equilibria depending on the values of $s$. Either no one invests, if $s<I /(Y+I)$, or in the contrary eventuality, everyone does. Investment, production, and exchange thus increase with the portion of trustworthy persons in the population, and consequently with trust in others.

Assuming that trust emerges because certain persons are spontaneously cooperative has 
the advantage of explaining with simplicity why it is that cooperation may arise out of anonymous, non-repetitive interactions. This explanation provides a simple framework to analyze the determinants of trust and its role in the functioning of the economy.

\subsection{Dynamics of Cooperation}

How does cooperation evolve over time? How can cooperative values persist in certain environment and disappear in others? To address this issue, recent works endogenize the transmission of values, along the seminal work of Bisin and Verdier (2001) stressing the role of family transmission. Parents may inculcate moral values into their children, but these childrearing choices pose coordination problems, for being honest only pays if others are being honest too. The more other parents are inculcating moral values that will render them trustworthy as adults into their children, therefore, the better an option it becomes to raise your children that way too. Building on Hauk and Saez-Marti (2002), François and Zabojnick (2005), Tabellini, (2008b), Aghion et al. (2010), Bidner and François (2011), we show how such a mechanism might work by introducing education into our model.

Let us assume that the parents get psychological gains, denoted by $G>0$, an expression of utility, for inculcating honesty-based values into their children and thus ensuring that as adults they will systematically be cooperative. In this context, trustworthy adults bear, as before, a psychological cost $C>Y+I$, when they behave dishonestly. Parents get the psychological gain only if their children do behave cooperatively, i.e. do invest. When children do not invest, or in other words, do not display their cooperative behavior, parents do not derive any gain from the values that have been inculcated.

Parents opt for values that maximize the expected utility of their offspring plus their utility gains obtained from inculcating honestly-based values, in the knowledge that each of those children will in turn be randomly encountering others and having to decide whether to go ahead and invest with them or not. The parents payoff to inculcate honestly based value equals $G+s Y-(1-s) I$, if $s>I /(Y+I)$ and to zero otherwise since their children invest when adult only if $s>I /(Y+I)$. Parents who do not inculcate such values get $s(2 Y+I)-(1-s) I$ if if $s>I /(Y+I)$ and to zero otherwise. The expected gains of education depend on the proportion of trustworthy persons in the generation of the children. It is optimal to bring your own up honestly if the offsetting gains are expected to be equal or greater., i.e. if $G>s(Y+I)$ and $s>I /(Y+I)$. If this condition is not fulfilled, parents have no incentives to inculcate honesty-based values into children. There will thus be no investment: an economy populated with persons rendered untrustworthy by their upbringing will arrive at a "bad" and feebly productive equilibrium. On the other hand, if one is convinced that 
the upbringing the other children are receiving from their parents is honesty-based, there may be utility in bringing one's own up the same way. In this case, the economy arrives at a "good" equilibrium, with trustworthy persons and augmented investment and production.

The array of equilibria arrived at in the models of François and Zabojnick (2005), Tabellini (2008b), Aghion et al. (2010) and Bidner and François (2011) highlight the fragility of the mutual confidence that flows from settling at a good equilibrium. This approach also brings into focus the interaction between moral values and institutions. For example, Aghion et al. (2010) assume that a government elected by majority vote may lay down regulations meant to facilitate mutually advantageous exchange, for the purpose of countering the low levels of spontaneous cooperation that are a concomitant of populations with relatively small proportions of trustworthy persons in their midst. But these regulations give rise to significant corruption precisely because the proportion of trustworthy persons is small, which keeps distrust alive. Distrust and corruption nourish each other and lead on to bad equilibria characterized by weak production and highly burdensome regulation.

Let us enrich this perspective by introducing a dynamic dimension. Let us assume that the gains from inculcating honestly-based values increases as the proportion of trustworthy parents rises. This might be because children are influenced not only by the upbringing they received from their parents, but also by that received from others encountered outside the family circle. Cavalli-Sforza and Feldman (1981) distinguish three modes in which values may be imparted: vertical, oblique, and horizontal. The vertical mode corresponds to transmission from parents to children. The transmission is oblique when the influence comes from adults other than the parents. Horizontal transmission is what those of the same generation have in common. Guiso et al. (2008c) set forth a model that represents several simultaneous modes of transmission, assuming that parents impart beliefs to their children as to the trustworthiness of others, and that children revise this belief set as a function of those whom they encounter. The economy may then be blocked at a "bad" equilibrium without production, if the beliefs imparted by the parents are too pessimistic, for mutual distrust may impede all exchange (in the game above: everyone passes on the opportunity to invest), and thus stifle all possibility of testing and revising inherited beliefs. Such dynamic sequences have the merit of accounting for the intergenerational transmission of trust empirically observed (Dohmen et al. 2012). They may also explain not only the persistent effect of trust-destroying shocks like the onset of the slave trade in west Africa (Nunn and Wantchekon, 2011), bad colonial institutions (Acemoglu et al., 2001), and legal origins (La Porta et al. 2008), but also the persistent effects of positive shocks like the presence of 
participatory institutions in the free communes of the Italian Middle Ages (Putnam, 1993, Guiso et al. 2008b).

\section{2/ Empirical Measures of trust}

To measure the impact of cooperative values on economic development and institutions, one has to define the empirical counterpart of the trusting behavior at play in the previous theoretical games.

\subsection{Definition of trust}

Research on the relationship between trust and growth focuses essentially on generalized trust, in other words on relations among individuals who are not bound by the kind of personal ties that bind members of the same family, or fellow workers. In this context, the generally used definition of trust is taken from Coleman (1990), according to whom "an individual trusts if he or she voluntary places resources at the disposal of another party without any legal commitment from the latter, but with the expectation that the act of trust will pay off'. One of the advantages of this approach is to define trust as a behavior that can be directly measured with experimental games, as shown by Fehr (2009). Defined this way, trust is also linked to the notion of social capital utilized by Fukuyama (1995), Putnam (2000) and Guiso et al. (2011), for whom social capital is the ensemble of "those persistent and shared beliefs and values that help a group overcome the free rider problem in the pursuit of socially valuable activities."

\subsection{Measures of trust}

Trust can be measured by using surveys and laboratory experiments. Empirical research investigating the link between growth and trust usually draws on answers from survey questions. The reason for this is the availability of surveys, which cover a large number of countries since the beginning of the 1980s. Nevertheless, these surveys evoke difficulties in interpretation. Besides the polysemy of questions and responses, it is not sure that the individuals who declare to have strong trust in others actually behave in a more cooperative way. For that reason, researchers have undertaken laboratory experiments as well as field experiment paired with surveys, in order to better capture their scope.

\section{a) Surveys}

In surveys, the measure of trust is most often measured with the "generalized trust question," first introduced by Almond and Verba (1963) in their study of civil society in post-war 
Europe. This question runs as follows: "Generally speaking, would you say that most people can be trusted, or that you can't be too careful when dealing with others?" Possible answers are either "Most people can be trusted" or "Need to be very careful." The same question is used in the European Social Survey, the General Social Survey, the World Values Survey, Latinobarómetro, and the Australian Community Survey. Surveys generally include other questions related to trust. For instance, the WVS asks the "fair question": "Do you think most people would try to take advantage of you if they got the chance, or would they try to be fair?". The GSS includes the trust question, the fair question and adds the "help question": "Would you say that most of the time people try to be helpful, or that they are mostly just looking out for themselves?". These different questions are sometimes used to build indexes that intend to provide alternative measures of trust or get an average indicator of moral values or civic capital (Tabellini, 2010; Guiso et al., 2011).

The resulting survey data supply us with subjective information that certainly demands cautious interpretation. These questions raise concerns of interpretation. In particular, individuals who respond that you need to be very careful to the trust question could be motivated by a strong aversion against risk (see for these topics, Fehr, 2009, Bohnet and Zeckhauser, 2004 et Guiso et al. 2010). However, most important for investigating empirically the relation between growth and trust is to know whether the responses to the trust question are linked to actual cooperative behavior.

\section{b) Experimental games in the lab}

Contributions have analyzed the relation between responses to the trust questions or to connected questions and the behavior in experimental games. In general, these works use variants of the "investment game", known also under the name "trust game", of Berg et al. (1995) presented above. In laboratory experiments, this game is played as follows. In stage 1, the subjects in rooms A and B are each given 10 dollars as a show-up fee. While subjects in room B pocket their show-up fee, subjects in room A must decide how much of their 10 dollars to send to an anonymous counterpart in room $\mathrm{B}$. The amount sent, denoted by $\mathrm{M}$, is tripled resulting in a total return $3 \mathrm{M}$. In stage 2 , a counterpart in room $\mathrm{B}$ is given the tripled money and must decide how much to return. One measures "trust in others", as defined by Coleman (1990), by the amount sent initially by the sender. Trustworthiness is measured by the amount sent back by the player in room B.

The first contributions that analyzed the relationship between survey-answer from the generalized trust question and the amount sent in the trust game found mixed results. Glaeser et al. (2000) have measured the relation between questions related to trust in surveys and the 
behavior of participants in trust games. This study was carried out at Harvard University, where 274 students were asked the trust question before they played the trust game either in the role as a sender or receiver. The authors find that although questions about trusting attitudes do not predict trusting behavior, such questions do appear to predict trustworthiness. Holm and Danielson (2005) find a positive correlation between behavior in games and answers to the trust question in Sweden, but not in Tanzania. Lazzarini et al. (2004) find a correlation for face-to-face non-anonymous trust games in Brazil. Other experiments have been run on representative survey, with also contrasting results. While Fehr et al. (2002) find that the trust question does predict trusting behavior but not trustworthiness, Ermish et al. (2009) find exactly the opposite results on a representative sample of the British population.

These results are difficult to compare, as the designs of the games are not perfectly identical between the different experiments. While in the game organized by Glaeser et al., the second movers do not receive any initial payment, in the game of Berg et al. all participants get a show-up fee. This could explain, why a great fraction (70\%) of first movers send all their initial endowment to the second movers in the experiment of Glaeser et al. To measure the level of trust, it thus reveals to be necessary to distinguish this component from other attitudes, such as risk aversion, altruism and reciprocal behavior. In addition, do trusting behavior measured during those different experiments really capture deep-seated preferences, or do they just relate to beliefs about the level of civicness of others, which can be quickly revised?

This kind of behavior observed in experiments might be as much motivated by altruism as by trust, in the sense of the definition by Coleman. With regard to the positive correlation between the responses to the trust questions and the amounts send back by the second mover, this correlation could be the consequence of a concern about reciprocity, characterizing the individuals who declare themselves to trust strongly. Thus, the absence of a correlation between the responses to the trust question and the amounts sent by the first movers in the study of Glaeser et al., does not necessarily imply that the trust questions it not correlated with trust in the sense of Coleman, because the amounts sent by the senders are probably strongly influenced by motivations of altruism.

Cox (2004) has proposed an experimental design with the goal of identifying the relative contributions of trust and altruism to the amounts sent in the first stage of the trust game. To achieve this, he compares the results of a trust game, as described above, with those of a dictator game, in which the only difference to the trust game is the absence of a decision of the second movers: thus, they do not have an opportunity to return any money that they receive. The 
dictator game serves to measure altruism, whereas trust is measured by the difference between the amount sent during the first stage of the trust game and the amount sent in the dictator game. The experiments conducted by Cox show that the trust motive in fact exists, in addition to altruism. The experimental design created by Cox also allows us to identify motives of reciprocity, by comparing the amounts returned in the second stage of the trust game with those sent in a game which differs from the trust game. Here too, the experiments realized by Cox shows the existence of reciprocity.

Cox's design allows us to distinguish between motives of altruism, trust and reciprocity. Capra et al. (2008) have used this design to analyze the relation between those motives as defined above and attitudes gained from answers to survey questions by conducting experiments with students from Emory University. They find the same results as Glaeser et al. concerning the trust question, that is the responses are not correlated with the amounts sent by the first movers, but with the amounts sent back by the second movers, which sent back more the stronger they declare themselves trusting others in the survey.

However, this correlation disappears as soon as the level of altruism is controlled for. Besides, the amounts sent by the first movers are well correlated with the responses to the "help question" or the "fair question" when altruism is controlled for. Responses to the trust question are not correlated significantly with the amounts sent by the first movers, but the sign of the coefficient indicates an increasing relation between declared trust and the amounts sent. It is possible that the absence of a significant relation results from the low number of observations (62), which is especially problematic for the trust question, whose wording is particularly vague. In short, this contribution suggests an experimental design which distinguishes the motives of trust, altruism and reciprocity, allowing to identify coherent relations between attitudes declared in answers to survey questions and actual behavior in trust games.

Other studies have also made use of neurobiological methods to measure with greater precision the role of trust in comparison with other individual characteristics in the behavior of participants of the trust game. It is known that oxytocin, a hormone released especially during breast-feeding and delivery, is associated with sentiments of affinity and socialization. In particular, research in neurobiology has shown that this hormone plays a central role in behavior related to social connectivity, such as parental and couple relations. Additionally, this hormone reduces significantly stress and anxiety in situations of social interaction. It is known for deactivating the transmission of feelings of anxiety related to the belief of being betrayed. Kosfeld et al. (2005) have had the ingenious idea to evaluate the effect of oxytocin on pro-social 
behavior of individuals participating in trust games. The authors proposed furthermore additional experimental designs to distinguish the pro-social preferences from risk-taking behavior and from beliefs like the level of optimism of the participants. The participants in this study were randomly allocated into two groups. The first group inhaled oxytocin through a spray, the second inhaled a placebo and served as the control group. The results of this experiment is illuminating. Those individuals who received oxytocin tend to display stronger behavior of trust. What is even more remarkable, is that those individuals continue to behave trustingly in the exchange with the others, even if the later do not show any reciprocity. By contrast, other attitudes, such as prudence and risk-aversion, or even other beliefs such as optimism in the actions of the others, are not affected. Kosfeld et al. (2005) conclude that the trust game measures veritable preferences for cooperation, and not risk-aversion or anticipations of the others' actions (see Fehr, 2009, for a survey on experimental measures of trust).

\section{c) Experimental games in the field}

Obviously, the presence of a relation between survey answers and behavior in trust games does not imply that answers to survey questions allow us to predict daily behavioral patterns, in so far as the latter can be different from those observed in laboratory experiments. We still know very little, however, about whether and to what extent the experimental results established in the lab carry over to field situations. At this stage, it thus seems key to investigate the relationship between the experimental measures usually elicited in the lab and the field outcomes of interest if we are to rely on the experimental method to make inferences about the real world.

In his pioneering work, Karlan (2005) uses the trust game to obtain individual measures of taste for reciprocity, and shows that it can be used to predict loan repayment among participants, up to one year later, in a Peruvian microcredit program. De Oliveira et al. (2009a) elicit subjects' taste for cooperation in the lab using a traditional public goods game. They show that the results are correlated with subjects' contributions to local charities in a donation experiment and with whether they self-report contributing time and/or money to local charitable causes. Similarly, Laury and Taylor (2008) use public goods games to elicit their subjects' taste for cooperation and show that it is associated with the probability to contribute to a field public good in a donation experiment. One prominent limitation of these two studies is that they both obtain information about "field" behavior in the lab itself, either through contextualized experiments or self-reports. In this case, one might worry about possible spurious correlations caused by demand effects and/or individuals' willingness to remain self-consistent. Still relying on highly contextualized donation experiments, Benz and Meier (2008) address part of this concern by collecting field data about their subjects' 
behavior in a charitable giving situation prior to conducting a charitable giving experiment in the classroom, and obtain a significant correlation between both measures.

A promising avenue of research is to extend experimental games to online economics or wikieconomics. In particular, the emergence of large organization based on cooperation and nonmonetary incentives, such as wikipedia and open softwares, provides a perfect field experiment to test the relationship between experimental measures and field behavior.

In a recent contribution, Algan, Benkler and Hergueux (2012) explore this question in one of the most successful contemporary instances of massive voluntary contributions to a public good: the online encyclopedia Wikipedia. Using an Internet-based experimental economics platform, the author elicit preferences for cooperation, altruism and reciprocity among a sample of 850 Wikipedians directly in the field (i.e. online, in interaction with other Internet users who are not Wikipedia contributors) and relate those measures to their real-world contribution records. They find that contributions to Wikipedia - as measured by subjects' number of edits to the encyclopedia - are related to their propensity to cooperate in a traditional Public Good game and to the level of reciprocity that they exhibit both in a conditional Public Good game and in a Trust game. Moving from the position of a non-contributor with a registered Wikipedia account to that of an experienced Wikipedia contributor is associated with a 10 to $13 \%$ rise in public good contribution levels and with a 7 to $10 \%$ rise in reciprocity levels.

\subsection{Correlation between generalized trust and limited trust}

We stressed that most of the research about the economic consequences of trust deals with generalized trust. But what is the relationship between the various forms of trust? Since the seminal work of Banfield (1958) and Coleman (1990), social scientists make a distinction between limited versus generalized morality. Societies with limited morality only promote codes of good conduct within small circles of related persons (family or kin), whereas selfish behavior is regarded as morally acceptable outside the small network. This behavior was famously described as "amoral familism" by Banfield (1958) in his ethnographic description of a rural village. Societies with generalized morality promote good conduct outside the small family/kin network, offering the possibility to identify oneself with a society of abstract individuals or abstract institutions. Coleman (1990) proposes a similar distinction between strong ties, defined as the quality of the relationship among family members, and weak ties, defined as the strength of social relationships outside the family circle.

Enrich and Gambetta (2010), using trust games with a representative sample of the British population find that people with strong family ties have a lower level of trust in strangers 
than people with weak family ties, and argue that this association is causal. They show that the explanation for this opposition comes from the level of outward exposure: factors that limit exposure limit subjects' experience as well as motivation to deal with strangers.

Greif and Tabellini (2010) provide an historical analysis of this opposition by comparing the bifurcation of societal organization between pre-modern China and Medieval Europe. Premodern China sustained cooperation within the clan, e.g a kinship-based hierarchical organization in which strong moral ties and reputation among clan members played the key role. By contrast, in Medieval Europe, the main example of a cooperative organization is the city, whereby cooperation is across kinship lines with weak ties, and external enforcement played a bigger role.

\subsection{Heterogeneity of trust across space}

As early as the 18th century, Adam Smith (1997 [1766]) was already alluding to substantial differences across nations in what he called the "probity" and "punctuality" of their populations. For example, the Dutch "are the most faithful to their word." Similarly John Stuart Mill observed: "There are countries in Europe ... where the most serious impediment to conducting business concerns on a large scale, is the rarity of persons who are supposed fit to be trusted with the receipt and expenditure of large sums of money" (Mill, 1848, p. 132).

Recent advances in international social survey technique have yielded further evidence of the enormous differences in trust level that may exist across countries. In social survey data there is to be observed a sizable variation in the extent to which people trust others across countries as well as within countries.

Figure 1 and 1 bis show average levels of generalized trust for 111 countries, generated from responses to the World Values Survey, the European Values Survey, and the Afrobarometer. ${ }^{1}$ These surveys ask the trust question, and the trust variable takes on the value 1 if the respondent answers that "Most people can be trusted" and 0 if he or she thinks that one "Need to be very careful." Trust levels vary very considerably from one country to another. In Norway, the country with the highest level of trust in the sample, more than 68 percent of the population trusts others. At the opposite end of the ranking lies Trinidad and Tobago, where only 3.8 percent of the population exhibits interpersonal trust. The United States ranks in the top quarter, with an average trust level of more than 40 percent. In general, northern European countries lead the ranking with high average levels of interpersonal trust, while populations in African and South American countries seem not to trust others very much.

1 The data set is constructed by combining the five waves of the WVS (1981-2008) with the four waves of the EVS (1981-2008), and adding the third wave of the Afrobarometer (2005). 
The extent to which people trust others, however, varies not only across countries, but also across regions belonging to the same country. Figure 2 shows average trust levels for 69 European regions used in Tabellini (2010); the source is the World Values Survey (1990-1997). As we see from the figure, trust levels vary remarkably between regions lying not very far apart. While in the Dutch region of Oost Nederland more than 64.1 percent trust, in the French Bassin Parisien region this figure is only 14.2 percent. There is wide divergence between regions within European countries. In Italy, the trust level is almost twice as high in Trento (49 percent) as it is in Sicilia (26 percent). In France, trust is 13 percentage points higher in the Sud Ouest region compared to the Nord region. Finally, a divergence in trust levels is also observable in federations. Figure 3 displays mean trust levels for 49 U.S. states, computed by averaging individual responses from the General Social Survey (GSS, 1973-2006) of the United States. We note wide differences in the degree of trust the citizens of these States have in others. While in North Dakota more than 60 percent of the respondents trust others, in California less than 40 percent, and in Mississippi not even 20 percent, of the respondents think that they can trust people in general.

\subsection{An heterogeneity linked to national specificities}

What are the reasons for the divergence in trust levels across countries? Besides individual characteristics (e.g. age, social status, gender, education, income and religion), time invariant country characteristics can account for a large share of the disparity of trust levels around the world.

Table 2 reports a micro-regression of individual trust on age, age squared, gender, education, income level and various types of religious affiliation. Some of these individual characteristics are highly correlated with individual trust. Maleness correlates positively with trust, and age displays a hump-shaped relationship with trust. More educated individuals have significantly higher trust, a relationship documented at length by Helliwell and Putnam (2007). A one standard deviation increase in education (roughly 2.2 years) increases trust by 11 percent of its sample mean. Trust also correlates positively with income: a one standard deviation increase in income (roughly 0.79) increases trust by 6 percent of its sample mean. In a seminal paper on the determinants of trust, Alesina and La Ferrara (2002) document the role of additional characteristics negatively correlated with trust, such as a recent history of traumatic experiences or belonging to a group that historically felt discriminated against, such as women or ethnic minorities.

But the feature that especially stands out in Table 2 is the very weak predictive power of 
individual characteristics for explaining cross-country heterogeneity in trust compared to country fixed effects. Including country fixed effects in this regression increases the coefficient of determination, $\mathrm{R}$ sq., by about 10 percentage points from 0.027 to 0.12 . Furthermore, the correlation between average country trust levels and the predicted mean trust is of magnitude 0.52 without fixed effects, and rises to an almost perfect correlation of 0.99 when country fixed effects are included in the micro-regression.

Figure 4 displays country fixed effects in relation to Norway, the country with the highest mean trust in the sample, taken from the above described micro-regression. The figure thus documents the percentage point reduction in trust flowing from the fact of living in a country other than Norway, with all individual characteristics (age, gender, education, income and religion) held constant. In comparison to Norway, trust would be reduced by more than $60 \mathrm{pp}$ (percentage points) in Uganda, Peru, Kosovo or Algeria; by more than $50 \mathrm{pp}$ in Greece or France; and by around $40 \mathrm{pp}$ in Italy, Germany or the United States. The country fixed effects thus differ by an order of magnitude from the effects of individual characteristics. This result suggests that it is necessary to look at national characteristics (institutions, history, geography, public policy...) in order to understand how trust is built up.

\section{The dynamics of trust}

International surveys underline how important the heterogeneity of average levels of trust across countries is, for identical characteristics of the inhabitants, such as age, income, education, and religion. These surveys also show that average trust changes little over the course of time: the countries with the weakest levels of trust at present also had weak trust at the beginning of the 1980s. This observation, though, tells us little. For one thing, it is confined to the relatively short period for which survey data are available. For another, it says nothing about the causal factors that may explain the persistence or the evolution of trust. A cluster of recent studies make it their goal to seek these out.

\subsection{Climate}

Four centuries before our era, Aristotle underlined the influence of climate on attitudes: "The nations that live in cold regions and those of Europe are full of spirit, but somewhat lacking in skill and intellect; for this reason, while remaining relatively free, they lack political cohesion and the ability to rule over their neighbors. On the other hand the Asiatic nations have in their souls both intellect and skill, but are lacking in spirit; so they remain enslaved and subject. The Hellenic race, occupying a mid-position geographically, has a measure of both, being both 
spirited and intelligent" (Politics 7.7, 1327b18-1328a21, trans. Sinclair and Saunders).

When Aristotle wrote, sampling was unknown, and there was no way to establish a statistical relationship between climate and attitudes; today it is at least feasible to contemplate doing so. Durante (2010) posits that the inhabitants of Europe's regions are today more trusting to the extent that they were subjected to significant climatic variations between 1500 and 1750 . The explanation advanced by Durante is that greater climatic variability, which heightens the undependability of harvests, makes it necessary to stock larger reserves, manage them collectively, and develop trade between regions affected by differing and therefore offsetting climatic shocks. All this favors cooperation and leaves an imprint on the overall social structure. Family bonds are less binding in regions where the amplitude of climatic variation is greater. Young people leave the family nest earlier, since they cannot count on family solidarity to meet their needs when harvests are poor, as they frequently are. Experiments in cooperation induced by climatic harshness may thus have effects persisting across a span of centuries, even as societies are profoundly transformed by the passage from the agricultural stage to the industrial stage.

In a similarly-oriented contribution Ostrom (1990) found that trust is high in upland regions where farmers must cultivate scattered plots irrigated by communally-maintained ditches. In such regions, mutual trust and cooperation in all facets of life are more frequent than on flatland that can be farmed with much less coordination.

Natural catastrophes can also influence trust, sometimes in unforeseen ways. A portion of those who survive experience a post-traumatic phase during which they turn to others, show altruistic behavior, and invest in communal action. This "catastrophe syndrome," (Valent, 2000, Wallace, 1956) may last a long time and have a durable effect. Castillo and Carter (2011) and Zylberberg (2011) have shown that destructive hurricanes may favor cooperation and trust over a period of years.

\subsection{The Weight of History}

The traffic in slave labor to work plantations in the Americas began in the sixteenth century, when West African men and women were captured and enslaved during raids led from the coast by Europeans, or sold as slaves to the Europeans after being captured in the course of military conflicts among African belligerents. But the system underwent evolution, for some inhabitants of West Africa found they could survive and even thrive by capturing and selling other humans-passing travelers, neighbors, even members of their own families- to the slave merchants. It may be surmised that these practices, widespread at the time, instilled profound 
mistrust in the population. Nunn and Wantchekon (2011) have shown that it is still present three centuries later. The inhabitants of these regions still reveal greater mistrust of others, including their neighbors, the members of their ethnic group, and even their own families, than the inhabitants of neighboring regions. The slaves may of course have been captured and sold primarily in areas of conflict, where distrust would have been higher to start with, and the task of the slave merchant correspondingly easier. Nunn and Wantchekon have shown, however, that dwellers in regions more remote from the Atlantic coast, whose ancestors were relatively more sheltered from the slave trade, are less distrustful than those who dwell nearer the coast. They also show that this pattern of diminishing distrust with increasing distance from the coast is not observed in other regions of the globe. This would tend to show that the regions where the slave trade flourished are the ones with distrustful inhabitants, not the converse.

Thus, even across a span of many generations, history may have the effect of shaping trust in ways that we can still perceive. Rohmer, Thoenig and Zilliboti (2013) provide a theory for the long-run impact of war and conflicts on distrust. Accidental conflicts, e.g. conflicts that do not represent economic fundamentals, might still lead to a permanent breakdown of trust, since agents observe the history of conflicts to update their beliefs and to transmit them over generations. Becker et al. (2011) have studied the imprint left by the Habsburg Empire, which dominated much of central Europe from the eighteenth century to the beginning of the twentieth, and employed administrators who, with respect to the norms of the age, were better educated and less corrupt. The borders of the countries that have come into existence since the collapse of the Empire at the end of World War One may have altered more than once in the interval, as a result of conflicts and political events. Yet in regions that once lay within the boundaries of the Empire, the administration is still more transparent, less corrupt, and better trusted by the population. The improved administrative practices of the Habsburgs left traces that have survived well beyond the dissolution of their Empire.

The weight of this example is more than anecdotal. Numerous circumstances of European history reveal that political decisions can affect trust over the course of many centuries. Today the inhabitants of Italian cities that in the Middle Ages achieved a form of participatory self-government, the communal regime, comparable to that of the city-states of antiquity, and whose ancestors were thus deeply engaged in civic/political life, participate more in elections, give more blood, and are more likely to join associations than the inhabitants of other Italian cities (Guiso et al. 2008b). Regions of Europe endowed with higher levels of education and a more democratic or participatory state form at the end of the eighteenth century today have more trusting and civic-minded inhabitants (Tabellini, 2010). This line of research suggests that 
education and democracy shape civic behavior in ways that last for centuries.

In the same vein, Jacob and Tyrell (2010) have shown that the activities of the Stasi, the state security agency of the former DDR or East Germany as it was known, which by 1989 employed more than 90,000 permanent members and had more than 170,000 informers, have left a durable mark on the civic attitudes of the inhabitants of East Germany. Everyone knew that, in every building and factory, they were being watched by informers among them, and that electronic eavesdropping was in widespread use. Anything one said about the regime might be reported, and twisted in such a way as to ruin one's life. Jacob and Tyrell show that this climate of delation shredded the social fabric. Two decades after the wall came down, the inhabitants of regions in which the Stasi were once particularly active are less inclined to do their civic duty: their rate of voter turnout, their rate of participation in voluntary associations, and their rate of voluntary organ donation are all measurably lower than those in the rest of the Bundesrepublik.

More generally, Aghion et al. (2010) highlight a steep decline of trust in the former Soviet bloc countries at the time of their conversion to "capitalism." The market liberalization at the turn of the 1990s, with its attendant corruption, in this Eastern bloc setting of pervasive distrust and minimal transparency, seems to have degraded any trust the citizens might have had in their state, their justice system, or their fellow citizens, even further. The effect was most detectable in regions where trust was already low at the time the wall came down.

\subsection{Inherited trust}

Studies of how immigrant attitudes evolve as a function of their country of origin and country of arrival shed an interesting light on the malleability of trust. They show that the beliefs and behaviors of immigrants are influenced by their countries of origin: that football players who grew up in countries undergoing civil war are more violent than other players, that they get yellow-flagged or red-flagged more often (Miguel et al., 2011). Fisman and Miguel (2007) observed that UN diplomats from countries with low levels of trust and civic spirit frequently violate the New York City parking laws, from which diplomats are legally immune, whereas ones from Scandinavian and Anglophone countries make it a point not to, although they enjoy the same immunity.

Still, the attitudes and beliefs of immigrants are not poured in concrete but are influenced by their countries of residence. As a general rule, trust rises among immigrants right from the first generation, if they have moved from a low-trust country to a high-trust one. The converse holds true as well. This phenomenon has been observed in both the US and Europe (Algan and Cahuc, 
2010, Dinensen, 2011, Dinensen and Hooghe, 2010). In fact, it is detectable in cases of internal migration too: the civic spirit of Italians who move from southern Italy to the north tends to ameliorate and converge gradually on the prevailing local norm. Conversely, the civic spirit of Italians who move from the north to the south shows some signs of degrading (Ichino and Maggi, 2000, Guiso et al., 2004). Algan et al. (2012) illustrates this pattern with the evolution of trust among the first and second generation of immigrants in European Countries. In the European Social Survey, the level of trust of first generation immigrants correlates significantly with the level of trust in their country of origin. By contrast, the level of trust of second generation immigrants is more correlated with the average level of generalized trust and trust in institutions in their new country of residence than with trust in their home country.

Individual distrust, therefore, is not something poured and set for eternity. The environment can modify it. But it is something systematically characterized by the kind of inertia that can leave its mark on at least one and perhaps more generations.

\section{4/ Trust, Income per capita and Growth}

To what extent can the above mentioned cross-sectional heterogeneity in trust level account for cross-sectional differences in income per capita? To what extent can a boost in trust explain economic success within a country? This section first documents the evidence on the strong correlation observed between trust and economic outcome. We then document the main issues raised by the identification of the causal impact of trust, and the recent attempts in the literature to address them.

\subsection{Cross-section correlation}

The interest of the economic literature in social capital is fueled by the strong positive correlation between income per capita and average trust levels across countries or regions, first illustrated by the seminal work of Knack and Keefer (1997). The classic book by Putnam, Leonardi and Nanetti (1993) also suggested the existence of such a relationship across regions in Italy by arguing that the Northern regions developed faster than the Southern ones because the former had a higher stock of social capital measured by association membership.

Figure 5 plots the average (ln) income per capita between 1980 and 2009 against average trust between 1981 and 2008 for a sample of 106 countries. Countries with higher levels of trust also display higher income levels. The correlation is steady; one fifth of the cross-country variation in income per capita is related to differences in generalized trust.

Table 3 shows the regressions of income per capita ( $\ln$ ) on trust. A one standard 
deviation increase in trust, about 0.14 , increases (ln) income per capita by 0.59 , or 6.8 percent of its sample mean. When additional controls for education, ethnic fractionalization and population are included (column 2), the coefficient for trust remains significant but decreases in magnitude. Increasing trust by one standard deviation leads to a rise in income per capita of 0.18 , or 2 percent of the sample mean. As a comparison, increasing fractionalization by one standard deviation (2.5) decreases income by 0.225 or 2.5 percent of the mean. We additionally control for several institutional measures, such as legal origins (column 3) and political institutions (column 4). Trust remains significant at the 5 or 10 percent level, while the institutional variables are insignificant.

To compare the importance of generalized trust for income relative to other measures of trust, we run regressions replacing the measure of generalized trust by measures of limited trust, controlling for education, ethnic fractionalization and population. As Table 3 makes clear, only generalized trust is significantly associated to income per capita. Limited trust (such as trust in family, neighbors, people one knows personally) is positively associated to income levels, but not significantly (columns 5-7). This result suggests that it is only the ability to cooperate outside the inner circle of family and relatives that is associated to economic performance, and is consistent with Banfield's analysis of the poor performance of Italian villages characterized by amoral familism. This result explains why the economic literature has made generalized trust the primary focus of analysis.

The same steady positive correlation between generalized trust and income per capita holds when we look at more local variations across regions in Europe or across states in the US. Figure 6 shows the correlation between generalized trust and average income per capita (ln) in 69 European regions using data taken from Tabellini (2010). Some European countries show a high degree of regional variation both in generalized trust and income per capita. In particular northern Italy and northern Spain are high-trust regions and have high income per capita while southern Spain and southern Italy fare much worse on both dimensions. Figure 7 shows that the same positive correlation between trust and income per capita holds across US states. The southern states, in particular the former French colonies, have weak levels of trust and are also outperformed economically by the states of the north-eastern US.

Finally, using novel income data for more than 800 regions around the world collected by Gennaioli et al. (2012), we can observe that trust correlates with GDP at the region level around the world. Figure 8 displays the cross correlation of (ln) GDP per capita and trust for three different samples. Table 4 gives the associated regression output. Trust correlates positively with per capita income in 771 regions around the world, even stronger when the sample is restricted to 
regions belonging to groups of high income countries such as the EU27 (including Norway, but excluding Cyprus, Malta, and Luxembourg) and the OECD. Table 4 also displays regression results, when additionally education is controlled for. Since the number of individuals polled varies greatly between region, we account for this by running weighted regressions using precisely this number as our weight. No matter which sample is used, trust is positively and significantly associated with a higher regional per capita income across regions. However, as soon as we introduce country fixed effects, we do not observe any significant correlation between trust and GDP. This result shows that the cross-country heterogeneity in trust and income per capita is much more substantial than the within country variation, and drives the result.

Not only is trust positively correlated with income per capita, but also with growth. This point was first documented by Knack and Keefer (1997, 1999). Their study is based on 29 countries, mostly western European countries, between 1980 and 1992. Table 5 enlarges their result on the relation between trust and economic growth to cover 52 countries, regressing average annual growth between 1990 and 2009 on average trust between 1981 and 1990. We control for initial income and initial education. Trust is positively associated with economic growth. The correlation between trust and growth is statistically significant at the 10 percent level. A one standard deviation increase in trust, about 0.14 , increases growth by 0.5 percentage points or 20 percent of its sample mean. Column 2 controls for the initial level of investment and the correlation becomes statistically significant at the 5 percent level. Column 3 includes an interaction term between trust and initial income per capita. This interaction term captures the fact that trust should have a stronger effect on growth in poor countries that lack credit markets and appropriate rule of law. Both trust and trust interacted with initial income are statistically significant. The interaction term is strongly negative, which provides support for the view that trust is more important when enforcement of formal institutions is weak.

\subsection{Identification issues}

The previous section documents a strong correlation between trust and economic outcomes across countries or regions. However, how can we identify the causal impact of trust on economic performance? To answer this question, we must confront the various identification issues raised by the estimation of the following equation

$$
Y_{c}=a_{0}+a_{1} T_{c}+a_{2} X_{c}+e_{c}
$$


where $Y_{c}$ denotes economic performance in the geographic location c (country or region), $T_{c}$ denotes trust, $X_{\mathrm{c}}$ is a vector of characteristics of the location, including the educational level of the population, current and past institutions, and past economic development in the locality, and $e_{c}$ is an unobserved error term.

The identification of equation (1) raises two main issues. The first is reverse causality: contemporaneous trust is likely to be influenced by the current state of economic development in locality $c$. The second issue is that of omitted variables that might co-determine both trust and economic performance. Specifically, institutions (Hall and Jones, 1999, Acemoglu et al., 2001, Rodrick, 1999), geography (Sachs, 2003) and more recently deep historical events (Nunn, 2009) and biology (Ashraf and Galor, 2013; Spoalore and Wacziarg, 2013, Haushofer and Fehr, 2013) have been found to affect economic performance. However, as pointed out above, those factors also shape trust. In principle it might be possible to control for institutional quality, but such variables are well known to present difficulties of measurement, and in any case cannot capture informal norms. Worse, if equation (1) is estimated in cross-section, it is impossible to include in the regression a fixed effect at the geographic location level c. This implies that trust and the unobserved error term can be correlated: $\operatorname{cov}\left(T_{0} e\right)$ is different from zero and the OLS estimates of equation (1) lead to biased estimates of the effect of trust. This opens up the possibility of a confounding factor: it is impossible to isolate the impact of trust from other time-invariant characteristics of location c, such as other cultural values or local institutions. The most recent research in economic development precisely tries to find good strategies to control for any timeinvariant features at the local level. For instance, to measure the role of institutions in Africa, Papaioannou and Michalopoulos (2013) look at within ethnic variation in economic development by controlling for ethnicity fixed effects. They show that a very same ethnic group that belongs to different countries turn out to have similar contemporary income per capita, despite the institutional heterogeneity across countries. This result suggests that inherited traits specific to each ethnic group would explain much better economic development than institutions do.

In the following, we discuss the two main strategies proposed so far in the literature to address these identification issues to single out the causal impact of trust on economic development.

\subsection{Identification using historical events}

A first strategy is to search for historical events as an exogenous variation in trust that could be used as instruments. To rationalize the use of historical events, the literature draws on the theory of the transmission of values. Studies by Bisin and Verdier (2001), Guiso et al. (2008c), 
and Tabellini (2010) stress the role of two main forces. A portion of current values is shaped by the contemporaneous environment (horizontal transmission of values), and another portion is shaped by beliefs inherited from earlier generations (vertical transmission of values). These theories suggest estimating the following equation for the formation of trust:

$$
T_{c t}=b_{0}+b_{1} T_{c t-1}+b_{2} X_{c t}+G_{c}+G_{t}+r_{c t}
$$

where contemporaneous trust $T_{c}$ in locality $c$ is explained by the initial trust present in the previous generation $T_{\mathrm{c}, 0}$, initial economic performance, and the initial and current other characteristics of the locality $X_{c} r_{c}$ is a random residual

The two-step estimation of equations (1) and (2) raises two main concerns. First, we do not have any information on initial trust $T_{\mathrm{c}, 0}$ since standardized cross-country databases on the level of trust present in earlier generations are not available. At best, it is possible to go back only to the 1980s to get a measure of trust in a cross-section of countries using the World Values Survey. Second, even if we could get a good proxy for initial trust $T_{\mathrm{c}, 0}$, the correlation between initial trust and contemporaneous economic outcomes may be interpreted as a causal effect from initial trust to contemporaneous outcomes only if these two variables are not codetermined by common factors.

Tabellini (2010) addresses these two issues in the following way. He estimates the causal impact of culture on regional economic development in Europe, where culture is broadly defined as moral values of good conduct, including trust. Importantly, Tabellini estimates the impact of trust within European countries, across regions. This means that it is possible to include country fixed effects in the vector $X_{c}$. and control for national specificities. Tabellini uses two historical variables as an instrument for contemporaneous trust: past education and past political institutions. The political and social history of Europe ensures that these do vary widely at the regional level. He measures past education by the literacy rate around 1880, and early political institutions by constraints on executive power in the years 1600-1850. Tabellini shows in firststep estimates that contemporaneous trust is strongly correlated with these two instruments. Historically more backward regions, with higher illiteracy rates and worse political institutions, tend to have less generalized trust today. In the second step estimate, Tabellini shows that this historical variation in trust is strongly correlated with current regional development: regions with lower trust also have lower income per capita and lower growth rates, after controlling for country fixed effects, contemporaneous regional education, and past urbanization rates. The relationship is substantial: variation in trust could explain half of the observed income difference between Lombardy and southern Italy.

Tabellini's strategy is very insightful but raises two main concerns though. The first one is 
how validly the instrument satisfies the exclusion restriction. The key assumption is that education and political institutions from the distant past do not directly affect contemporaneous output, after controlling for contemporaneous education and institutions. This assumption is likely to be violated. The literacy rate in the past is likely to have persistent effects on the formation of human capital, a key determinant of output. Similarly, there is much evidence that past institutions do have long-term effects on economic performance (Acemoglu et al., 2001). The second issue is linked to omitted variables. Since the author estimates cross-regional income per capita, he can control for country fixed effects. Thus he can exclude that trust picks up time invariant characteristics at the country level. However, since the estimates draw on cross-sectional regressions at the regional level, it is impossible to include regional fixed effect in equation (1). Thus trust can pick up any other time invariant regional characteristics such as local geography or local formal and informal institutions.

Guiso et al. (2008b) follow a similar strategy to identify the impact of trust on income per capita in Italy. However, they look at more disaggregated historical variation in trust across cities within the same regions to exclude the influence of regional invariant characteristics. To estimate equation (2) with historical variables, Guiso et al. revisit Putnam's conjecture that today's difference in trust between the north and the south of Italy is due to the history of independence that certain cities experienced in the north after the turn of the second millennium. They thus instrument today's trust (and more generally civic capital) with the past history of independence of certain cities. Additionally, they can exploit historical variation in the degree of independence of cities belonging to the same region: the communally governed cities were clustered in north central Italy, but not every city between the Apennine and the Alps experienced that form of regime. This strategy has one main advantage compared to Tabellini. Guiso et al. can estimate the impact of trust on output within the same region, across cities. This approach alleviates part of the concern that regional invariant characteristics could determine both today's trust and income per capita. Guiso et al. find striking results. Northern cities that experienced independence and self-government in the Middle Ages now have 17 percent more non-profit associations than similar northern cities that never shared that experience. This higher level of social capital is associated with higher contemporaneous output: a one standard deviation increase in social capital increases income per capita by around 20 percent.

Still, as Guiso et al. stressed, their strategy cannot fully alleviate the identification concerns faced by Tabellini. First, the concern about the validity of the exclusion restriction for the instrument used for trust remains. One cannot exclude the possibility, that the historical shocks that affected cities at the turn of the millennium have a direct impact on income today. 
Having been a free city in the thirteenth century could have shaped other values or factors that exert long-lasting effects on economic outcomes. For example, free cities might have bred the spirit of entrepreneurship, or enhanced human capital. Second, trust can still pick up the effect of invariant local characteristics. Even if Guiso et al. identify the effect of trust within regions, they cannot control for geographic fixed effect at the city level.

This concern applies generally to all the literature that looks at the historical determinants of trust. As documented in Section 3, a burgeoning literature shows that trust is affected in the long-run by climate shocks, natural catastrophes or history like the slave trade. But using those shocks as an instrument for trust in a growth equation is questionable. In particular, it is likely that climate shock or the slave trade affect growth by other channels than social capital, making the exclusion restriction disputable.

\subsection{Time varying instruments: Inherited Trust and Growth}

The historical approach leaves open the question of whether the level of trust does matter per se in explaining economic development, or whether it is not rather picking up the deeper influence of time invariant features such as legal origins, the quality of institutions, initial education, the extent of ethnic segmentation, and geography. What is needed is to find a measure for trust with time variation, allowing the investigator to control for time invariant specific factors. The difficulty in performing such an exercise is that there is no extended-time series on the evolution of trust.

Algan and Cahuc (2010) propose to use this time variation in inherited trust in the growth equation (2). Since it is already well established that the parents' social capital is a good predictor of the social capital of children, they use the trust that US descendants have inherited from their forebears who immigrated from different countries at different dates to detect changes in inherited trust in the countries of origin (see Fernandez for a synthesis on the impact of culture on economic performance by using this epidemiological approach, 2011). For instance, by comparing Americans of Italian and German origin whose forebears migrated between 1950 and 1980, they can detect differences in trust inherited from these two source countries between 1950 and 1980. They can get time varying measures of trust inherited from these two countries by running the same exercise for forebears who immigrated in other periods, for instance between 1920 and 1950. With time varying measures of inherited trust, they can estimate the impact of changes in inherited trust on changes in income per capita in the countries of origin. This method allows us to address the main challenges mentioned above that arise in identifying the effect of trust on economic development. By focusing on the inherited component of trust, the authors 
avoid reverse causality. By providing a time varying measure of trust over long periods, they can control for both omitted time invariant factors and other observed time varying factors such as changes in the economic, political, cultural, and social environments.

More specifically, Algan and Cahuc re-estimate equations (1) and (2) by allowing time variation in trust and economic performance, and including local fixed effects. We can rewrite the system of equations in the following way:

$$
\begin{gathered}
Y_{c t}=a_{0}+a_{1} T_{c t}+a_{2} X_{c t}+F_{c}+F_{t}+e_{c t} \\
T_{c t}=b_{0}+b_{1} T_{c t-1}+b_{2} X_{c t}+G_{c}+G_{t}+r_{c t}
\end{gathered}
$$

where $\mathrm{t}$ is an index of the time period, and $\left(F_{0} G\right)$ and $\left(F_{0} G_{t}\right)$ denote country fixed effect and time effect respectively. The authors thus estimate the impact of the variation in trust on the variation in income per capita within countries. In the benchmark estimation of the model, data availability led them to consider two periods: 1935-1938 and 2000-2003. More distant periods are also considered, but with fewer observations. The estimates are based on 24 countries from all over the world, including Anglophone countries, Continental European countries, Mediterranean European countries, Nordic countries, Eastern European countries, India, Mexico, and Africa

To cope with the lack of information on trust of the previous generations in equation (2'), the authors proxy the inherited trust of people living in country $\mathrm{c}$ by the trust that the descendants of US immigrants have inherited from their ancestors coming from country c. This yields an estimate of the term $b_{1} T_{\text {ct- } 1}$ in equation (2'), which can be used as a proxy for inherited trust. This strategy leads to estimating a single equation of the form $\left(1^{\prime}\right)$, where $T_{\mathrm{ct}}$ is replaced by the proxy of inherited attitudes.

This strategy can address part of the identification issues discussed above. First, by using the trust US immigrants inherited from the home country instead of the average trust of the residents, we can exclude reverse causality. While trust in the home country has evolved according to what happened in that country, the inherited trust of US immigrants is only affected by shocks to the US economy. Besides, since we can have a direct measure of inherited trust, we do not have to worry about instruments that are unlikely to satisfy the exclusion restriction. Second, by looking at different waves of immigration, one can get time variation in inherited trust and thus include country fixed effects in equation (1').

The authors estimate the trust inherited by US immigrants from their home countries by using the General Social Survey. Inherited trust is measured as the country of origin fixed effect on individual regression of the generalized trust question, controlling for individual characteristics. The authors focus on inherited trust in the two periods 1935-1938 and 2000- 
2003 (1935 and 2000 henceforth) and impose a lag of 25 years between inherited trust and income per capita at time t. Therefore, inherited trust in 1935-1938 is that of second-generation Americans born before 1910 (i.e., whose parents certainly arrived one generation before 1935, a generation being defined as a 25 year period), of third-generation Americans born before 1935, and of fourth-generation Americans born before 1960. In the same way, the level of inherited trust in 2000-2003 corresponds to the trust inherited by: second-generation Americans born between 1910 and 1975; third-generation Americans born after 1935; and fourth-generation Americans born after 1960. This decomposition excludes any overlap in the inherited trust of the two groups.

The authors show that inherited trust for the period 2000 strongly correlates with trust in the home country during the same period, measured from the WVS. Additionally the authors document substantial variation in inherited trust between 1935 and 2000. Swedish Americans have inherited higher trust in 2000 relative to the period 1935. Inherited trust from continental European countries, and to a lesser extent from the United Kingdom, has deteriorated over the period. Trust inherited in 2000 from French ancestors is 4.7 percentage points lower relative to trust inherited from Sweden in 1935. Inherited trust has decreased even more among the immigrants from eastern European countries and Mediterranean countries. The authors do not address the explanation for such variations-but there is a rich set of candidates. The ancestors of the current US respondents are likely to have undergone very different national crises. The ancestors who transmitted their trust for the period 1935 mainly migrated before World Wars One and Two. The level of trust of immigrants from countries deeply affected by these crises, like France, Germany, and eastern European countries, might have deteriorated over the intervening period compared to descendants from Sweden, since this latter country is one of the European countries least affected by these traumatic mid-century events.

Algan and Cahuc (2010) then estimate the impact of change in inherited trust on changes in income per capita within country between 1935 and 2000. The estimates also control for changes in lagged income, political institutions, education and other values (like work ethic or family values) over the period to isolate the specific effect of trust. The impact of inherited trust is substantial.

Figure 9 displays the change in income per capita in period 2000-2003 that countries would have experienced if the level of inherited trust in a given country had been the same as the trust inherited by Swedes. Income per capita in 2000 would have been increased by 546 percent in Africa (not reported) if the level of inherited trust had been the same as inherited trust from Sweden. Inherited trust also has a non negligible impact on GDP per capita in eastern European 
countries and Mexico. Income per capita would have increased by 69 percent in Russia, 59 percent in Mexico, 30 percent in Yugoslavia, 29 percent in the Czech Republic, and 9 percent in Hungary had these countries inherited the same level of trust as Sweden. The effect, if less important, is also sizable in more developed countries. Income per capita would have been up by 17 percent in Italy, 11 percent in France, 7 percent in Germany, and 6 percent in the United Kingdom if these countries had had the same level of inherited trust as Sweden. The authors also compare the effect exerted by trust to the effect exerted by initial income per capita, or by time invariant factors such as geography, or by time invariant institutions. For poor countries from Africa or Latin America, initial economic development and invariant factors have a larger impact on income per capita. In striking contrast, change in income per capita within developed countries is overwhelmingly explained by inherited trust.

\subsection{Individual Trust and Individual economic performance}

Very few studies have explored whether high trusting individuals have higher economic performances in terms of wages or economic prospects. This is because of the difficulty of identifying the causal impact of individual trust on individual economic outcomes. Guiso et al. (2006) show, using the General Social Survey, that high trusting individuals are more likely to become entrepreneurs in the US. To test for causality, they use inherited trust of US immigrants from their home country as an instrument for individual trust in the destination country. They find a significant, but somewhat too larger effect of inherited trust compared to the OLS estimates. As stressed by the authors, since inherited trust is time invariant, this variable may be picking up other inherited traits from the home country like risk aversion or saving behavior. This would explain the large difference in the OLS and 2SLS estimates. Ljunge (2012) draws on the same methodology by looking at how inherited trust of second generation US-immigrants is correlated with their economic success: second generation immigrants with higher trusting ancestry earn significantly more than those with lower trust. They also have a higher labor supply, lower unemployment spell, and higher education. The correlation remains significant, even after controlling for additional ancestral influences such as income per capita and institutions. The paper cannot control for country of origin fixed effect though.

In another contribution, Butler et al. (2009) use the European Social Survey to test the relationship between individual trust and individual economic performance. The advantage of the ESS is to provide a question on generalized trust whose answers are scaled from 1 to 10 , rather than just binary answers. The authors show that individual income is hump-shaped with the intensity of trust. Individuals whose level of trust is too high in relation to the civic-mindedness 
of their fellow citizens have levels of income inferior to those of individuals whose level of trust is intermediate. Being more frequently deceived by their fellow citizens hampers them. At the other extremity, individuals with little trust in others miss out on opportunities to make beneficial exchanges. Thus there exists a "good" intermediate level of trust, the one that matches the level of civic-mindedness of the fellow citizens with whom one deals.

The conclusions drawn in this article might be limited by the quality of the ESS data. In these international values surveys, the measure of income levels is very imprecise and noisy. Nor do the questions about having been the victim of deceit focus on economic exchanges that might have a real impact on income, such as the interactions of professional life. But this article has the great merit of showing that the relationship between trust and economic performance is not necessarily monotonic. Trusting too much can have detrimental consequences. The recent financial crisis is a good illustration. The Icelanders, one of the most trusting peoples in international rankings, must still regret their excessive trust in their banks. Bernard Madoff's victims were likewise overly trusting.

If the analysis of the relationship between trust and economic performance at the individual level is to be advanced, the way ahead would seem to be field experiments, with an experimental measure of trust that measures behaviors precisely in economic exchanges and within firms. At the moment, the literature has done little to develop this approach. The only real study done on the terrain is that of Karlan (2005), who shows that, among Peruvian villagers, those most trusting in experimental games are also those who most often repaid their loans. But this study is not focused on the economic impact of trust on income. Some recent work head into this direction but on limited samples. Barr and Serneels (2009) use a standard trust game to establish a relationship between experimental measures of reciprocating behavior among Ghanaian colleagues and the observed labor productivity of the firm in which they work. Similarly, Carpenter and Seki (2011) have Japanese fishermen play a repeated public goods game with and without an option for "social disapproval". They show that fishing crews that exhibit higher levels of reciprocity and more disapproval of shirking are more productive.

The way ahead in attempting to pin down the impact of trusting behavior on individual economic performance must be to combine the insights of experimental economics with experimentation-field, natural, and randomized. Doing so is a prerequisite if we are to better understand the channels through which trust affects economic performance and growth. 


\section{5/ Channels of influence of trust on economic outcomes}

The empirical work presented in the previous section suggests that trust does indeed have an impact on growth. Macroeconomic in scope, this research is limited to the study of the relations obtaining among variables of a highly aggregated kind. It can therefore shed no more than a feeble light on the mechanisms or channels by which trust may act upon growth. Analyses more microeconomic in scope, focused on the relations obtaining among finance, insurance, the organization of firms, the labor market, public regulation, and trust, meet this need.

\subsection{Financial markets}

In order to function, financial markets must rely heavily on trust, inasmuch as operations on these markets consist of promises of future payment which carry effect by reason of the fact that debtors are largely trustworthy, for legal protection would necessarily be costly and undependable. Figure 10 illustrates this positive relationship between trust and the development of financial markets in 86 countries over the course of the last three decades. As a gauge of the development of financial markets, we use the sum total of the credit granted by banks and financial institutions to private actors, as a percentage of GDP (see Levine ,2004).

Recent contributions to the literature have aimed at going beyond this positive correlation between trust and financial development, and pinpoint more closely the causal impact of trust. Guiso, Sapienza and Zingales (2004) study the relationship between the development of financial markets and trust in the regions of Italy in the 1980s and 1990s. They observe that households make more frequent use of cheques, keep a smaller portion of their savings in cash and a larger one in the stock market, and resort more frequently to credit-granting institutions, in the northern regions of the peninsula, where there is prevalent trust and high rates of blood donation and political participation. In the southern ones, moreover, borrowers resort more frequently to their families or near circles for loans than they do in the north.

As well as the composition of assets and volume of credit, trust can influence the propensity of investors to seek the counsel of financial intermediaries and delegate decisions to them. In a setting where financial products are complex, delegation to intermediaries who have a good knowledge of these products can ameliorate the diversification of investments and their rate of return. Guiso and Jappelli (2005) have shown that investors who have more trust in financial intermediaries delegate more decisions to them and thus obtain better-diversified and more efficient portfolios. The part played by trust in the propensity to turn to financial intermediaries 
capable of supplying products that will ameliorate risk coverage is replayed when it comes to insurance. Cole et al. (2012) have looked at the reasons why insurance contracts covering climate risks to their harvests in two rural regions of India were hesitantly received by locals, even though they bore a low cost. A priori, such contracts ought to have been attractive to households where variations in income are largely determined by the vagaries of precipitation during harvest season. Cole et al. show that lack of trust in and comprehension of the contracts explains a significant part of the refusal of households to take up this insurance. A randomized experiment shows that instructors who explain to folk the content of the contracts can have a significant influence on the take-up of this insurance, but only if they come recommended by a microcredit agency with a well-established reputation in the households. If so, the intervention of the instructors increases the uptake of the insurance by $36 \%$. If the instructor does not have this backing, or if the households are not acquainted with the institution backing him, his intervention has no significant impact.

Trust patently plays a part in situations of financial crisis. The GSS shows that trust in financial institutions declined steeply after the failure of Lehman Brothers in 2008 (Guiso, 2010). Such failures are themselves provoked by drops in confidence. Guiso observes that persons who had the least trust in their banks withdrew their savings earliest in periods of financial distress. And trust during these periods of financial distress is linked to trust prior to their onset. This observation suggests that a structural deficit of trust in financial intermediaries may favor the onset of financial crises.

The interpretation of the correlation between trust and finance is beset with difficulties. First, the correlation may result from other factors, like optimism or risk aversion, potentially linked to trust and exerting influence on the propensity to utilize financial products. Trust, however, is identified in the available research as a quite distinctive characteristic, different from risk aversion or optimism and exerting a specific effect on the utilization of financial products (Guiso, Sapienza and Zingales, 2008b). Second, in the correlation between finance and trust, the causal sequence may run the other way: the quality of finance, itself linked to the quality of institutions, may explain trust. Guiso, Sapienza and Zingales (2004) show, however, that there does exist an inherited portion of trust, independent of environmental influence on the development of financial markets, and that it does influence the resort to financing. The authors observe that residents of northern Italy who arrived there from regions in the south characterized by weak trust and weak civic spirit view financial products more distrustfully than do those born in the north. On identical observable characteristics, moreover, they get fewer loans from financial institutions. Such influence exerted by region of birth suggests that trust, and civic spirit 
as well, constitute partly heritable traits that may act as obstacles to the development of finance.

\subsection{Innovations and Firm Organization}

\section{a) Innovations}

Trust must play a preponderant role in the sort of economic activities-investment and especially innovation - that are attended by uncertainty on account of moral hazard and the difficulties of contract enforcement. In their path breaking article on the link between trust and growth, Knack and Keefer (1997) already threw into relief a positive correlation between trust and investment as percentage of GDP. The correlation should be even more significant for research and development, and factor productivity.

Figure 11 documents the steady positive correlation between trust and a measure of total factor productivity, taken from Hall and Jones (2009), for a sample of 62 countries. Around one third of the cross-country variation in TFP is associated to differences in trust across countries. Figure 11a illustrates the positive cross-country variation between average trust and innovation in 93 countries, with innovation measured by expenditure on research and development as percentage of GDP. The countries where trust is highest are the ones with elevated $R \& D$, in point of fact, the Anglophone and nordic countries. Trust on its own explains more than a third $(37 \%)$ of the dispersion of rates of expenditure on R\&D across countries. This relationship remains statistically significant at the 5 percent level after controlling for initial income per capita, population density and education. Figure $11 \mathrm{~b}$ shows that the same correlation between innovation and trust holds across US states, whereby innovation is measured by the (ln)-number of patents per state. Remarkably, we find that this relationship also remains statistically significant at the 1 percent level after controlling for income per capita, population density and the share of the population holding a Ph.D. at the state level. The relationship between trust and innovation operates through a specific channel different from education or population density.

While the correlation between innovation and trust appears strong, we have as yet few studies that attempt to pin down the direction of the causality. The literature gives much greater prominence to another mechanism influencing innovation-the organization of firms and especially their degree of decentralization.

\section{b) Firm organization}

By facilitating cooperation among anonymous persons, trust favors the emergence and growth of private and public organizations (Fukuyama, 1995, La Porta et al., 1997, Bertrand and 
Schoar, 2006). Trust favors the decentralization of decisions within organizations, allowing them to adapt better to alterations in the environment.

Figure 12 documents this relationship by showing a positive correlation between firm decentralization and generalized trust for 72 countries. Firm decentralization is measured by the following question from the Global Competitiveness Report 2009 (GCR): "In your country, how do you assess the willingness to delegate authority to subordinates? $1=$ low: top management controls all important decisions; 7 = high: authority is mostly delegated to business unit heads and other lower-level managers." Generalized trust is measured as the country average from WVS 1981-2009. The positive relationship is substantial: 37 percent of the cross-country variation in firm decentralization is associated with country differences in trust.

This aspect of trust is illustrated by Cingano and Pinotti (2012) who find that trust is associated with greater decentralization and larger firm size across Italian regions. Exploiting industry variation (and controlling for region- and industry-specific factors) they show that hightrust regions exhibit a larger share of value added and exports in industries characterized by greater need-for-delegation. The effect is driven by a shift of the firm size distribution away from the smallest units toward firms in higher size classes. Their estimated relationships are not only statistically significant but also economically meaningful when compared to such other determinants of industry specialization and firm organization as human capital, physical capital or judicial quality. For example, they imply that increasing trust by an amount corresponding to the inter-quartile range of its distribution across Italian regions would raise value added in a delegation-intensive industry (such as "manufacture of machinery and equipment") relative to a less intensive industry (such as "leather, leather products and footwear") by $24 \%$ (or by $19 \%$, when using cross-country data). This amounts to around two-thirds of the implied effect of raising human capital, and is larger than the effect of physical capital or contract enforcement.

In the same vein, Bloom, Sadun and Van Reenen (2012) show that trust can improve aggregate productivity by facilitating firm decentralization. They first provide a model supplying a rational foundation for the correlation between trust and decentralization of firms. Following Aghion and Tirole (1997) in their analysis of the congruence of preferences between CEOs and managers, the authors posit two opposite ways of organizing production. The CEO can either solve production problems directly or delegate these decisions to plant managers. When trust is high, plant managers tend to solve problems in congruence with the CEO's expectations rather than exploiting resources for their own interest. The CEO is thus more likely to delegate. In this perspective, trust affects the economic performance of firms through two channels. First, greater 
trust within the firm improves performance thanks to decentralized decision-making. A low-trust environment is a hindrance to the growth of the most productive firms. Second, economies characterized by low trust may orient themselves toward sectors in which decentralized decision making is less imperative. Sectors close to the leading edge of technology such as IT have to grant space for individual decision-making in order to innovate and constantly adapt to the environment. Bloom et al. (2012) test these predictions empirically. They collect new data on the decentralization of investment, hiring, production, and sales decisions from corporate headquarters to local plant managers in almost 4,000 firms in the United States, Europe, and Asia. They find substantial differences in the cross-country decentralization of firms: those in the United States and northern Europe appear to be the most decentralized and those in southern Europe and Asia the most centralized. The authors match their database on management practices with the level of trust where the headquarters are located, using regional information from the WVS. They find that firms headquartered in high trust regions are significantly more likely to decentralize. To identify the causal impact of trust on decentralization, they examine multinational firms and show that higher levels of bilateral trust between the multinational's country of origin and subsidiary's country of location increases decentralization. Finally, the authors show that more decentralized firms are also more productive and tend to specialize in innovation and information technology. Trust, indispensable for the decentralization of firms, thus affects innovation and aggregate productivity.

\subsection{The labor market}

Trust likewise exerts influence on the functioning of the labor market, through several channels affecting growth.

\section{a) The quality of labor relations}

Countries with higher generalized trust also have higher levels of cooperative relations between labor and management and higher levels of unionization. Unions have more members when generalized trust is high. Opportunistic and non-cooperative behavior constitutes a significant barrier to joining a union (Olson, 1965). Mutual trust and cooperation make it possible to lift these barriers. Cross-country analyses also show that relations between employers and employees are more cooperative when unions are more powerful (Aghion, Algan, Cahuc, 2011). The quality of employer-employee relations is associated to an array of factors that favor growth. The first is low unemployment (Blanchard and Philippon, 2004). Next, firms that have unions representing their employees are better able to adapt to new management methods, have more 
cooperative labor relations, and better productivity (Black et Lynch, 2001). Unions can ameliorate the quality of labor relations by allowing wage-earners to voice their views rather than be forced to stark either-or alternatives. Conceived this way, the role played by unions recalls Tocqueville's account of associations as little social laboratories where persons might learn cooperation at first hand. It has been noted that farmers are more careful to use water sparingly the more they have had a voice in the framing of the irrigation regulations. Communes and cantons where political democracy is most strongly rooted, with high rates of voter turnout, have the lowest levels of tax evasion (Frey, 1998). Laboratory experiments confirm this observation as shown in the next section: players who decide on the rules governing their cooperation are more generous and trusting than those upon whom the same rules are imposed by an outsider. In other words, regulation and policy have a better chance of favoring cooperation to the extent they have been decided by a shared resolution and not imposed (Ostrom, 1990).

Hence the reaction of governments when there is a failure of the union-management dialogue, the social dialogue as it is called in Europe, can help make it worse. Aghion, Algan and Cahuc (2011) show that state regulation of labor markets is negatively correlated with the quality of labor relations. They argue that these facts reflect different ways of regulating labor markets, either through the state or through the civil society, depending on the degree of cooperation in the economy. They rationalize these facts with a learning model of the quality of labor relations. Distrustful labor relations lead to low unionization and high demand for direct state regulation of wages. In turn, state regulation crowds out the possibility for workers to experiment with negotiation and grasp the possibilities of cooperation in labor relations. This crowding out effect can give rise to multiple equilibria: a "good" equilibrium characterized by cooperative labor relations and high union density, leading to low state regulation, high employment and production; and a "bad" equilibrium, characterized by distrustful labor relations, low union density and strong state regulation of the minimum wage.

\section{b) Flexicurity}

The countries of southern Europe have chosen to offset the shocks that affect all working lives by prioritizing employment through rigorous employment protection, rather than prioritizing individuals through a generous unemployment benefit and an effective public agency to help in the job search. Conversely, the countries of northern Europe have adopted a "flexicurity" model that combines generous unemployment benefit, effective public job search agencies, and weak employment protection. Flexicurity is associated to better labor market performance, with higher rates of employment and a better reallocation of jobs toward more 
productive enterprises. On this basis, international institutions like the OECD and the European Commission recommend the adoption of flexicurity. Yet this model has a low rate of take-up outside northern Europe. Algan and Cahuc (2009) show that a trust deficit can create a barrier to the adoption of flexicurity. They provide evidence of cross-country correlations between national civic attitudes and the design of labor market insurance. Countries displaying high trust tend to insure their workers through unemployment benefits instead of using stringent employment protection. Such a relationship is robust to the inclusion of country fixed effects which account for time invariant national features and which could affect the design of unemployment insurance and employment protection. This finding is consistent with the strongly-marked contrast between the flexicurity model in Nordic countries such as Denmark, and the continental European and Mediterranean countries. Naturally, the correlation between civic attitudes and the design of labor market institutions does not mean that there is a straight causal relationship going from social attitudes to the unemployment benefits/employment protection trade-off. There is a potential for reverse causality, since labor market institutions are likely to affect civic attitudes. For instance, administrative inefficiencies in the provision of unemployment insurance could influence guilty feelings about cheating on unemployment benefits. To deal with this reverse causality issue, Algan and Cahuc (2009) estimate the inherited part of civic attitudes that are not instantaneously influenced by the economic and institutional environment of the country in which people are living, by estimating the civic attitudes inherited by the American-born from their ancestors' country of origin, using the General Social Survey database. Using this inherited part of civic attitudes by country of origin as an instrument for civic attitudes in the home country, the authors show that there is a significant impact of civic attitudes on unemployment benefits and on employment protection in OECD countries during the period 1980-2003.

\section{6/ Institutions, Policies and Trust}

\subsection{Can trust be changed? Putnam I versus Putnam II}

If trust plays a key role to explain economic outcomes, it becomes urgent to identify the institutions and public policies for it to develop. Research related to this subject is still in its early stages. As discussed in Section 3.3, a large part of the literature considers trust to be a cultural component hardly malleable, whose determinants have to be searched for in the long history of each country, and little room for immediate action. Yet, recent studies looking at immigrants show that their level of trust converge gradually to the average level of trust in their country of destination. 
This ambiguity is well illustrated by the two conflicting view of the evolution of trust given by Putnam in his two books dating from 1993 and 2000. According to Putnam I (1993), social capital is largely determined by history. Elevated levels of social capital in the regions of North Italy compared to those in the South originated in the free-city experience during the medieval.

Contrarily, according to Putnam II (2000), trust evolves quickly and is strongly influenced by the environment. In his book Bowling Alone Putnam shows that the levels of social capital, as measured by associations and club membership, have starkly declined in the United States since World War II. One of his main explications of this decline is the individualization of leisure activities, with an increasing amount of time spent to watching television. Olken (2011) also identifies a negative impact of television and radio on association membership and self-reported trust in Indonesia by using variation in Indonesia's mountainous terrain and differential introduction of private television.

Depending on which perspective we take from Putnam I or Putnam II, the room for policy intervention would be rather small or large. Section 3.3 above documents that both approaches have an element of truth. Trust is partly inherited from past generation and shaped by historical shocks, because the underlying beliefs regarding the benefits of trust and cooperation are transmitted in communities through families (Bisin and Verdier 2001, Benabou and Tirole 2006, Tabellini 2008b, Guiso et al. 2008b). But another part of trust is shaped by personal experience from the current environment, let it be social, economic and political. In Bisin and Verdier's terminology, both the vertical channel of transmission from parents and the oblique/horizontal channel from the contemporaneous environment are at play in the fabric of trust.

This debate on the adjustment of trust to its environment also depends on what generalized trust really measures. If trust consists of beliefs about the trustworthiness of others, it is likely that individuals can update upward or downward their beliefs depending on the environment where they live, the civic spirit of their fellow citizens and the transparency of their institutions. If trust consists of ingrained preferences and moral values, transmitted in early childhood and disconnected from personal experience as suggested by Uslaner (2002) and others, it might take more time to adjust. In the latter case, the action steps necessary to increase trust differ and depend on long term policy, such as education. In this section, we consider the various policies that can shape both contextual beliefs and deeper preferences. 


\subsection{Institutions and Trust}

How can institutions, and which institution, shape trust? Do formal rules and norms embedded in institutions act as a complement or a substitute to informal values such as trust? Those questions are key to identify how and which specific institution could build up trust.

\section{a) Relation between trust and institutions}

Figure 14 shows a strong positive correlation between trust and the quality of the legal system for a sample of 100 countries. Figure 15 displays a similar correlation between trust and the quality of governance in 163 European regions. These correlations are robust to using different measures of institutional quality commonly used in the economic literature (see Table 6 a) and b)), such as the rule of law, the strength of property right protection, the enforcement of contracts, as well as government effectivity, accountability, corruption (Rothstein and Uslaner, 2005) and to controlling for other influences of institutional quality.

Recent papers try to go beyond this correlation by showing a causal impact of legal enforcement on trust. Tabellini (2008b) provide suggestive evidence that generalized morality is more widespread in European regions that used to be ruled by non-despotic political institution in the distant past. Using data from the General Social Survey, Tabellini regresses individual trust of US immigrants on various indicators of legal enforcement at stake in their ancestor's country at the end of the $19^{\text {th }}$ century. He finds that immigrants from countries with more democratic institutions in the distant past have inherited higher level of trust, even when controlling for historical economic development and school enrollment in the home country.

Naturally, this approach does not prove that past democratic institutions have a causal impact on trust. Since those institutions are invariant, they could pick up any other invariant aspect of the home country. Yet, Tabellini's analysis are intriguing since historical political institutions could explain up to $57 \%$ of the country of origin fixed effect. This share is much larger than the one explained by income per capita and education in the distant past. Institutions can have longlasting impact on social and economic outcomes, but the persistence channel goes through their effect on values. This is really different from the traditional explanation of the persistence of institutions through elites capture (Acemoglu et al., 2001). Weak legal enforcement forces citizens to rely on informal and local rules and to develop limited trust as opposed to generalized trust. A good illustration of this diffusion of limited morality in presence of weak institution is given by 
the Mafia. Gambetta (1993) documents that feudalism was formally abolished in Sicile much latter than in the rest of Europe (in 1812). The State was too weak to enforce the introduction of private property rights of the lands. The Mafia benefited from this institutional vacuum and offered local protection through informal patronage, drawing a clear distinction between those under its protection and the others. In the same vein, Section 3.2 above has documented recent studies showing that non-democratic and corrupt institutions in the long past in Italy or in the Hasburg Empire are related with lower trust nowadays.

Other contributions use natural experiments to show the effect of democratic institutions on cooperative behavior. Bardhan (2000) finds that farmers are less likely to violate irrigation rules when they themselves have set up those rules. Frey (1998) shows that tax evasion in Swiss cantons is lower when democratic participation is greater. All these different works are suggestive of an impact of democracy on cooperation. But even those latter natural experiments cannot rule out the existence of omitted factors determining both the selection of institutions and the response to institutions. Besides the precise mechanism through which democracy, and more generally formal rules, shapes cooperative behavior and the identification of its effect still needs more research (see Benabou and Tirole for a theoretical model that rationalize the interplay between laws and norms, 2011).

\section{b) Experimental games}

An alternative approach for identifying the effect of institutions on cooperation is to mimic formal and legal rules in the context of experimental games. Naturally formal and legal rules in experimental games differ from real institutions. But this has the advantage to provide a controlled experiment to estimate how people change their level of cooperation and trust depending on exogenous variations in the rules of the games.

Initially, the literature has looked at the interaction between formal and informal institutions, but in the context of cooperation with reputational incentives, such as repeated games (Kranton, 1996). One main conclusion of this approach is that legal enforcement can crowd out reputational incentives and thus can undermine informal institutions. Yet, this prediction seems to be very specific to situation of cooperation with reputational incentives, and do not apply to cooperation embedded in moral values such as generalized trust.

Fehr and Gatcher (2000) analyze cooperation in a public good game. The interesting idea of the two authors is to change the set-up of the traditional public good experiment by allowing the cooperators to punish the defectors. They show that the free riders are heavily punished even if punishment is costly and does not provide any material benefits for the punisher. The 
opportunity for costly punishment causes a large increase in cooperation levels because potential free riders face a credible threat. In the presence of a costly punishment opportunity, almost complete cooperation can be achieved and maintained during the games. The main conclusion is that human beings are conditional cooperators, they cooperate providing that other do. The introduction of formal rule is key for enforcing this conditional cooperation

Herrmann et al. (2008) have used this set-up to measure conditional cooperation in 16 different cities over the world. They find that cooperation for the funding of the public good is the highest in Boston or Melbourne and the lowest in Athens and Muscat. This ordering is highly correlated with the rule of law and the transparency of institutions in the corresponding country. More strikingly, Herrmann et al. find that participants in some cities like Athens display antisocial punishment behavior: that is they punish the high contributor instead of the low contributor. The weakness of the rule of law is a strong predictor of this anti-social behavior. Similarly, Rothstein (2011) have used various experiments with students in Sweden and Romania showing that their generalized trust and trust in civil servants decline substantially when they witness a police officer accepting a bribe. His interpretation is that the absence of transparency of institutions and civic spirit of public officials can have very large damaging effects on generalized trust. If public officials, who are expected to represent the law, are corrupt, people infer that most other people cannot be trusted neither.

Another promising research looks at the impact of democracy on cooperation in an experimental setting. Contrary to natural experiments, it is possible to control in the lab how cooperation changes when a policy is imposed endogenously through a democratic process or imposed exogenously. This is the design used by Dal Bo et al (2010). Subjects participate in several prisoners' dilemma games and may choose, by simple majority, to establish a policy that could encourage cooperation by imposing fines on non-cooperators. In some cases the experimental software randomly overrides the votes of the subjects and randomly imposes, or not, the policy. Before proceeding to play again with either the original or the modified payoffs, the subjects are informed of whether payoffs are modified and whether it was decided by their vote or by the computer. The authors show that the effect of the policy on the percentage of cooperative actions is 40 percent greater when it is democratically chosen by the subjects than when it is imposed by the computer.

All in all, these studies show that formal rules and conditional cooperation might work as a complement in sustaining cooperative behavior. This is the case when the content of the rules as in Dal Bo et al. (2010) create focal points or provide signals about the group members' willingness to cooperate. In other cases, the sudden introduction of formal rules or tougher 
incentives to cooperate might signal instead that principals do not trust agents or that noncooperative behavior is diffused in the society. For example, Falk and Kosfeld (2006) study the behavior of experimental subject in a role of agents choosing a level of production that was costly to them and beneficial to the principal (the authority). Before the agent's decision, the principal could decide to leave the choice of the level of production completely to the agent's discretion or impose a lower bound on the agent's production. In postplay interviews, most agents agreed with the statement that the imposition of the lower bound was a signal of distrust. In another study Galbiati, Schlag and Van der Weele (2011), investigate a similar effect in the context of cooperation in a minimum effort game. In this case the authors find that, when principals opt to introduce a formal cooperation rule after having observed agents' efforts levels in the first experimental round, most cooperative individuals might reduce their effort level. Eliciting individuals' expectations about others' efforts the authors find that if principals opt to introduce a formal sanctions for those that do not cooperate, most cooperative individuals infer to live in a society where non-cooperation is widespread.

\section{c) Co-evolution of trust and institutions}

Rather than stressing the causal impact of institutions, recent contributions look at the coevolution of trust and institutions, leading to multiple equilibria. The diffusion of limited morality can reinforce the weakness of institutions because a society with limited morality can be more tolerant of weaker compliance with legal enforcement. The society might thus be trapped in a bad equilibrium where mistrust and weak institutions reinforced each other. In this context, promoting better enforcement might not have any support and effect since limited morality makes the trade opportunities too negligible anyway. Several contributions have documented more precisely the type of institutions that could co-evolve with trust. In particular, recent contributions show the interplay between trust and regulation (Aghion et al. 2010, Pinotti 2012, Carlin, Dorobantu, and Viswanathan, 2009; Francois and Ypersele, 2009).

Figure 13 shows that there exists a negative correlation between generalized trust and the extent of market regulation, measured by the number of steps required to open a business. Aghion et al. (2010) document that this correlation works for a range of measures of trust, from trust in others to trust in firms and political institutions, as well as for a range of regulatory measures from product markets to labor markets.

Explanations of this negative correlation between trust and regulatory intervention by the public authorities are grounded in the assumption that the state must step in to regulate the relations among individuals when they are incapable of cooperating spontaneously. In this perspective, Aghion et al. (2010) present a simple model explaining this correlation. In their 
setup, individuals make two decisions: whether or not to become civic, and whether to become entrepreneurs or choose routine (perhaps state) production. Those who become uncivic impose a negative externality on others when they become entrepreneurs (e.g., pollute), whereas those who become civic do not. The community (through voting or some other political mechanism) regulates entry into entrepreneurial activity when the expected negative externalities are large. Regulation narrows choices and hence negative externalities. But regulation itself is implemented by government officials, who demand bribes when they are not civic-minded. In this model, when people expect to live in a civic-spirited community, they expect low levels of regulation and corruption, and so become civic. Their beliefs have a self-justifying property, as their choices lead to civic-mindedness, low regulation, and high levels of entrepreneurial activity. When, in contrast, people expect to live in an uncivic-minded community, they expect high levels of regulation and corruption, and do not become civic. Again, their beliefs are justified, as their choices lead to uncivic-mindedness, high regulation, high corruption, and low levels of entrepreneurial activity. The model has two equilibria: a good one with a large share of civic individuals and no regulation, and a bad one where a large share of uncivic individuals support heavy regulation. Production and welfare are higher in the good equilibrium.

The model explains the correlation between regulation and distrust, and also has a number of further implications which are empirically documented using international surveys. The model predicts, most immediately, that distrust influences not just regulation itself, but also the demand for regulation. Distrust generates demand for regulation even when people realize that the government is corrupt and ineffective; they prefer state control to unbridled activity by uncivic entrepreneurs.

The most fundamental implication of the model, however, is that beliefs (as measured by distrust) and institutions (as measured by regulation) co-evolve. Beliefs shape institutions, and institutions shape beliefs. The interactions between institutions and beliefs comprise complementarities that induce multiple equilibria, as in Aghion, Algan and Cahuc (2011).

Beyond regulation, trust and social capital are likely to affect the overall quality of institutions and government through political accountability. This is the point made by Nannicini et al. (2012). In a political agency model, the authors show that civic agents are more likely to hold politicians accountable for the aggregate social welfare of the community. They tend to punish politicians who pursue vested interests and grab rents for some specific groups. In contrast, uncivic agents votes are based on their own or group-specific interest and are more tolerant with amoral politicians. Nannicini et al. (2013) convincingly test the prediction of their model by using cross-district variation in the criminal prosecution of members of the Parliament 
in Italy. They find that the electoral punishment of political misbehavior, corresponding to receiving a request of criminal prosecution or shirking in parliamentary activity, is considerably larger in electoral districts with high social capital.

\subsection{Community characteristics}

Distinguished from formal institutions, a large body of the research stresses the role of community characteristics in building trust. One of the most prominent factors identified in this realm is the extent of inequality and ethnic fractionalization.

\section{a) Inequality}

The focus on inequality is fueled by the strong negative correlation between trust and Gini indexes across countries and US states in Figures 16 and 17. High-trusting societies are also more equal, measured by low Gini coefficients, while low-trusting societies show typically higher levels of income inequality, as given by high Gini coefficients. Cross-country and cross-US states regressions controlling for income, population, education and ethnic fractionalization confirm this correlation (see Table 7). Alesina and La Ferrara (2000) shows that this negative relationship between trust and income inequality also holds at a more local level within US localities and municipalities. Rothstein and Uslaner (2005) documents a within US states correlation between the rise in equalities and the decline of trust over the last decades.

A pending issue is that of causality. Inequality might correlate negatively with trust for several reasons. First, as suggested by Rothstein and Uslaner, high levels of trust and cooperation might go along with high preferences for redistribution and can so contribute to lower inequality. On the reverse, high inequality can possibly make individuals to perceive themselves unfairly treated by people belonging to social classes different from their own, such that they restrict cooperative action and trust to members from their own class (Rothstein and Uslaner 2005). Future research is still needed to nail down the causal effect of inequality on trust.

\section{ii) Ethnic Fractionalization and segmentation}

The second community characteristic that has attracted attention is ethnic fractionalization or segregation. In a highly debated contribution, Putnam (2007) argues that ethnic diversity drives down trust. Using cross-cities evidence, the author shows that in ethnically diverse neighborhoods residents, trust is lower, altruism and community cooperation rarer and friends fewer. Alesina and La Ferrara $(2000,2002)$ find similar evidence across US-States. The 
explanation for this result is that individuals have natural in-group preferences and have a tendency to trust less people that are different from them. In the same vein, higher ethnic diversity is associated with lower cooperation as measured by the level of funding and the quality of public goods (Alesina et al. 1999 and Miguel and Gugerty 2005). The main explanation of why ethnic diversity affects those outcomes are the heterogeneity of preferences and the free-rider problem which undermines collective action. Uslaner (2012) challenges Putnam's thesis and argues that residential segregation, rather than ethnic diversity per se, drives down trust. Using cross-US states evidence, Uslaner shows that both integrated and diverse neighborhoods are associated with higher levels of trust only when people have diverse social networks. Conversely, in areas with a lot of segregation and where individuals from different ethnic backgrounds cannot meet each other, distrust is higher. One conclusion is that immigration and urbanization policy should avoid ethnic gethos to maintain trust.

Yet, the literature on the relationship between cooperation and diversity raises an important identification issue. Due to endogenous residential sorting of individuals on ethnic grounds, the estimates are likely to be biased. The attempts to establish causality rely mainly on instrumental variables. However convincing the instruments might be, this strategy cannot overcome the concern as to whether the instruments fulfill the exclusion restriction and do not have a direct effect on public goods. For instance, Miguel and Gugerty (2005) use the precolonial patterns of settlement as instruments, assuming that these variables have no direct impact on present-day ethnic relations. But since past settlement patterns are likely to have at least some direct impact on the present-day level of cooperation, the exclusion restriction might still be violated. Algan et al. (2013) address this issue by using a natural experiment in which households in France are allocated to public housing blocks without taking their ethnic origin or their preference for diversity into account. Due to a strongly republican ideology, the French public housing system allocates state planned moderate cost rental apartments to natives and immigrants without concern for their cultural and ethnic background, mixing people indiscriminately. Using data from housing blocks made up of twenty adjacent households, the authors show that higher ethnic diversity is associated with social anomia rather than distrustful relationships. Yet, more research has to be done before drawing policy conclusions. One of the most promising agenda would be to used a randomized housing mobility program, on the likes of the Moving to Opportunity (see Katz et al. 2012), to investigate how the changes in the ethnic composition of the neighbors modify cooperation and trust.

\subsection{Education and Trust}


A large literature argues that a central component trust derives from moral values deeply ingrained in personality traits, and does not just boil down to context-dependent beliefs about other's trustworthiness. A trusting person that accidentally meets an non-trustworthy person will not change his moral values right away. Moral values of cooperation have a rather stable component because they have been shaped in the early ages by parents or at school. In this section, we review the evidence on the relationship between education and trust.

There is some evidence that a greater quantity of schooling is associated with higher social capital (Helliwell and Putnam 2007, Glaeser et al. 2007). Yet, variation in the average years of education of the population across developed countries is too small to explain the observed cross-country differences in trust.

Algan, Cahuc and Shleifer (2012) propose a complementary explanation by looking at the relationship between how students are taught and students' beliefs in cooperation. They show that methods of teaching differ very widely across countries, and between schools and within schools within a country. Some schools and teachers emphasize vertical teaching practices, whereby teachers primarily lecture, students take notes or read textbooks, and teachers ask students questions. The central relationship in the classroom is between the teacher and the student. Other schools and teachers emphasize horizontal teaching practices, whereby students work in groups, do projects together, and ask teachers questions. The central relationship in the classroom is among students. Consistent with the idea that beliefs underlying social capital are acquired through the practice of cooperation, and that social skills are acquired in early childhood, Algan, Cahuc and Shleifer (2012) test whether horizontal teaching practices can develop social capital. They use various international surveys, like the Civic Education Study (CES), the Trends in International Mathematics and Science Study (TIMSS) and the Progress in International Reading Literacy (PIRLS), covering around sixty countries. They emphasize the distinction between "teacher lectures" and "students work in groups" as measures of vertical and horizontal teaching practices respectively.

Figure 18 show that teaching practices vary systematically across countries. The $\mathrm{x}$-axis represent the average gap between vertical teaching ("teachers lecture") and horizontal teaching ("students work in group") in a typical hour of class. The higher the indicator, the more the country is tilted towards vertical teachings. Students work in groups more in Nordic countries (Denmark, Norway, Sweden) and Anglophone ones (Australia, United States and to a lesser extent Great Britain). This teaching practice is less common in east European countries and in the Mediterranean (Greece, Cyprus, Portugal and, to a lesser extent, Italy). In these countries, teachers spend more time lecturing. Education in some countries like France is almost entirely 
based on vertical teaching. Figure 18 also shows that vertical teaching is highly negatively correlated with generalized trust across countries. This result still holds when per capita income, education expenditures and average years of education are controlled for.

The authors then investigate within-schools and within-classrooms variation in teaching practices to identify the causal impact of these practices on students' beliefs. By looking at teaching practices and student beliefs across classrooms within a school, the authors can alleviate concerns regarding omitted variables that might drive the self-sorting of parents, students and teachers into schools. They also use within-classroom variation in teaching practices and student beliefs. This strategy eliminates concerns about omitted variables linked to selection into classrooms. It also provides an alternative strategy for excluding reverse causality by comparing teaching practices of different teachers faced with exactly the same group of students. The authors show that horizontal teaching practices have a substantial positive impact on students' social capital (trust in teachers, in other students, association membership...), while vertical teaching practices crowd out beliefs in cooperation. The relationship between working in groups and student's social capital is robust whatever the specification: across schools, within schools and within classrooms. The within school (and within classroom) estimates allow the authors to address self-selection and reverse causality. But another concern is that horizontal teaching practices just proxy for a teacher being good or nice. This is a traditional issue raised by crosssection analysis since it is impossible to control for teacher fixed effect in this setting. The authors show that teaching practices are not a proxy for "good" or "nice" teachers based on observable teacher characteristics. But the teaching practice can still be driven by an unobserved teacher (or student) characteristic.

A promising avenue of research would consist in providing randomized evaluations of early childhood intervention aimed at developing children social skills, e.g their aptitude to cooperate with others. This investigation is timely and important given that recent longitudinal studies suggest that much of the impact of programs that improve adult achievement (such as the Perry Preschool program or project STAR) flows through some sort of non-cognitive channel, and thus raise the question of what those non-cognitive skills are, and how much of the impact comes through social skills (see Heckman et al. for a recent synthesis, 2012). In the literature, non-cognitive skills embrace all personality traits that are non-related to cognitive skills (e.g, IQ and grades), such as self-esteem and emotional well-being measured on psychological scales. This is thus a rather vague notion and it is still unclear how non-cognitive skills relate to social skills. Besides, there is little evidence on whether and how intervention can improve those skills, in particular among children the most at risk of becoming anti-social adults. 
Algan, Beasley, Tremblay, and Vitaro. (2012) provide a first attempt to estimate the longterm effects of an early intervention that is specifically dedicated to social skills development. The authors use data from a large and detailed longitudinal study following the social, cognitive, and emotional development of 895 men who were kindergarteners in neighborhoods of low socioeconomic status in Montreal in 1984. The study incorporates a randomized evaluation of an intensive two-year social skills training program at the beginning of elementary school for the most disruptive subjects $(\mathrm{n}=250)$. The training program involves the subjects themselves, parents, and peers. These detailed data are matched with self-reported outcomes and administrative records. As adults, the subjects in the treated group have significantly better labor market performance than the non-treated group, with an increase in the likelihood of employment at age 26 of 10 percentage points. Individuals who belong to the treated group have significantly more favorable social outcomes, measured by lower criminality rates and higher social capital. By distinguishing the different cognitive and non-cognitive channels through which this intervention operates, the authors find that the only significant channel for economic outcomes is social skills. The overall rate of return of this program in terms of expected lifecycle income ranges from $282 \%$ to $452 \%$, implying that every $\$ 1$ invested yields $\$ 2.8$ to $\$ 4.5$ in benefits. This result provides room for policy intervention to develop social skills in the early childhood. They call for future experiments to assess the deep personality traits that explains social skills and how they relate to non-cognitive skills.

\section{7/ Future avenues: Trust and Well-Being}

This survey documents two main findings. First, trust has a causal impact on economic development, through its channels of influence on the financial, product, and labor markets, and with a direct effect on total factor productivity and organization of firms. Second trust and institutions strongly interact, with causality running in both directions. These findings set new avenues of research to identify the policies that could promote social capital and cooperation, from rule of law and democracy to education policies.

This survey has mainly focused on economic and institutional issues related to trust. Yet there is a growing consensus that economic development is poorly measured by income per capita alone, and should include measures of well-being. One reason for that is the well-known Easterlin paradox, stressing that the increase in income per capita within countries have not been associated with an increase in happiness. To explain this result, recent contributions suggest that well-being depend essentially on the quality of social relationship, instead of individual income. From this perspective, we should expect a strong correlation between trust and well-being. 
Figure 19 illustrates this relationship by using measures of life satisfaction from the World Values Survey question: "All things considered together, how satisfied are with your life as a whole these days". Life satisfaction ranges from 1 to 10, a higher score indicating a higher life satisfaction. The correlation between life satisfaction and generalized trust is positive: 17 percent of the variance in life satisfaction is associated to cross-country differences in generalized trust, with few outliers like Portugal. The same positive correlation holds if we consider the question on happiness: "Taking all things together, would you say that you are: very happy, happy, quite happy, not happy, not at all happy?”. Similarly, the Human Development Index (a composite index of long and healthy life, knowledge and standard of living, from UNDP 2011).

Helliwell and Wang (2011) provide cross-country micro evidence on the positive relationship between trust and well-being. From the 2006 wave of the Gallup World Poll, they use the wallet trust question for 86 countries. Individuals are asked what is the hypothetical likelihood of the respondent's lost wallet (with clear identification and $200 \$$ cash) being returned if found by a neighbors, a police officer or a stranger. Helliwell et Wang estimate that an increase in income by two-third is necessary to compensate the welfare loss associated with thinking that no one will bring your purse and your documents. For example, to live in a country like Norway (highest mean expect wallet return of 80\%) rather than in Tanzania (lowest mean expected wallet return of $27 \%$ ) is equivalent to an increase by $40 \%$ of household income. Helliwell and al. (2009) shows that the same result holds in the workplace. Using micro data from Canada (2003 wave Equality, Security and Community Survey) and US (2000 wave of the Social Capital Benchmark Survey), the authors find that the climate of trust in the workplace, in particular trust in the managers, is strongly related to subjective well-being. On a 1-10 scale, an increase by one point of trust in managers has the same effect on life satisfaction as an increase in household income by thirty percent. .

Examining our psychological reactions allows us to better understand the importance of these relations. Imagine that you participate in the trust game, but that one measures now the level of oxytocin in your blood. As mentioned above, oxytocin is a neurotransmitter released by our lymbic system, the part of our brain which is responsible for pleasure or fright. Zak et al. (2004) have tried to find out if trust and reciprocity are equally linked to that love hormone. For that, they have applied the trust game during which levels of oxytocin are measured in the blood of the receiver, once he finds out whether the sender has trusted him by sending a non-negligible amount. The results indicate that trust "produces" happiness: the more the signaled level of trust is increased (meaning, the more the amount transferred is increased) the more the level of 
oxytocin increases in the blood of the receiver. Zak et al. (2004) have also experimented a variant particularly instructive, in which the receiver receives a monetary transfer not from a real person, but a from a lottery. In this variant, the level of oxytocin does not rise with the money received. This result well illustrates that it is trust that is associated with sentiments of happiness, and not the mere fact to receive money.

These results have been confirmed by brain images made by Sanfey et al (2003). As soon as the participants of the trust game note that the others do not cooperate, the insular part of the cortex in their brain illuminates. This brain part is known for being active in states of pain and disgust. The main conclusion of this line of research is that the non-monetary dimension of having cooperative social relationship with others affects more happiness than the monetary gains derived from cooperation. All in all, those results suggest that trust affects many dimensions of economic development, including both income and happiness, and is a key component of human development at large. 


\section{References}

Acemoglu, D., Robinson, J., Johnson, S., 2001, The Colonial Origins of Comparative Development: An Empirical Investigation, American Economic Review, 91: 1369-1401.

Aghion, P., Algan, Y., Cahuc, P., 2011, Can Policy affect culture? Minimum Wage and the Quality of Labor relations, Journal of the European Economic Association, vol 9(1): 3-42.

Aghion, P., Algan, Y., Cahuc, P., Shleifer, A., 2010, Regulation and Distrust, Quarterly Journal of Economics, 125(3): 1015-1049.

Aghion, P., Tirole, J., 1997, Formal and Real Authority in Organizations, The Journal of Political Economy, Vol. 105(1): 1-29.

Alesina A., Baqir, R., Easterley, W., 1999, Public Goods and Ethnic Divisions, Quarterly Journal of Economics, Vol. 114(4), pp. 1243-1284.

Alesina, A., La Ferrara, E., 2000, Participation in Heterogeneous Communities, Quarterly Journal of Economics, Vol. 115(3), pp. 847-904.

Alesina, A., La Ferrara, E., 2002, Who trust others?, Journal of Public Economics, vol (85)2, pp. 207-234.

Algan, Y., Cahuc, P., 2009, Civic Virtue and Labor Market Institutions, American

Economic Journal: Macroeconomics, 1(1): 111-145.

Algan, Y., Cahuc, P., 2010, Inherited Trust and Growth, American Economic Review, 100: 2060-2092.

Algan, Y., Cahuc, P., Sangnier, M., 2011, Efficient and Inefficient Welfare States, Institute for the Study of Labor, DP 5445.

Algan, Y., Cahuc, P., Shleifer, A., 2012, Teaching Practices and Social Capital, American Economic Journal: Applied Economics, forthcoming.

Algan, Y., Hémet, C., Laitin, D., 2012, Diversity and Public Goods in a Republican Setting., working paper, Sciences Po.

Algan, Y., Benkler, J., Hergueux, J., 2012, Cooperation and Trust on the Web: Field experiments from Wikipedia, working paper, Sciences Po.

Algan, Y., Beasley, E., Tremblay, R., Vitaro, F., 2012, The Long Term Impact of Social Skills Training at School Entry: a randomized controlled trial, Working paper.

Almond, G., Verba, S., 1989, 1st ed. 1963. The Civic Culture: Political Attitudes and Democracy in Five Nations. London: Sage Publications.

Ashraf, Q and O Galor. 2013. The 'Out-of-Africa' Hypothesis, Human Genetic Diversity, and Comparative Economic Development." American Economic Review.

Banfield, E., 1958, The Moral Basis of a Backward Society. New York: Free Press.

Barr, A., Serneels, P., 2009, Reciprocity in the workplace. Experimental Economics, 12(1), pp.99-112.

Becker, S., Boeckh, K., Hainz, C., Woessmann, L., 2011, The Empire Is Dead, Long Live the Empire! Long-Run Persistence of Trust and Corruption in the Bureaucracy, IZA, Discussion Paper No. 5584, Mars 2011.

Belloc, M., Bowles, S., 2009, International Trade, Factor Mobility and the Persisstence of Cultural-Institutional Diversity, CESIFO working paper 2762.

Belows, J., Miguel, E., 2009, War and Local Collective Action in Sierra Leone, Journal of Public Economics, 93(11-12): 1144-1157.

Benabou, R., Tirole, J., 2011, Laws and Norms, NBER Working paper n¹7579.

Benabou, R., Tirole, J., 2006, Incentives and Prosocial Behavior, American Economic Review, 96(5), pp. 1652-1678.

Berg, J., Dickhaut, J., McCabe, K., 1995, Trust, Reciprocity and Social History, Games and Economic Behavior, .10: 122-42. 
Bertrand M., Schoar A., 2006, The Role of Family in Family Firms, The Journal of Economic Perspectives, vol. 20(2): 73-96.

Black, S., Lynch, L., 2001, How to compete : the Impact of Workplace practices and Information Technology on Productivity, Review of Economics and Statistics, 83(3), pp. 434445.

Bidner, C., Francois, P., 2011, Cultivating Trust: Norms, Institutions and the Implications of Scale. Economic Journal, 121(5): 1097-1129.

Bisin, A., Verdier, T., 2001, The Economics of Cultural Transmission and the Dynamics of Preferences, Journal of Economic Theory, 97, 298-319.

Blanchard, O., Philippon, T., 2004, The Quality of Labor Relations and Unemployment, MIT Department of Economics Working Paper No. 04-25

Bardhan, P., 2000, Irrigation and Cooperation: An Empirical Analysis of 48 Irrigation Communities in South India, Economic Development and cultural change, 48(4): 847-65.

Black, S., Lynch, L., 2001, How to Compete: The Impact of Workplace Practices and Information Technology on Productivity, The Review of Economics and Statistics, 83(3), p. 434445.

Bloom N., Sadun, R., Van Reenen, J., 2010, Recent Advances in the Empirics of organizational Economics, Annual Review of Economics, vol. 2(1), pp. 105-137

Bloom N., Sadun, R., Van Reenen, J., 2011, The organization of firms across countries, Working Paper.

Bohnet, I., Zeckhauser, R., 2004, Trust, Risk and Betrayal, Journal of Economic Behavior \& Organization, v. 55, 467-484.

Bowles, S., Ginthis, H., 2007, Cooperation, in The New Palgrave Dictionary of Economics, eds L. Blume and S.Durlauf.

Bowles, S., Polania-Reyes, S., 2012, Economic incentives and Social Preferences: Substitutes or Complements?, Journal of Economic Literature, vol. 50(2), pp. 368-425. 15344

Butler, J., Paola, G., Guiso, L., 2009, The Right Amount of Trust, NBER Working paper

Capra , M., Lanier, K., Meer, S., 2008, Attitudinal and Behavioral Measures of Trust: A

New Comparison, working paper, Dept of Economics, Emory University.

Carlin, B. I., Dorobantu F., Viswanathan S., 2009, Public trust, the law, and financial

investment, Journal of Financial Economics, vol. 92(3), pp. 321-341.

Castillo, M., Carter, M., 2011, Behavioral, Responses to Natural Disasters, Working Paper, University of Wisconsin-Madison,

Cavalli-Sforza, L.L., Feldman, M., 1981, Cultural Transmission and Evolution: A Quantitative Approach, Princeton, Princeton University Press.

Cingano, F., Pinotti, P., 2012, Trust, Firm Organization, and the Structure of Production, Working paper.

Cole, S., Gine, X., Tobacman, J., Townsend, R., Vickery, J., 2012, Barriers to Household Risk Management: Evidence from India, American Economic Journal: Applied Economics, forthcoming.

Coleman, J., 1990, Foundations of Social Theory, Harvard University Press.

Cox, J., 2004, How to identify trust and reciprocity, Games and Economic Behavior, vol. 46, pp. 260-81.

Dal Bo, P., Forster, A., Putterman, L., 2010, Institutions and Behavior, Experimental evidence on the effects of democracy, American Economic Reveiw, vol 100(5), pp. 2205-2229.

Dinesen, P.T., 2011, Parental transmission of trust or perceptions of institutional fairness? Explaining generalized trust of young non-Western immigrants in a high-trust society, forthcoming, Comparative Politics.

Dinesen, P.T., Hooghe, M., 2010, When in Rome, Do as the Romans Do: The Acculturation of Generalized Trust among Immigrants in Western Europe, International 
Migration Review, 44(3), pp. 697-727.

Dohmen, T., Falk, A., Huffman, D., Sunde, U., 2012, The Intergenerational Transmission of Risk and Trust Attitudes, Review of Economic Studies, 79(2): 645-677.

Durante, R., 2010, Risk Cooperation and the Economic Origin of Social Trust: An Empirical Investigation, Working Paper, Economic Department, Sciences-Po.

Durlauf, S., 2002, On the empirics of social capital, Economic Journal, vol. 112(438), pp. 459-479.

Durlauf, S., Fafchamps, M., 2005, Social Capital, Handbook of Economic Growth, in Philippe Aghion and Steven Durlauf (ed.), Handbook of Economic Growth, vol. 1, chapter 26, pp. 1639-1699.

Ellison G., 1994, Cooperation in the Prisoner's Dilemma with Anonymous Random Matching, The Review of Economic Studies, vol. 61(3), pp. 567-588.

Ermisch, J., Gambetta, D., 2010, Do strong family ties inhibit trust?, Journal of Economic Behavior and Organisations.

Ermisch, J., Gambetta, D., Heather, L., Siedler, T., Uhrig, N., 2009. Measuring people's trust, Journal of the Royal Statistical Society Series A, Royal Statistical Society, vol. 172(4), pages 749-769.

Falk, A., Kosfeld, M., 2006, The Hidden Costs of Control, American Economic Review, vol. 96(5), pp. 1611-1630.

Fehr, E., Schimdt, K., 1999, A Theory of Fairness, Competition and Cooperation, Quarterly Journal of Economics, vol. 114(3) , pp. 817-868.

Fehr, E., Gatcher, S., 2000, Cooperation and Punishment in Public Goods Games, American Economic Review, vol. 4, , pp. 980-994.

Fehr, E., Fischbacher, U., Schupp, B., Von Rosenbladt, J., Wagner, G., 2002, A Nation Wide Laboratory. Examining Trust and Trustworthiness by integrating behavioral experiments into representative surveys, CESifo working paper.

Fehr, E., Camerer, C.F., 2004. Measuring Social Norms and Preferences Using Experimental Games: A Guide for Social Scientists. Foundations of Human Sociality, 1(9), pp.55-96.

Fehr, E., 2009, On the Economics and Biology of Trust, Presidential address at the 2008 meeting of the European Economic Association, Journal of the European Economic Association, v. 7 (2-3), 235-266, 04-05.

Fernandez, R., 2010, Does Culture Matter?, in J. Benhabib, A. Bisin and M.O Jackson (eds), Handbook of Social Economics.

Fisman, R., Miguel, E., 2007, Culture of corruption: evidence from diplomatic parking ticket," Journal of Political Economy, 115(6), 2007, pp. 1020-1048.

Francois, P., Zabojnik, J., 2005. Trust, Social Capital, and Economic Development, Journal of the European Economic Association, MIT Press, vol. 3(1): 51-94, 03.

Francois, P. , Ypersele van, T., 2009, Doux commerce: does market competition cause trust?, Working paper.

Frey, B., 1998, Institutions and Morale: The Crowding-out Effect, in Economics, Values, and Organization, ed. Avner Ben-Ner and Louis Putterman, pp. 437-460, New York: Cambridge University Press.

Fukuyama, F., 1995, Trust: The Social Virtues and the Creation of Prosperity, New York: Free Press.

Galbiati, R., Vertova, P. 2008, Obligation and Cooperative Behavior in Public Good Games, Games and Economic Behavior 64 (1), pp146-170

Gambetta, D., 1993, The Sicilian Mafia. The Business of Private Protection, Harvard University Press

Gennaioli, N., La Porta, R., Lopez-de-Silanes, F., Shleifer, A., 2012, Human Capital and Regional Development, Quarterly Journal of Economics, forthcoming 2013. 
Gintis, H., Bowles, S., Boyd, R., Fehr, E., 2005, Moral Sentiments and. Material Interests: Origins, Evidence, and. Consequences. chapter 1, in Moral Sentiments and. Material Interests, MIT Press.

Glaeser, E., Laibson, D., Scheinkman, J., Soutter, C., 2000, Measuring trust, Quarterly Journal of Economics 115, pp. 811-846.

Glaeser, E., La Porta, R., Lopez-de-Silanes, F., Shleifer, A., 2004, Do Institutions Cause Growth?, Journal of Economic Growth, 9 , 271-303.

Greif, A., 1993, Contract Enforceability and Economic Institutions in Early Trade: The Maghribi Traders' Coalition. American Economic Review, 83 525-48.

Greif, A., 1994, Cultural Beliefs and the Organization of Society: A Historical and Theoretical Reflection on Collectivist and Individualist Societies, Journal of Political Economy. 102: 912-50.

Greif, A., Tabellini, G., 2010. Cultural and Institutional Bifurcation: China and Europe compared, American Economic Review Papers and Proceedings, vol. 100(2), pp. 1-10.

Guiso, L., Jappelli, T., 2005, Awarness and Stock Market Participation, Review of Finance, 9(4), 537-567.

Guiso, L., 2010, A Trust-driven Financial Crisis, Implications for the Future of Financial Markets, EIEF Working paper.

Guiso L., Parigi, G., 1999, Investment And Demand Uncertainty, Quarterly Journal of Economics, vol. 114(1), pp. 185-227.

Guiso L., Sapienza, P., Zingales, L., 2004, The Role of Social Capital in Financial Development, American Economic Review, vol. 94, n. 3, pp. 526-56.

Guiso L., Sapienza, P., Zingales, L., 2006, Does Culture Affect Economic Outcomes?, Journal of Economic Perspectives, vol. 20(2), pp. 23-48.

Guiso L., Sapienza, P., Zingales, L., 2008a, Trusting the Stock Market, Journal of Finance, 63(6), pages $2557-2600$.

Guiso L., Sapienza, P., Zingales, L., 2008b, Long Term Persistence, Working Paper 14278, National Bureau of Economic Research August 2008.

Guiso L., Sapienza, P., Zingales, L., 2008c, Alfred Marshall Lecture: Social Capital as Good Culture. Journal of the European Economic Association, 6(2-3): 295-320.

Guiso L., Sapienza, P., Zingales, L., 2009, Cultural Biases in Economic Exchange, Quarterly Journal of Economics, 124(3).

Guiso, L., 2010, "A trust-driven financial crisis. Implications for the future of financial markerts”, EIEF Working Paper.

Guiso L., Sapienza, P., Zingales, L., 2011, Civic Capital as the Missing Link, Handbook of Social Economics, Volume 1A, Jess Benhabib, Alberto Bisin, and Matthew O. Jackson, eds.

Hall, R., Jones, C., 1999, Why Do Some Countries Produce So Much More Output Per

Worker Than Others, Quarterly Journal of Economics, v. 114 (1), 83-116. forthcoming.

Haushofer, J., Fehr, E., The psychology and neurobiology of poverty, Science,

Hauk, E., Saez-Marti, M., 2002, On the cultural transmission of corruption. Journal of Economic Theory, 107 (2), 311-335.

Helliwell, J., Putnam, R., 2007, Education and Social Capital, Eastern Economics Journal, 33(1): 1-19.

Helliwell, J., Huang H., Putnam, R., 2009, How is the Job? Are Trust and Social Capital Neglected in Workplace Investments? in Viva Bartkus et Jim Davis (editors), Social Capital, Reaching on Reaching in. Edward Elgar.

Helliwell J., Wang, S., 2010, Trust and Well-Being, International Journal of Well-Being, 1(2): 42-78

Heckman, J.J, Malofeeva, L., Pinto, R., Savelyev, P., 2012, Understanding the Mechanisms Through Which an Influential Early Childhood Program Boosted Adult Outcomes, 
American Economic Review, forthcoming.

Herrmann, B., Thöni, C., Gachter, S., 2008, Antisocial Punishment across societies, Science, vol. 319, 2008.

Hirshman, A., 1970, Exit, Voice, and Loyalty: Responses to Decline in Firms, Organizations, and States. Harvard University Press.

Hoff, K., Kshetramade, M. and E. Fehr, 2011, Caste and Punishment: the legacy of caste culture in norm enforcement, Economic Journal, 121, 449-475.

Holm, H., Danielson, A., 2005, Tropic trust versus Nordic trust: Experimental evidence from Tanzania and Sweden, The Economic Journal 115: 505-532.

Ichino, A., Maggi, G., 2000, Work Environment and Individual Background: Explaining Regional Shirking Differentials in a Large Italian Firm. Quarterly Journal of Economics, 115(3): 1057-1090.

Jacob, M., Tyrell., M., 2010, The Legacy of Surveillance: An Explanation for Social Capital Erosion and the Persistence of Economic Disparity Between East and West Germany. Mimeo, European Business School Oestrich-Winkel.

Kandori, M., 1992, Social Norms and Community Enforcement, Review of Economic Studies, 59, 63-80.

Karlan, D., 2005, Using Experimental Economics to Measure Social Capital and Predict Financial Decisions, American Economic Review, 95(5), pp. 1688-1699.

Kahneman, D., Tversky, A., 2000, Choices, Values and Frames, Cambridge University Press.

Kosfeld, M., Heinrichs, M., Zak, P., Fischbacher, U., Fehr, E., 2005, Oxytocin Increases Trust in Humans, Nature, 435, pp. 673-676.

Knack, S., Keefer, P., 1997, Does Social Capital Have an Economic Payoff? A CrossCountry Investigation, Quarterly Journal of Economics, v. 112 (4), 1252-88.

Knack, S., Zak, P., 1999, Trust and Growth, Economic Journal, v. 111 (470), 295- 321.

Kranton, R. 1996, Reciprocal Exchange, A Self-Sustaining System, American Economic Review, 830-851.

La Porta, R., Lopez-de-Silanes, F., Shleifer, A., Vishny. R., 1997, Trust in Large Organizations. American Economic Review Papers and Proceedings 87 (2): 333-8.

La Porta, R., Lopez-de-Silanes, F., Shleifer, A., 2008, The Economics Consequences of Legal Origins, Journal of Economic Literature, June.

Laury, S. K., Taylor, L.O., 2008. Altruism spillovers: Are behaviors in context-free experiments predictive of altruism toward a naturally occurring public good? Journal of Economic Behavior \& Organization, 65(1), pp.9-29.

Lazzarini, S., Artes, R., Madalozzo, R., Siqueira, J., 2005, Measuring trust: An experiment in Brazil, Brazilian Journal of Applied Economics 9(2) : 153-69.

Levine, R., 2004, Finance and Growth: Theory, Evidence and Mechanisms, Handbook of Economic Growth, ed., Aghion, P. and Durlauf; S., Amsterdam, Netherlands: North-Holland.

Lunje M., 2012, Inherited Trust and Economic Success of second generation immigrants, IFN Working paper

Michalopoulos, S., and Papaioannou, E., 2013, National Institutions and Subnational Development in Africa, Working Paper.

Miguel, E., M. K. Gugerty, 2005, Ethnic Diversity, Social Sanctions, and Public Goods in Kenya, Journal of Public Economics, Vol. 89(11), pp. 2325-2368

Miguel, E., Saiegh, S., Satyanath, S., 2011, Civil War Exposure and Violence, Economics and Politics, vol. 23, pp 59-73.

Mill, J.S. 1848, Principles of Political Economy. London: JohnW.Parker.

Nannicini, T., Stella, A., Tabellini, G., Troiano, U., 2013, Social Capital and Political Accountability, American Economic Journal: Economic Policy, forthcoming.

Nunn, N., 2008, The Long Term Effects of Africa's Slave Trades, Quarterly Journal of 
Economics, 123(1), pp. 139-176.

Nunn, N., Wantchekon, L., 2011, The Slave Trade and the Origins of Mistrust in Africa, American Economic Review, Vol. 101, No. 7, , 3221-3252.

Nunn, N., 2009, The Importance of History for Economic Development, Annual Review of Economics, vol. 1, 65-92.

Olson, M., 1971 [1965], The Logic of Collective Action: Public Goods and the Theory of Groups (Revised edition ed.). Harvard University Press.

Ostrom, E., 1990, Governing the Commons: The Evolution of Institutions for Collective Action, Cambridge: Cambridge University Press.

Putnam, R., Leonardi, R., and Nanetti, RY., 1993, Making Democracy Work. Princeton, NJ: Princeton University Press.

Putnam, R., 2000, Bowling Alone: The Collapse and Revival of American Community, New York: Simon and Schuster.

Rodrik, D., 1999, Where Did All the Growth Go? External Shocks, Social Conflict, and

Growth Collapses. Journal of Economic Growth, 4(4): 385-412.

Rohner D., Thoenig M., Zilibotti F., 2013, War Signals: A Theory of Trade, Trust and

Conflict, Review of Economic Studies, forthcoming.

Rothstein, B., Uslaner, E. M., 2005, All for One: Equality, Corruption, and Social Trust.

World Politics 58(1), 41-72.

Rothstein, B., 2011, The Quality of Government, Social Trust and Inequality in

International Perspective, University of Chicago Press.

Sachs, J, D., 2003, Institutions Don't Rule: Direct Effects of Geography on Per Capita

Income, National Bureau of Economic Research Working Paper 9490.

Sanfey, A.G, Rilling, J.K., Aronson, J.A., Nystrom, L.E et Cohen, J.D., 2002, The neural

basis of economic decision-making in the ultimatum game, Science, 300, pp. 1755-1758, 2003.

Smith, A. 1997[1766]), Lecture on the influence of commerce on manners. Reprinted in

(D. B. Klein,ed.) Reputation:Studies in the Voluntary Elicitation of Good Conduct,University of Michigan Press.

Spolaore, E., Wacziarg, R., How deep are the roots of economic development, Journal of Economic Literature, 2013.

Tabellini, G., 2008a, The Scope of Cooperation: Values and Incentives, The Quarterly

Journal of Economics, MIT Press, vol. 123(3): 905-950.

Tabellini, G., 2008b, Institutions and Culture, Journal of the European Economic

Association, Papers and Proceedings, vol. 6(2-3).

Tabellini, G., 2010, Culture and Institutions: Economic Development in the Regions of Europe, Journal of the European Economic Association, 8(4), pp. 677-716.

Uslaner, E.M., 2008. Corruption, Inequality and Trust, in Handbook on Social Capital,

Gert T. Svendsen and Gunnar L. Svendsen, ed., Edward Elgar.

Uslaner 2012, Segregatin and Mistrust: Diversity, Isolation and Social Cohesion, Cambridge University Press.

Valent, P., 2000, Disaster syndrome, in Encyclopedia of Stress. Ed. George Fink. New York: Academic Press.

Wallace, A., 1956, Tornado in Worcester: An Exploratory Study of Individual and Community Behavior in an Extreme Situation. Publication 392, National Academy of SciencesNational Research Council, Washington, D.C.

Zak, P., Kursban R., Matzner, W., 2004, The Neurobiology of Trust, Annals of the New York Academy of Sciences, pp. 224-227.

Zylberberg, Y., 2011, Do tropical typhoons smash community ties?, Working Paper, Paris School of Economics. 
FIGURES

Figure 1: World distribution of Trust

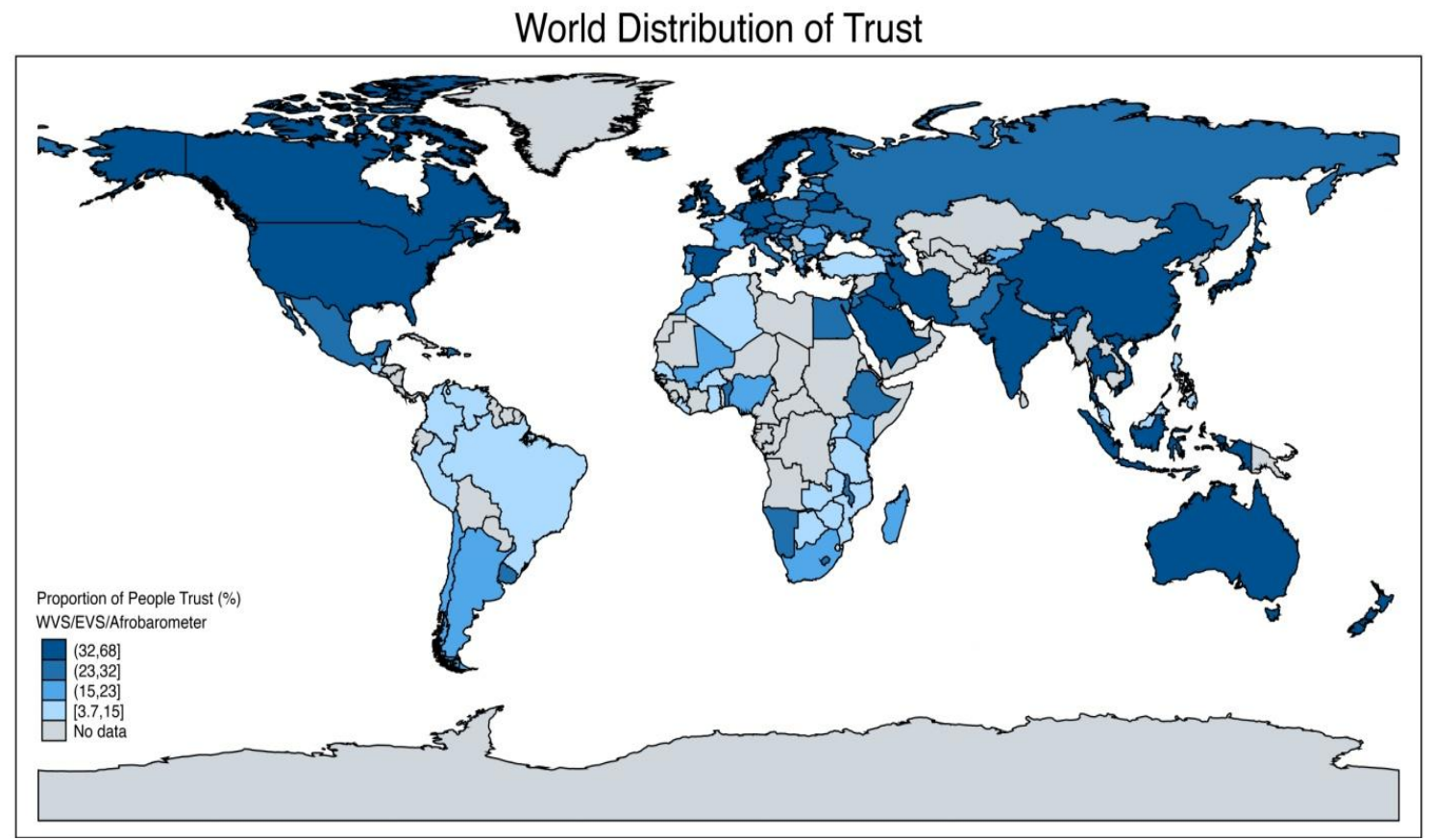

Sources: Trust is computed as the country average from responses to the trust question in the five waves of the World Values Survey (1981-2008), the four waves of the European Values Survey (1981-2008) and the third wave of the Afrobarometer (2005). The trust question asks "Generally speaking, would you say that most people can be trusted or that you need to be very careful in dealing with people?" Trust is equal to 1 if the respondent answers "Most people can be trusted" and 0 otherwise. 
Figure 1bis: Average Trust Levels in 111 countries

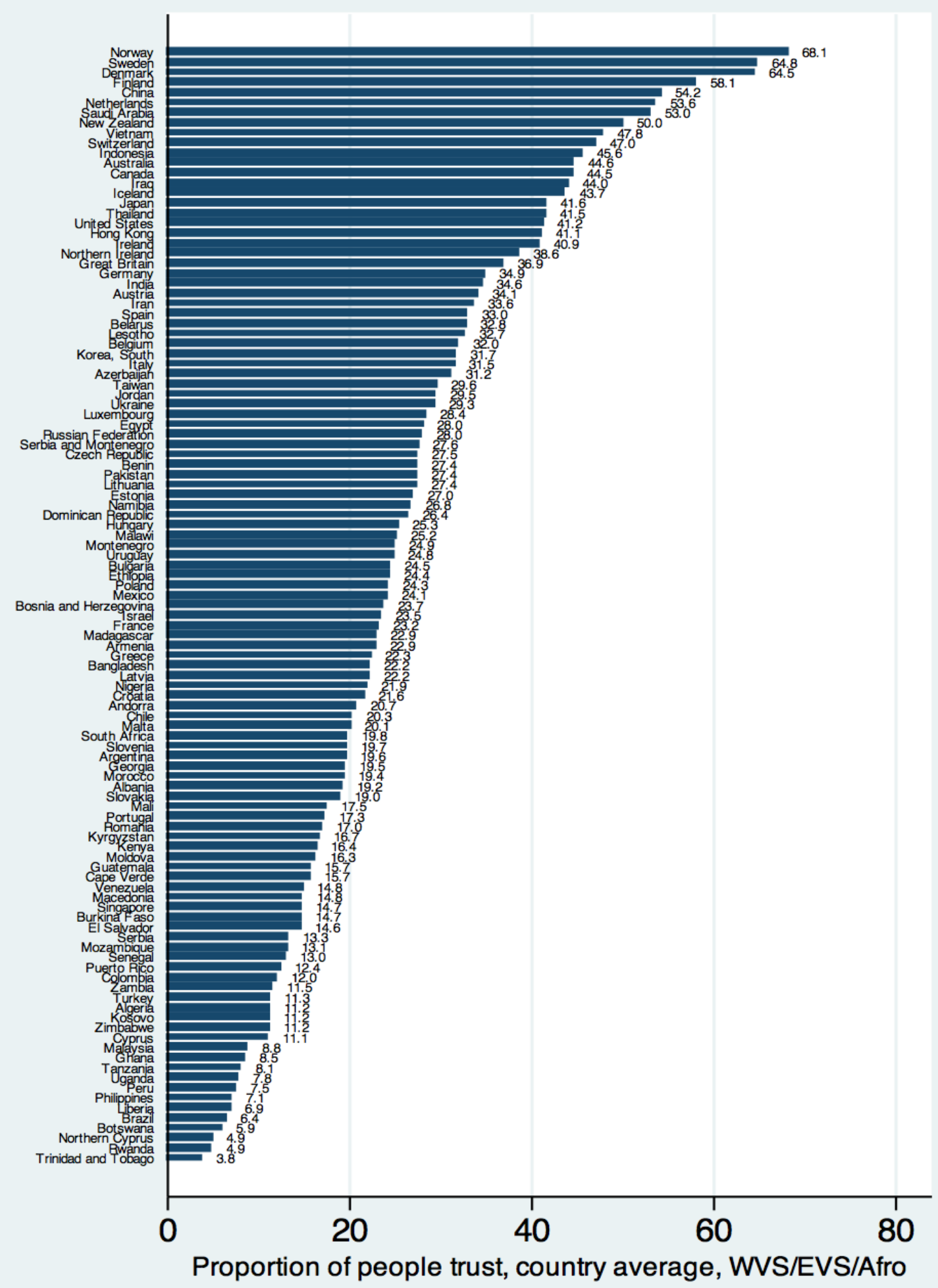

Sources: Trust is computed as the country average from responses to the trust question in the five waves of the World Values Survey (1981-2008), the four waves of the European Values Survey (1981-2008) and the third wave of the Afrobarometer (2005). The question asks "Generally speaking, would you say that most people can be trusted or that you need to be very careful in dealing with people?" Trust is equal to 1 if the respondent answers "Most people can be trusted" and 0 otherwise. 
Figure 2: Average Trust Levels in 69 European Regions

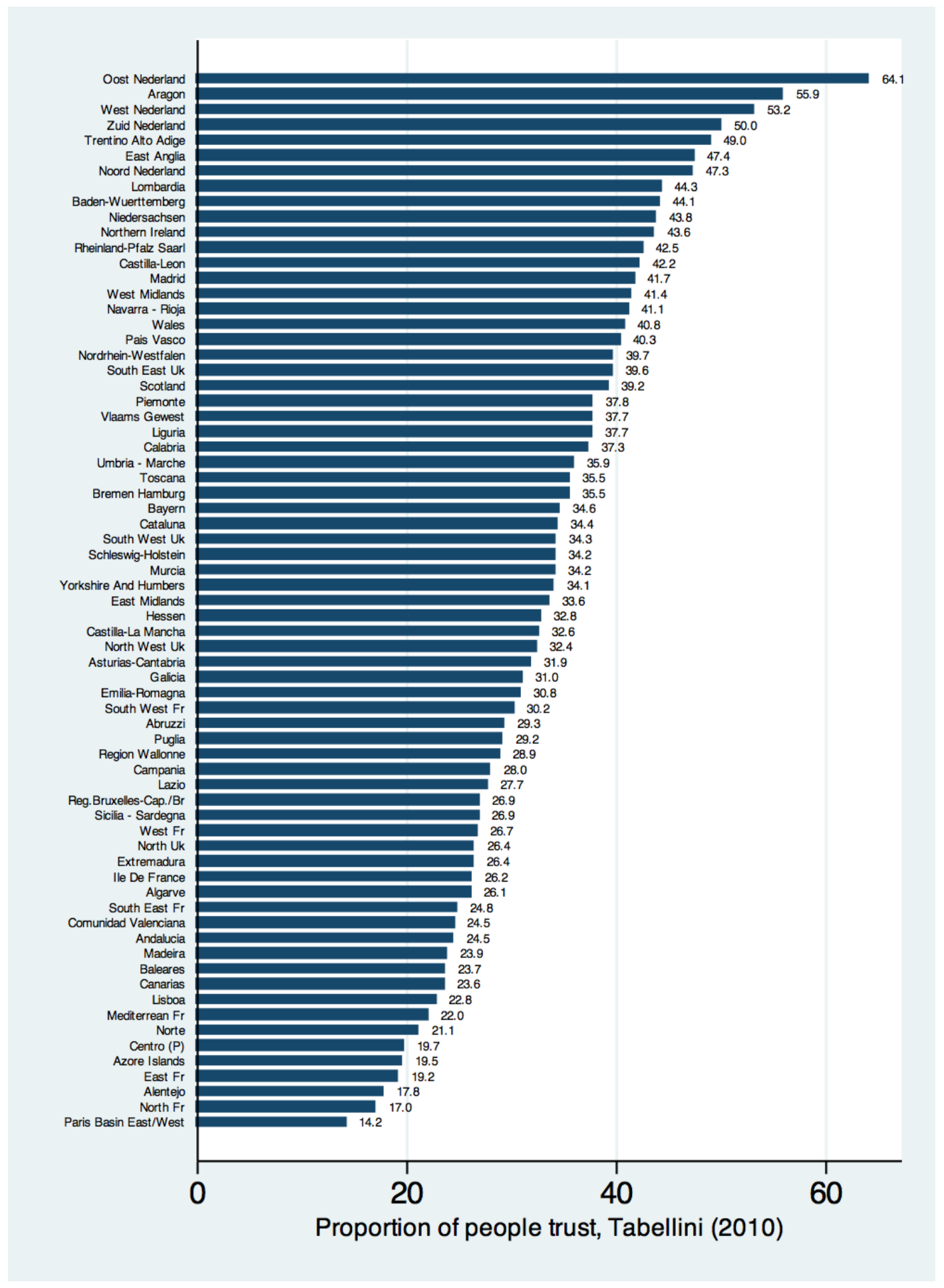

Source: The proportion of people that trust is taken from Tabellini (2010). The Trust measure is computed as the regional average from responses to the question "Generally speaking, would you say that most people can be trusted or that you need to be very careful in dealing with people?" Trust is equal to 1 if the respondent answers "Most people can be trusted" and 0 otherwise. 
Figure 3: Average Trust Levels in 49 U.S. States

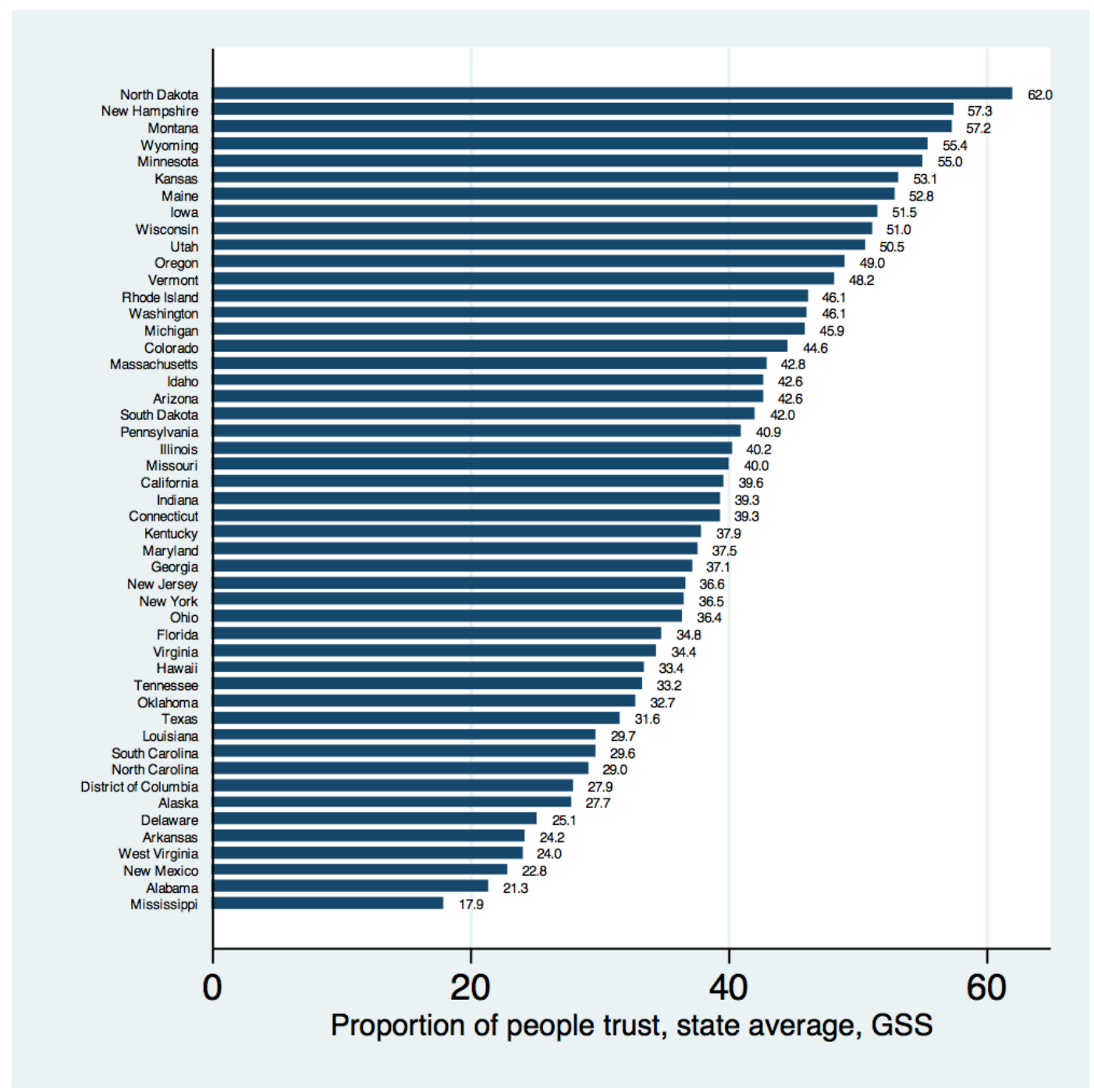

Sources: The proportion of people that trust is taken from the General Social Survey (1973-2006). The Trust measure is computed as the state average from responses to the question "Generally speaking, would you say that most people can be trusted or that you need to be very careful in dealing with people?" Trust is equal to 1 if the respondent answers "Most people can be trusted" and 0 otherwise. 
Figure 4: Country Fixed Effects relative to Norway (\%)

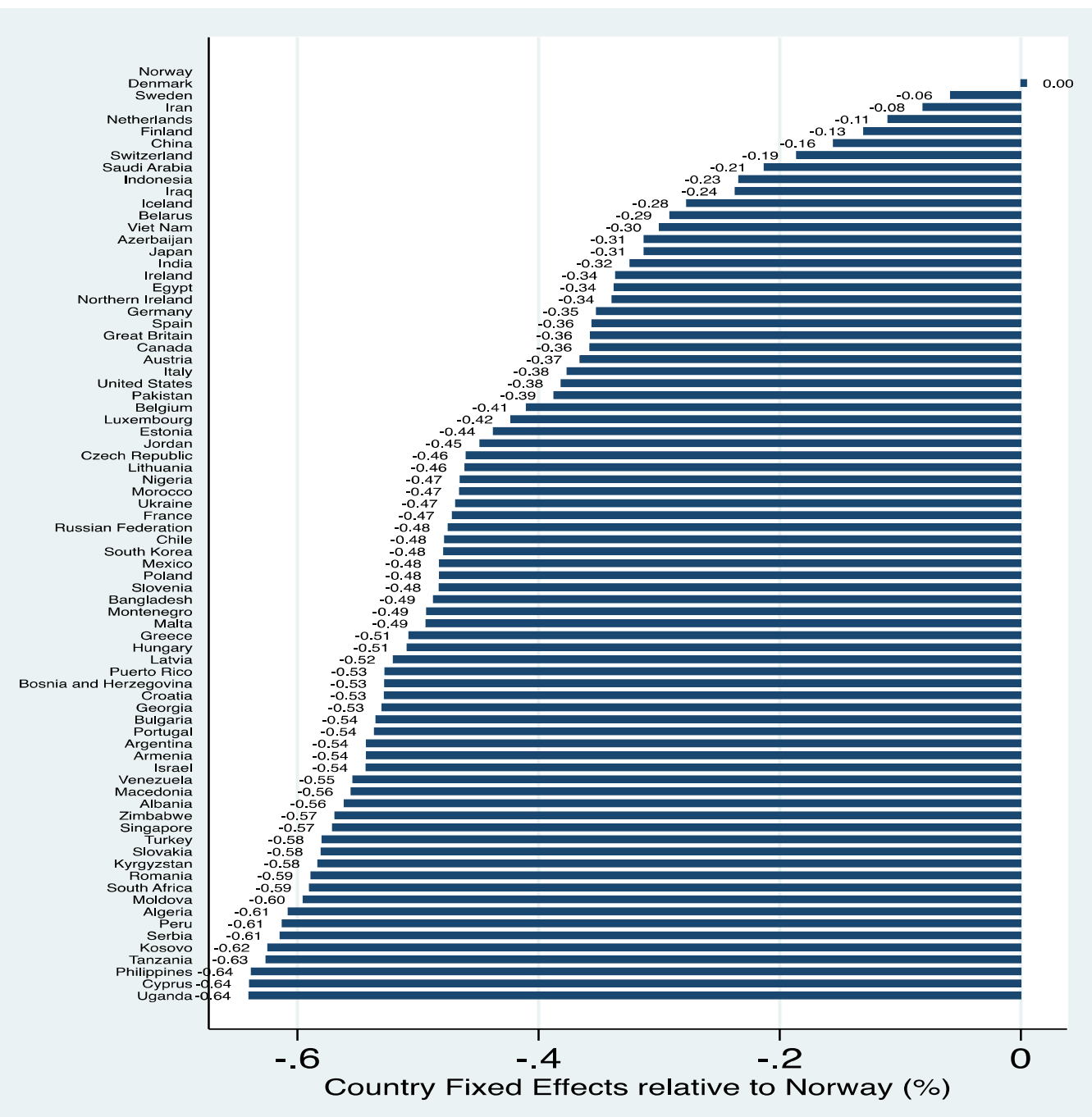

Interpretation: Holding individual characteristics constant, the fact of living in Uganda rather than in Norway reduces trust by 72 percentage points.

Sources: Trust is computed as the country average from responses to the trust question in the five waves of the World Values Survey (1981-2008), the four waves of the European Values Survey (1981-2008) and the third wave of the Afrobarometer (2005). The question asks "Generally speaking, would you say that most people can be trusted or that you need to be very careful in dealing with people?" Trust is equal to 1 if the respondent answers "Most people can be trusted" and 0 otherwise.

Additional controls: age, age (square), gender, education, income and religion. 
Figure 5: Cross-Country Correlation between average (ln)-Income per capita and Trust

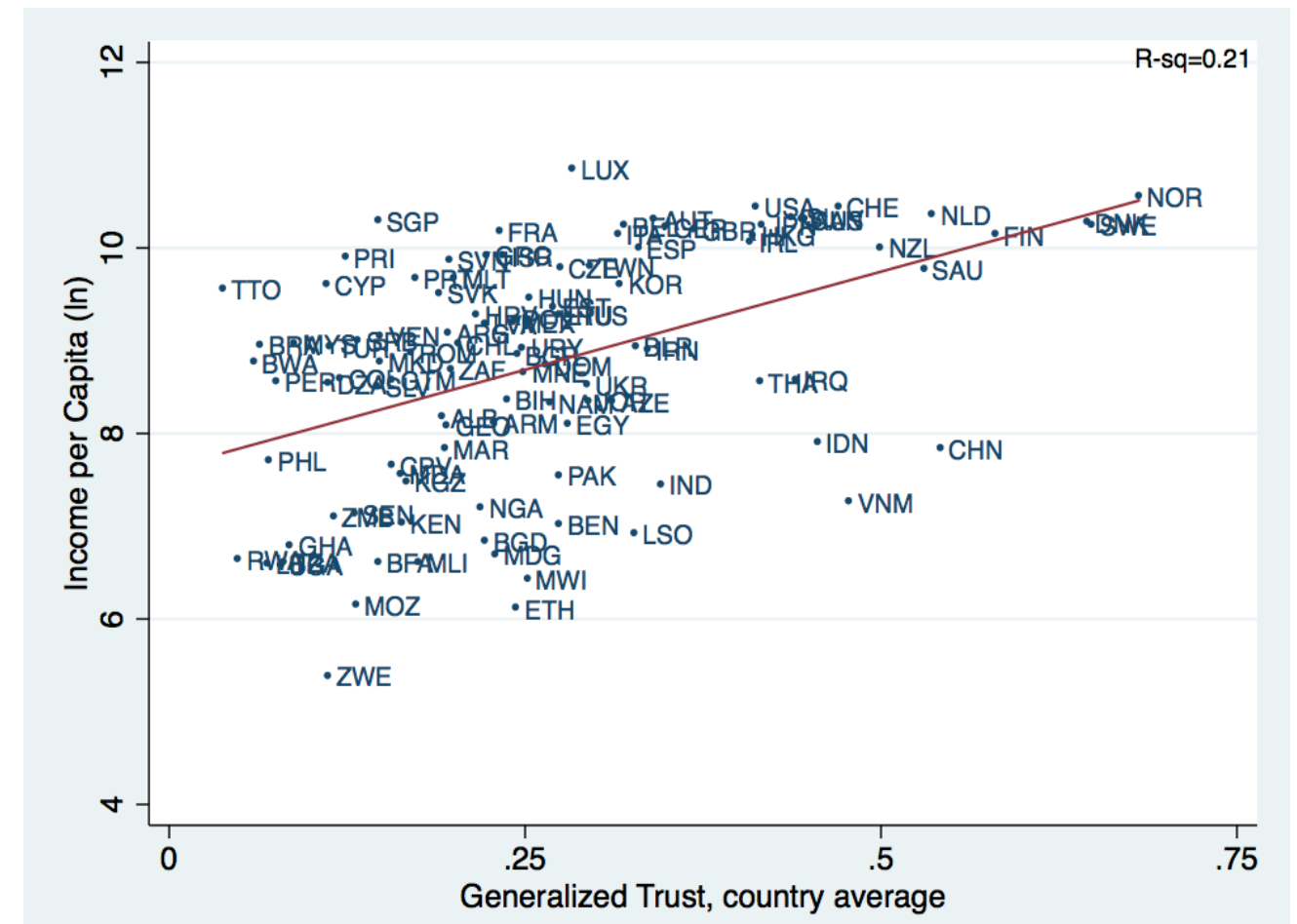

Sources: Average income per capita (1980-2009) has been obtained from the Penn World Tables 7.0. Trust is computed as the country average from responses to the trust question in the five waves of the World Values Survey (1981-2008), the four waves of the European Values Survey (1981-2008) and the third wave of the Afrobarometer (2005). The question asks "Generally speaking, would you say that most people can be trusted or that you need to be very careful in dealing with people?" Trust is equal to 1 if the respondent answers "Most people can be trusted" and 0 otherwise. 
Figure 6: Income per capita (ln) and Generalized Trust in 69 European Regions

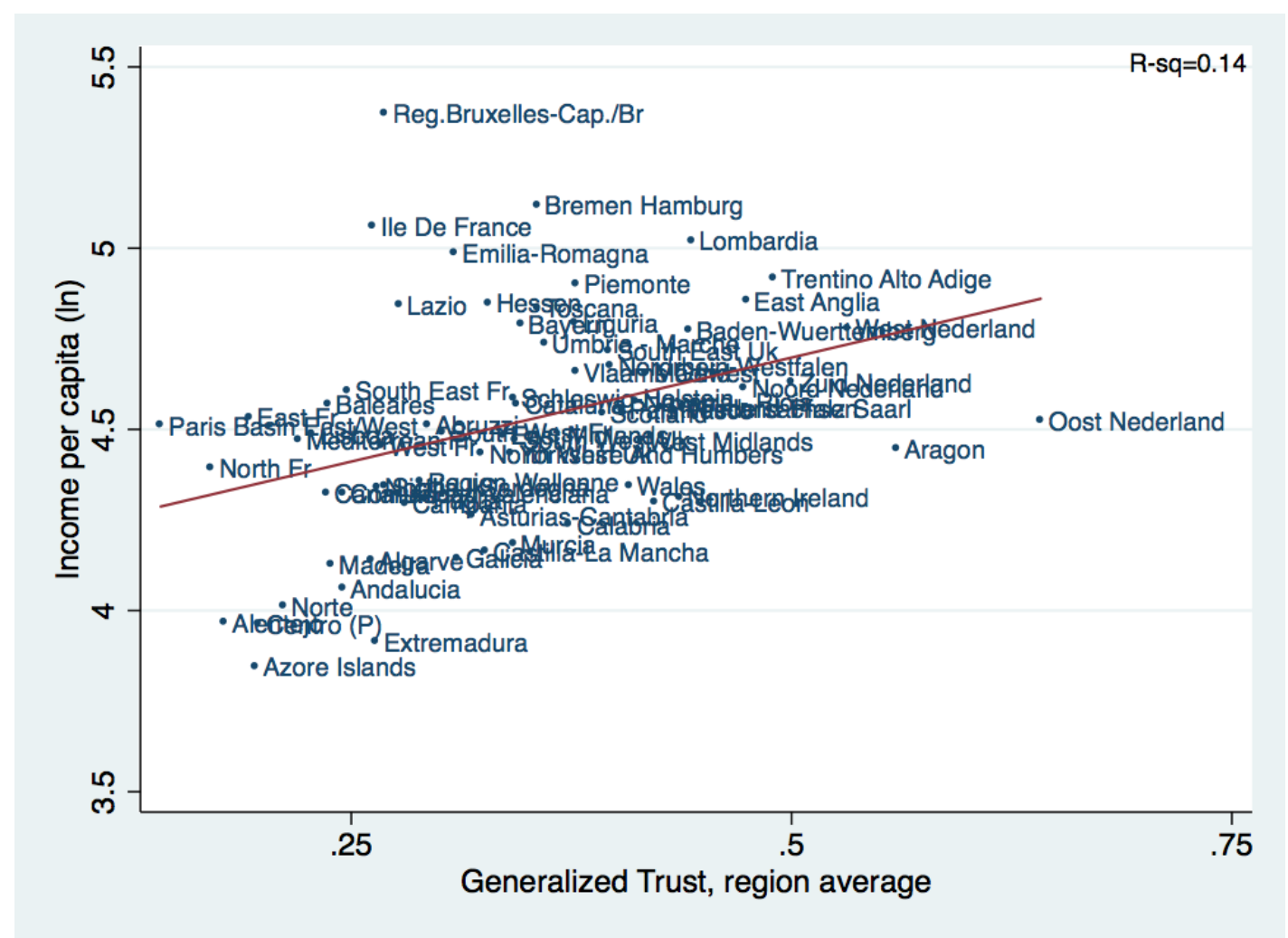

Source: Tabellini (2010). The Trust measure is computed as the regional average from responses to the question "Generally speaking, would you say that most people can be trusted or that you need to be very careful in dealing with people?" Trust is equal to 1 if the respondent answers "Most people can be trusted" and 0 otherwise. 
Figure 7: Income per capita (ln) and Generalized Trust in 49 U.S. States

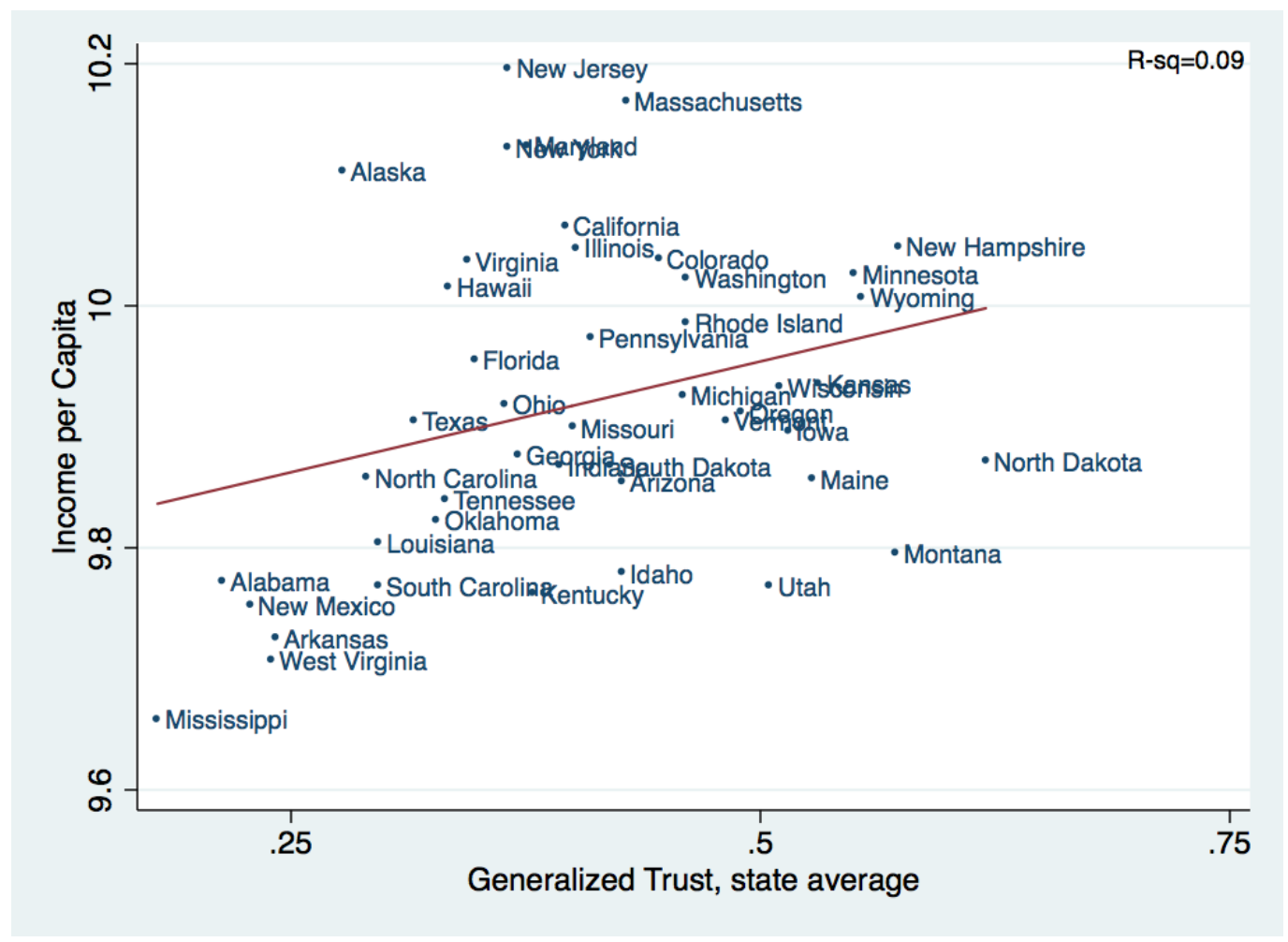

Sources: Income data is taken from the U.S. Census Bureau and averaged for the years 1972-2011. The proportion of people that trust is taken from the General Social Survey (1973-2006). The Trust measure is computed as the state average from responses to the question "Generally speaking, would you say that most people can be trusted or that you need to be very careful in dealing with people?" Trust is equal to 1 if the respondent answers "Most people can be trusted" and 0 otherwise. 
Figure 8: Regional Income per capita (ln) and Trust in 829 Regions around the World

(1) Whole Sample of 829 regions

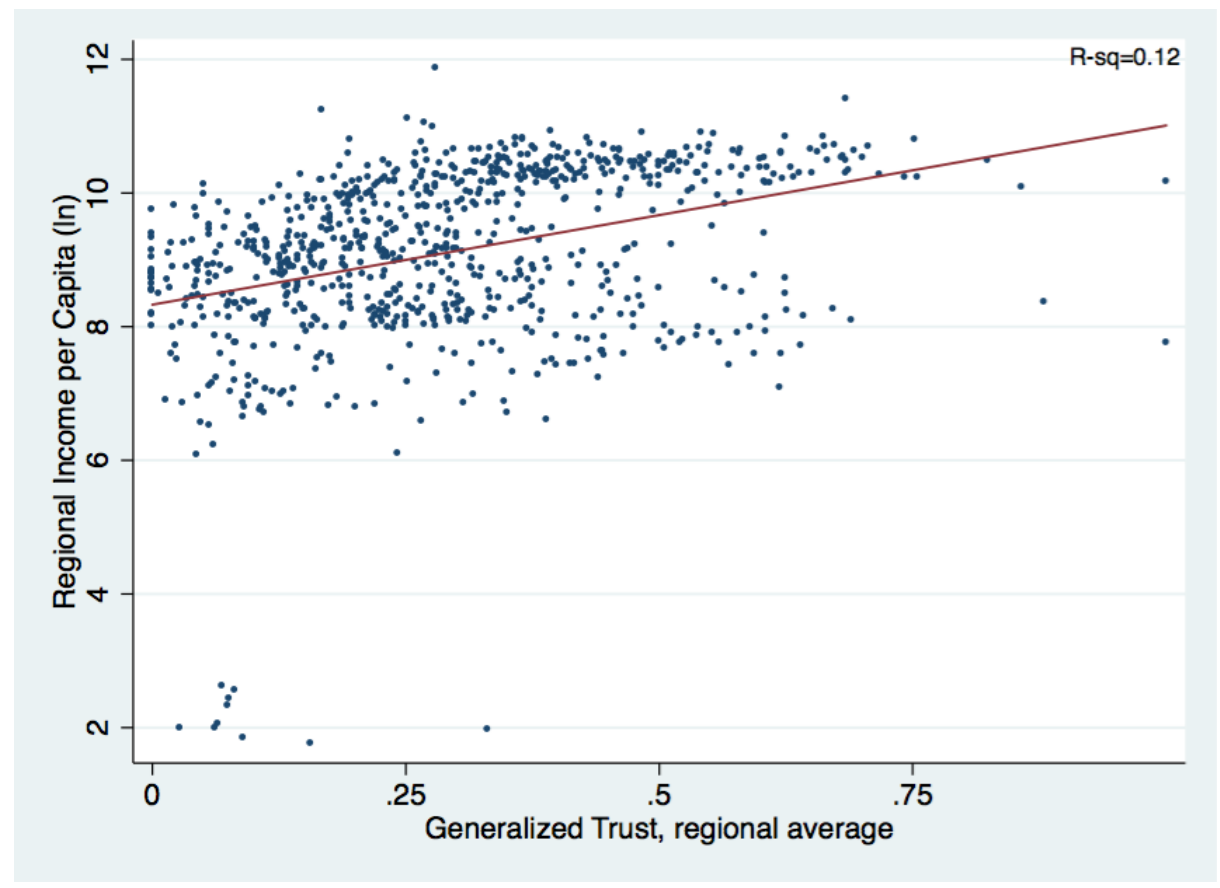

(2) Regions belonging to EU 27 Countries:

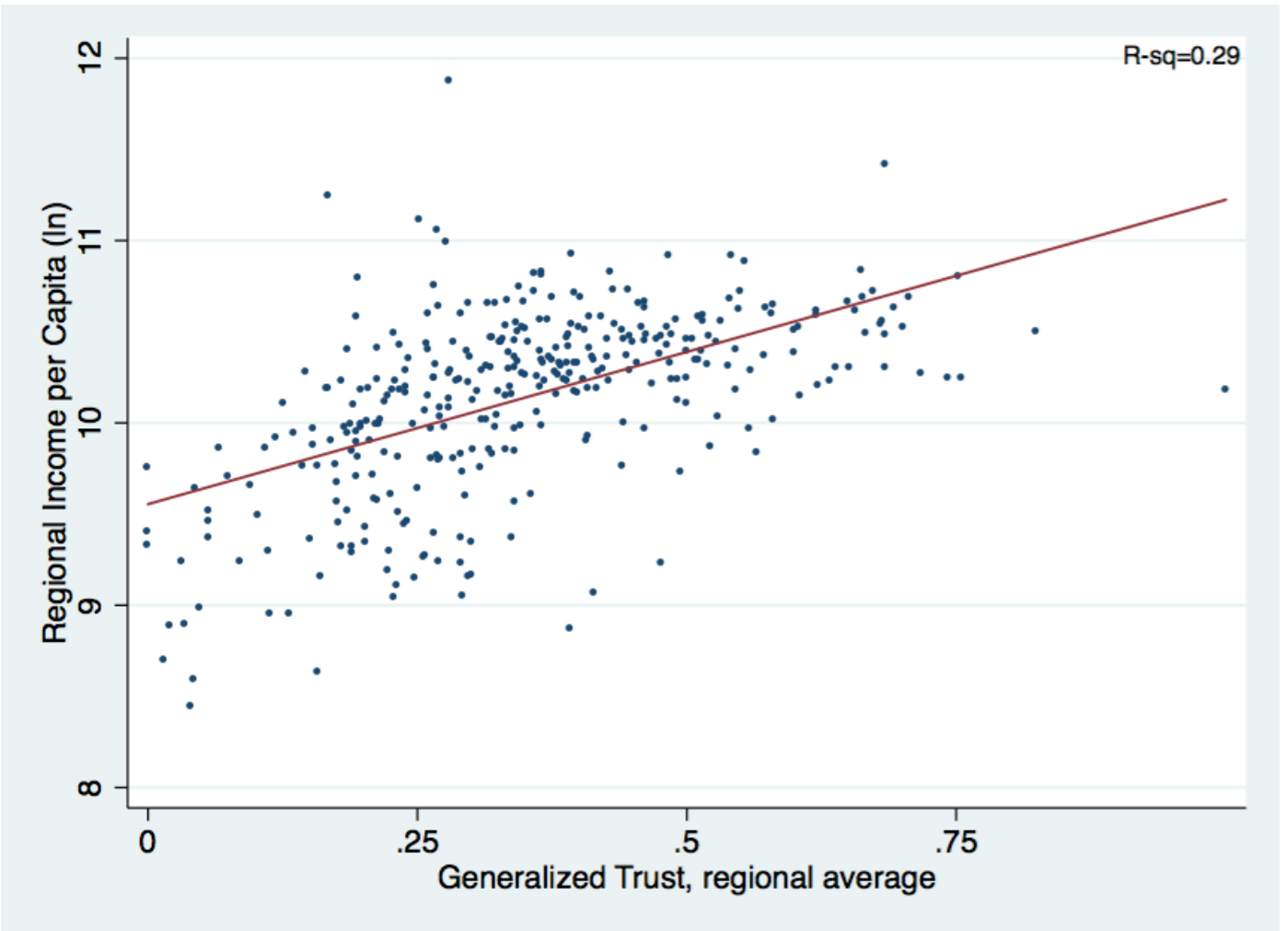


Figure 8 (ctnd): Regional Income per capita (ln) and Trust in 829 Regions around the World

(3) Regions belonging to the OECD

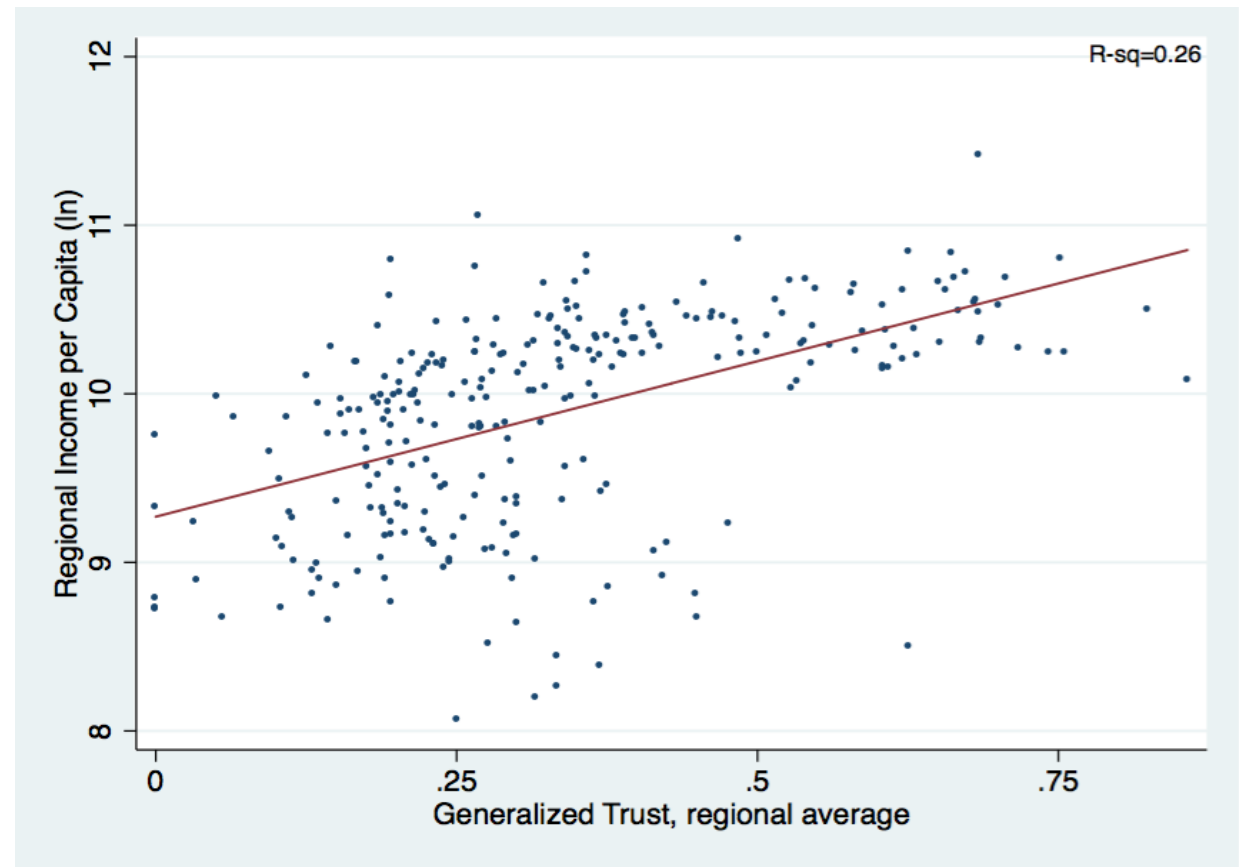

Sources: Regional Income is obtained from Gennaioli et al. (2012). Trust is computed as the country average from responses to the trust question in the five waves of the World Values Survey (1981-2008), the four waves of the European Values Survey (1981-2008), the third wave of the Afrobarometer (2005) and the General Social Survey (1973-2006). The question asks "Generally speaking, would you say that most people can be trusted or that you need to be very careful in dealing with people?" Trust is equal to 1 if the respondent answers "Most people can be trusted" and 0 otherwise. 
Figure 9: Predicted variation in GDP p.c. relative to Sweden

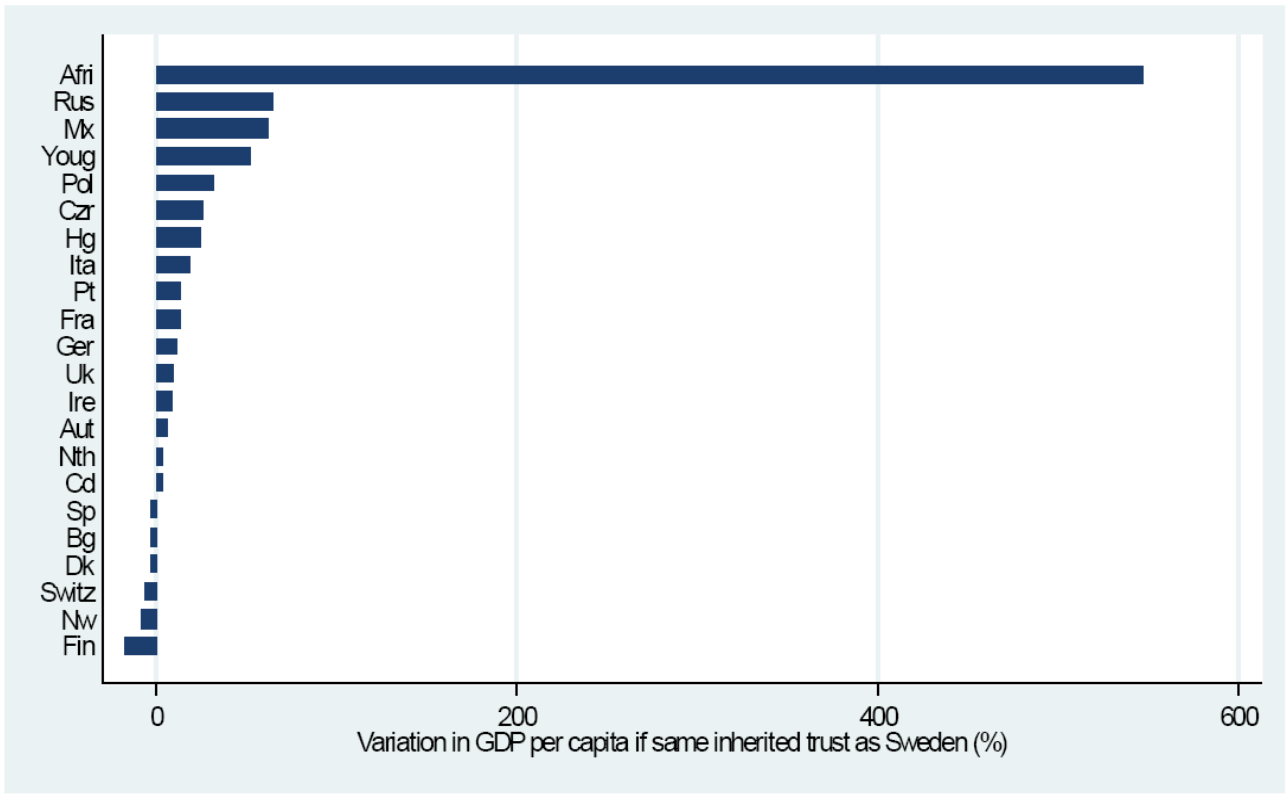

Interpretation: The figure shows the predicted variations in GDP per capita over the period 2000-2003 in a given country if it had had the same level of inherited social attitudes as Sweden.

Source: Algan and Cahuc (2010).

Figure 10: Financial Development and Generalized Trust in 88 Countries

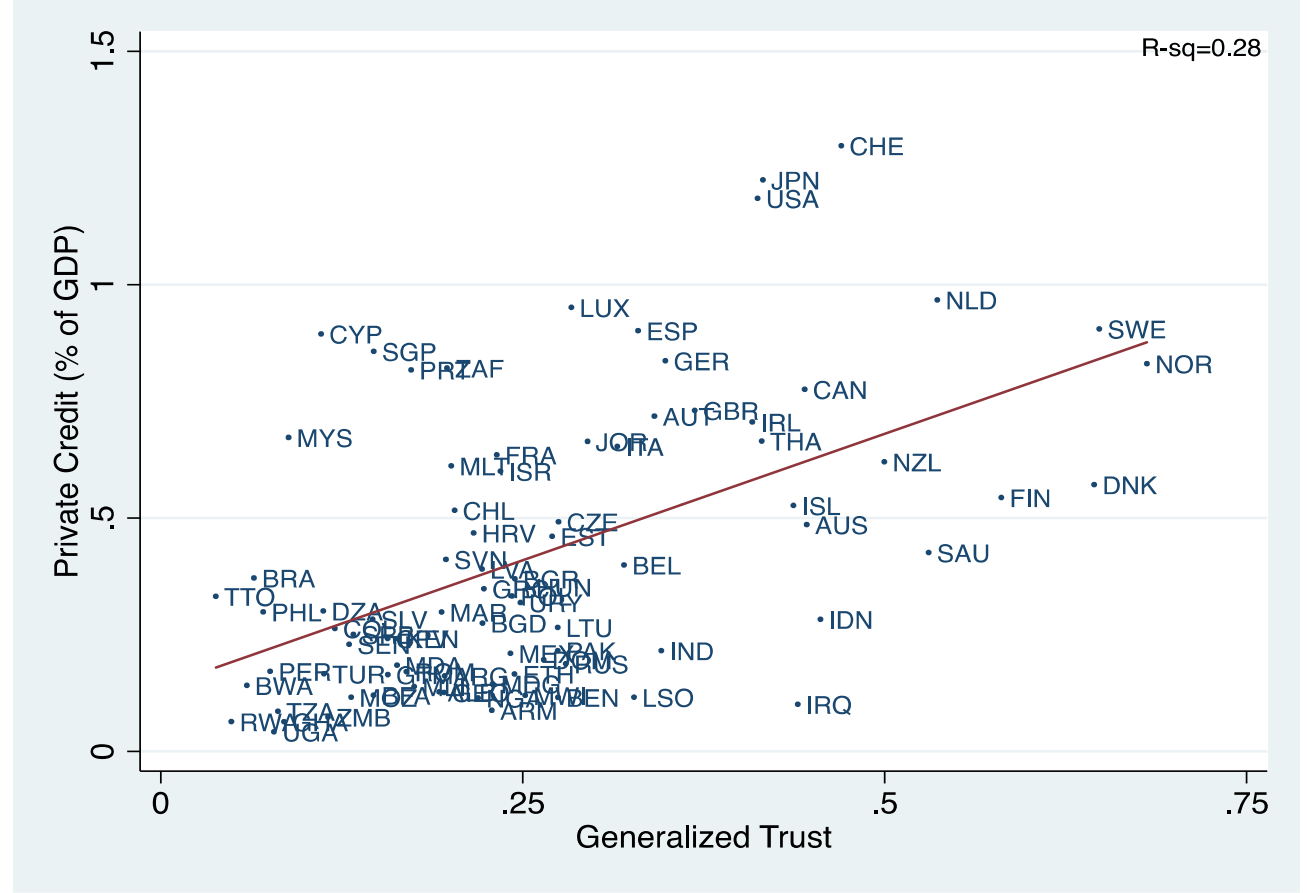

Sources: Financial Development: Private credit by deposit banks and other financial institutions as a percentage of GDP, obtained from the World Bank Indicators (1980-2010). Generalized Trust is taken from the World Values Survey (1981-2008). 


\section{Figure 11: Total Factor Productivity and Generalized Trust in 62 countries}

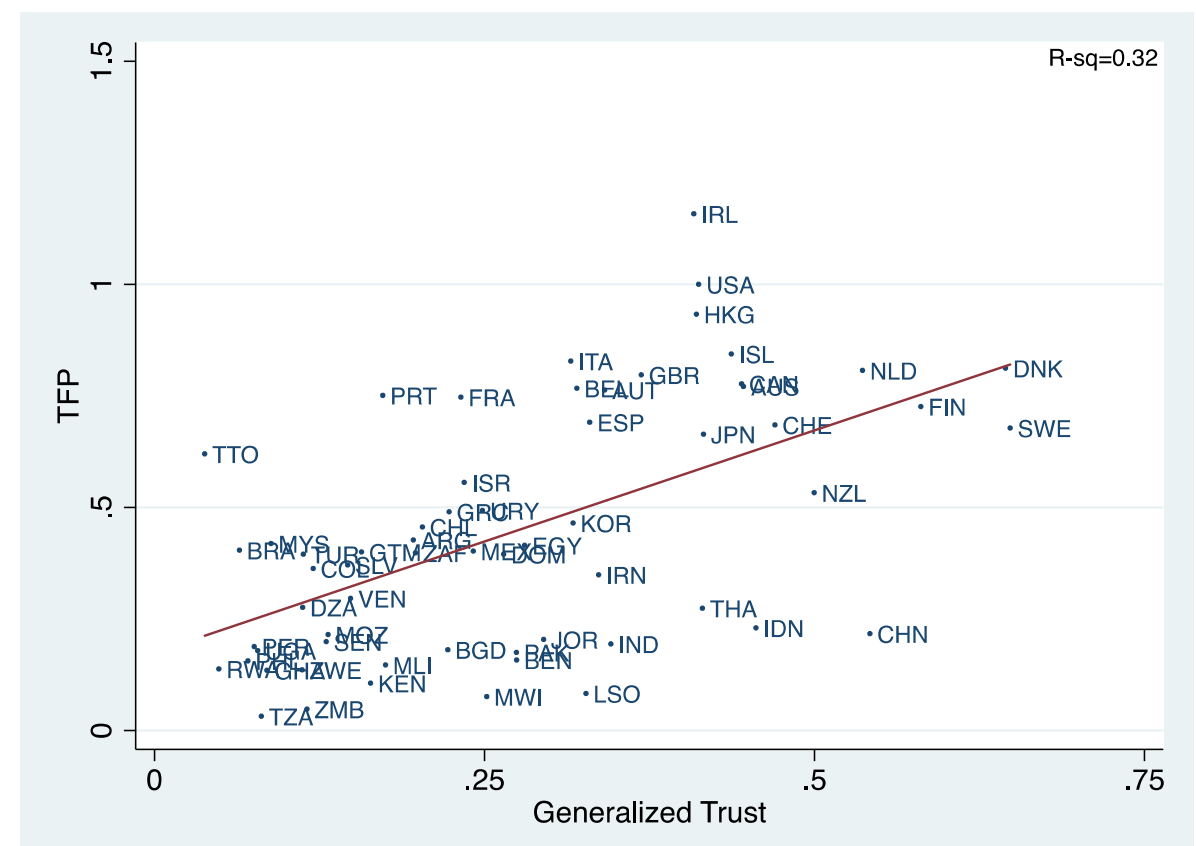

Sources: Total Factor Productivity is taken from Hall and Jones (1999). Trust is measured from the World Values Survey (1981-2008).

\section{Figure 11a: R\&D Expenses and Generalized Trust}

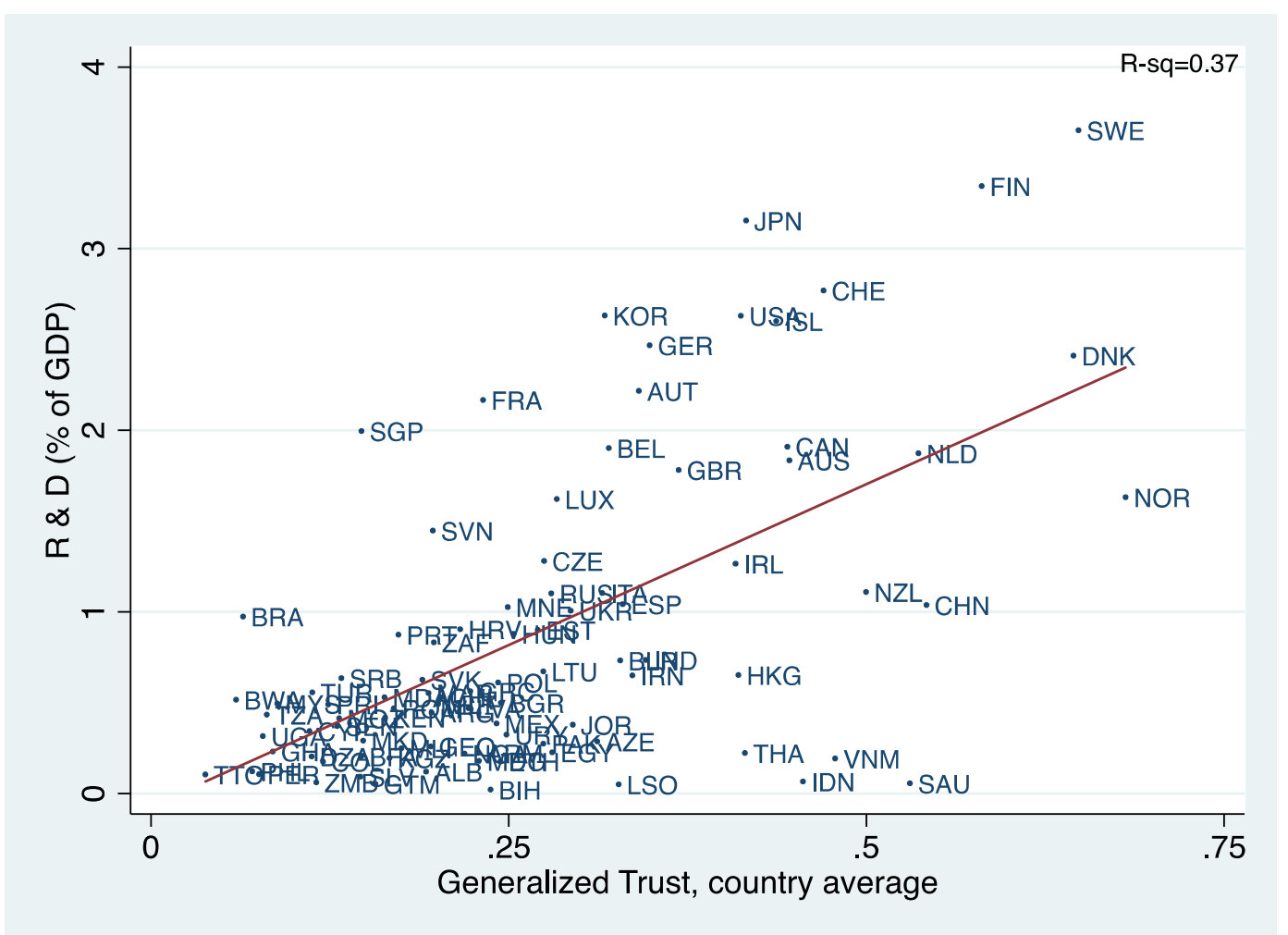

Sources: R\&D expenses as a percentage of GDP over the period 1980-2010 are taken from the World Bank Development Indicators. Trust is measured from the World Values Survey (1981-2008). 
Figure 11b: Cross US States Correlation between R\&D ((ln)-number of patents over the period 1980-2010) and generalized trust (1976-2008)

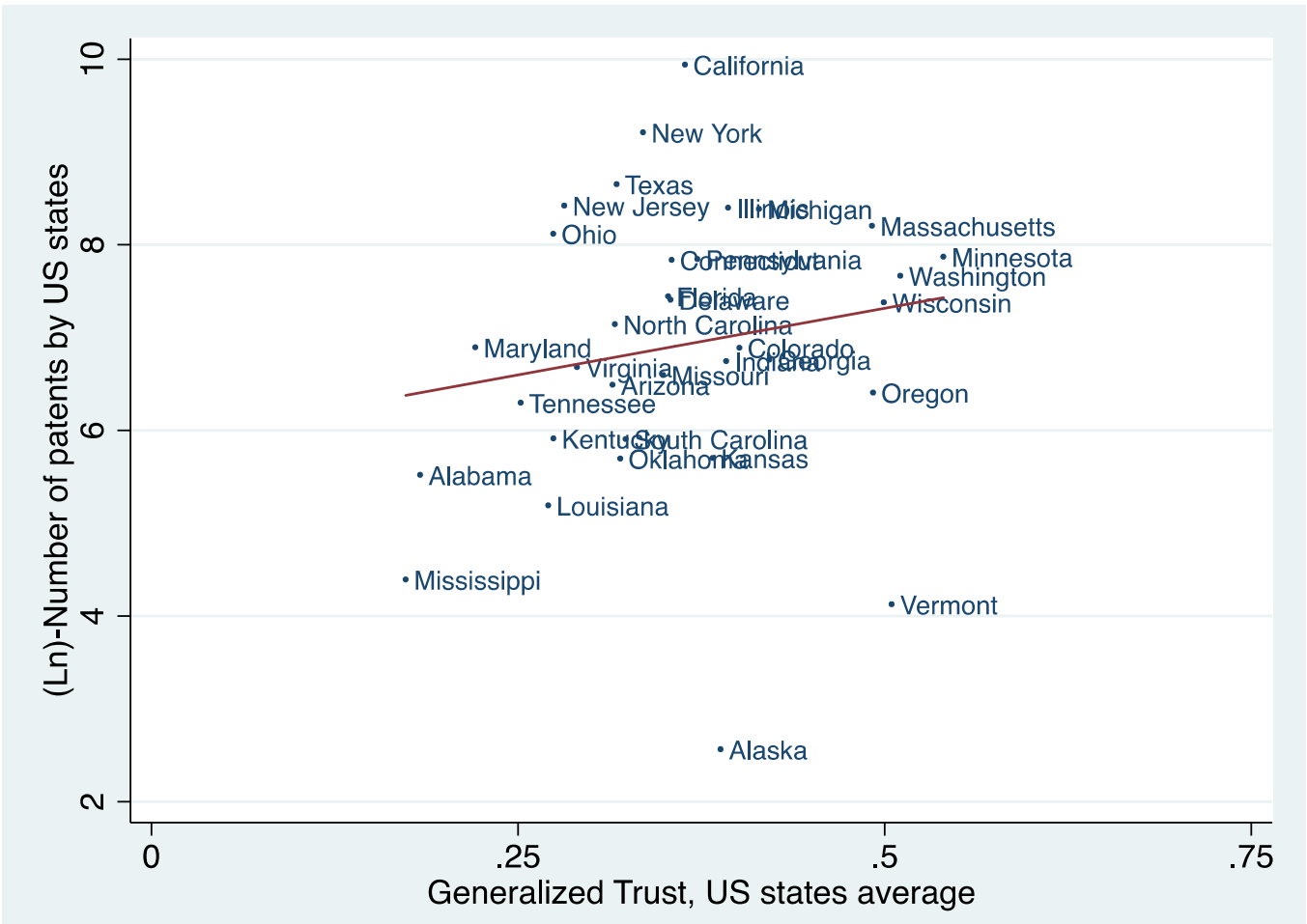

Sources: Income data is taken from the U.S. Census Bureau and averaged for the years 1972-2011. The proportion of people that trust is taken from the General Social Survey (1973-2006). The Trust measure is computed as the state average from responses to the question "Generally speaking, would you say that most people can be trusted or that you need to be very careful in dealing with people?" Trust is equal to 1 if the respondent answers "Most people can be trusted" and 0 otherwise. 


\section{Figure 12: Cross-Country Correlation between Decentralization of Firms and Trust}

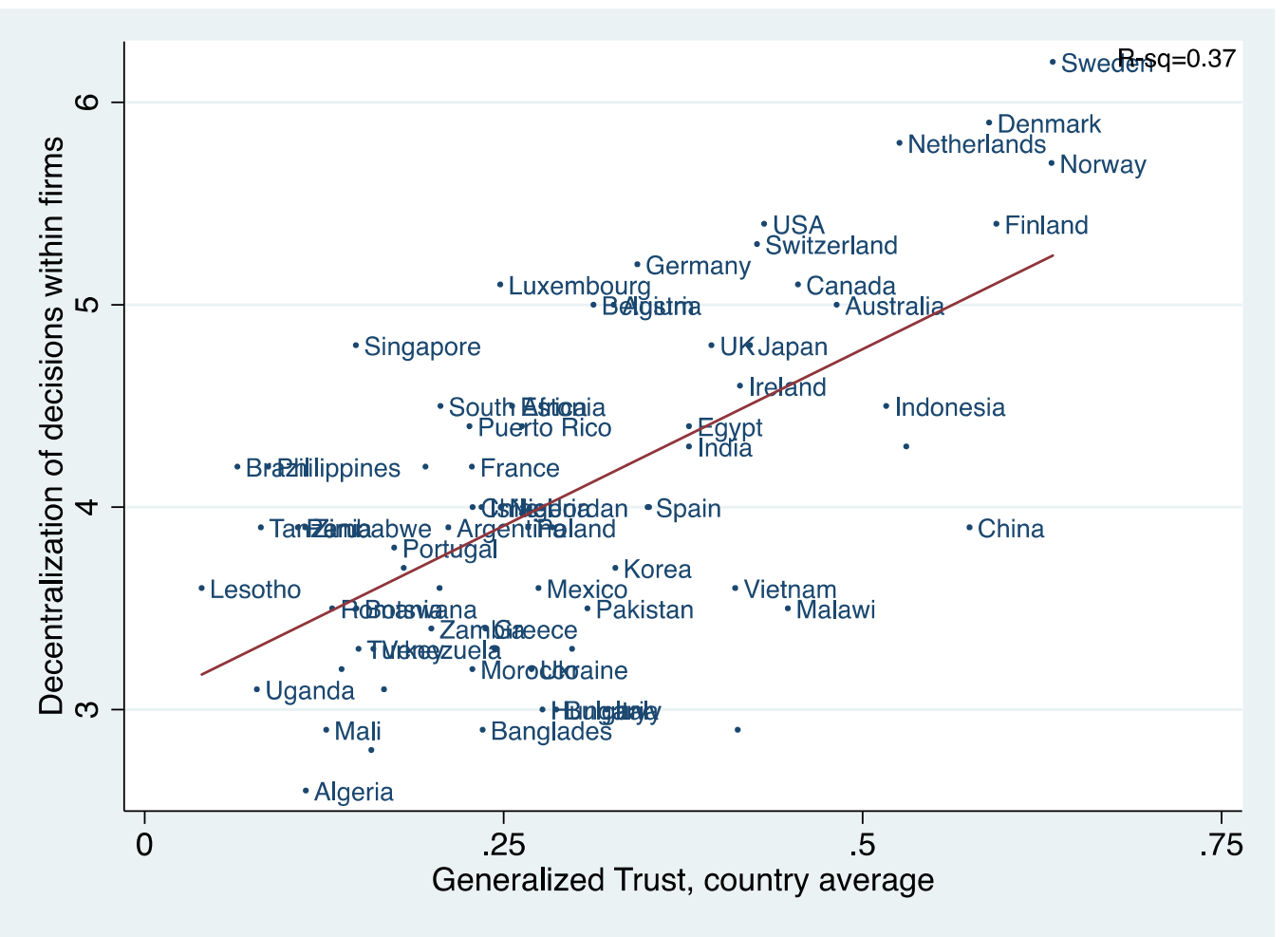

Sources: Firm decentralization is measured by the following question from the Global Competitiveness Report 2009 (GCR): "In your country, how do you assess the willingness to delegate authority to subordinates?" Answers range from "1 = low: top management controls all important decisions", to "7 = high: authority is mostly delegated to business unit heads and other lower-level managers". Generalized trust is measured as the country average from WVS 1981-2009. 
Figure 13: Product Market Regulation and Trust in 73 countries.

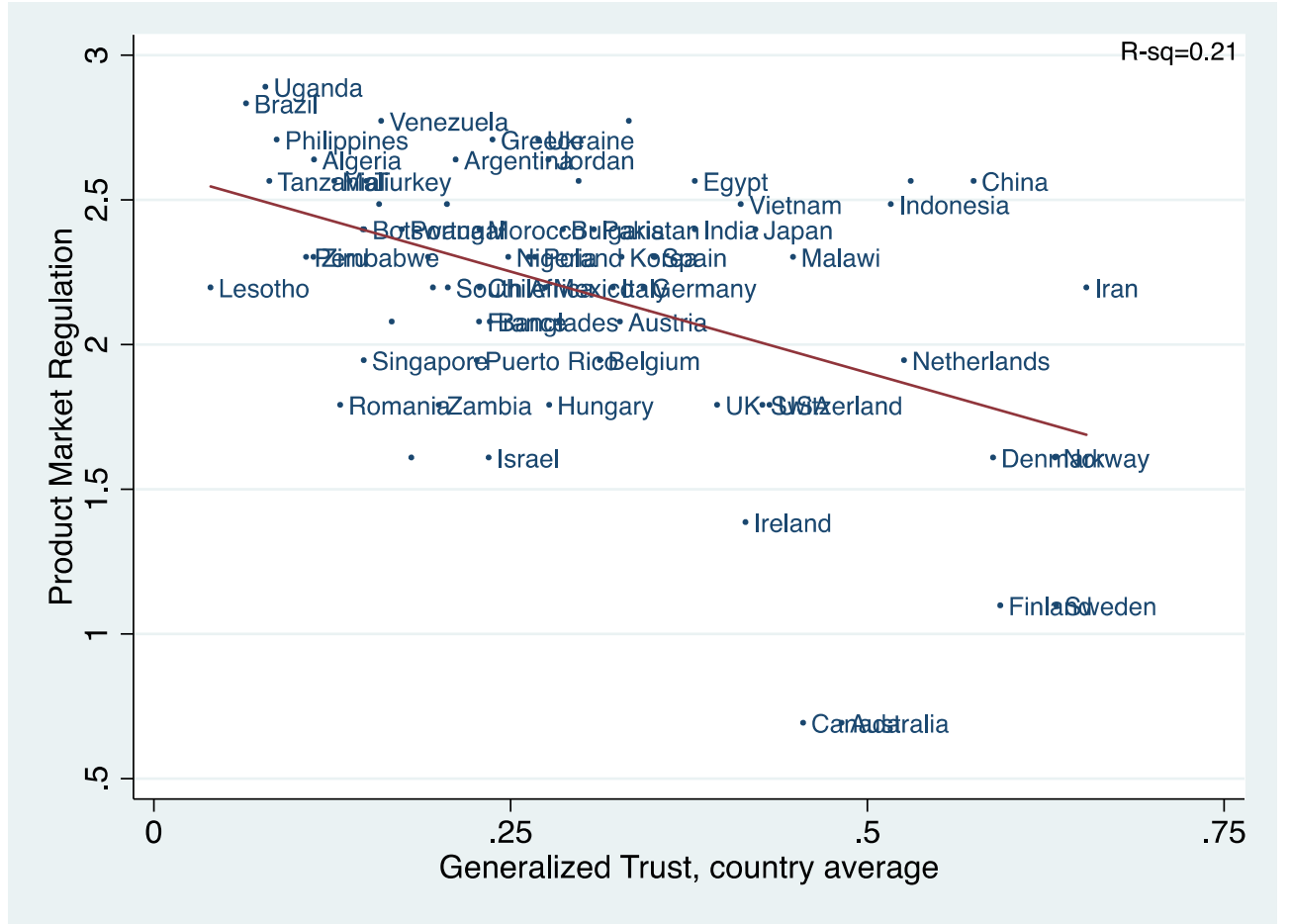

Sources: Product Market regulation is measured as the (ln)-number of steps for opening a business, taken from the World Bank (2009). Generalized trust is measured as the country average from WVS 1981-2009. 
Figure 14: Quality of the legal system and Trust in 100 countries

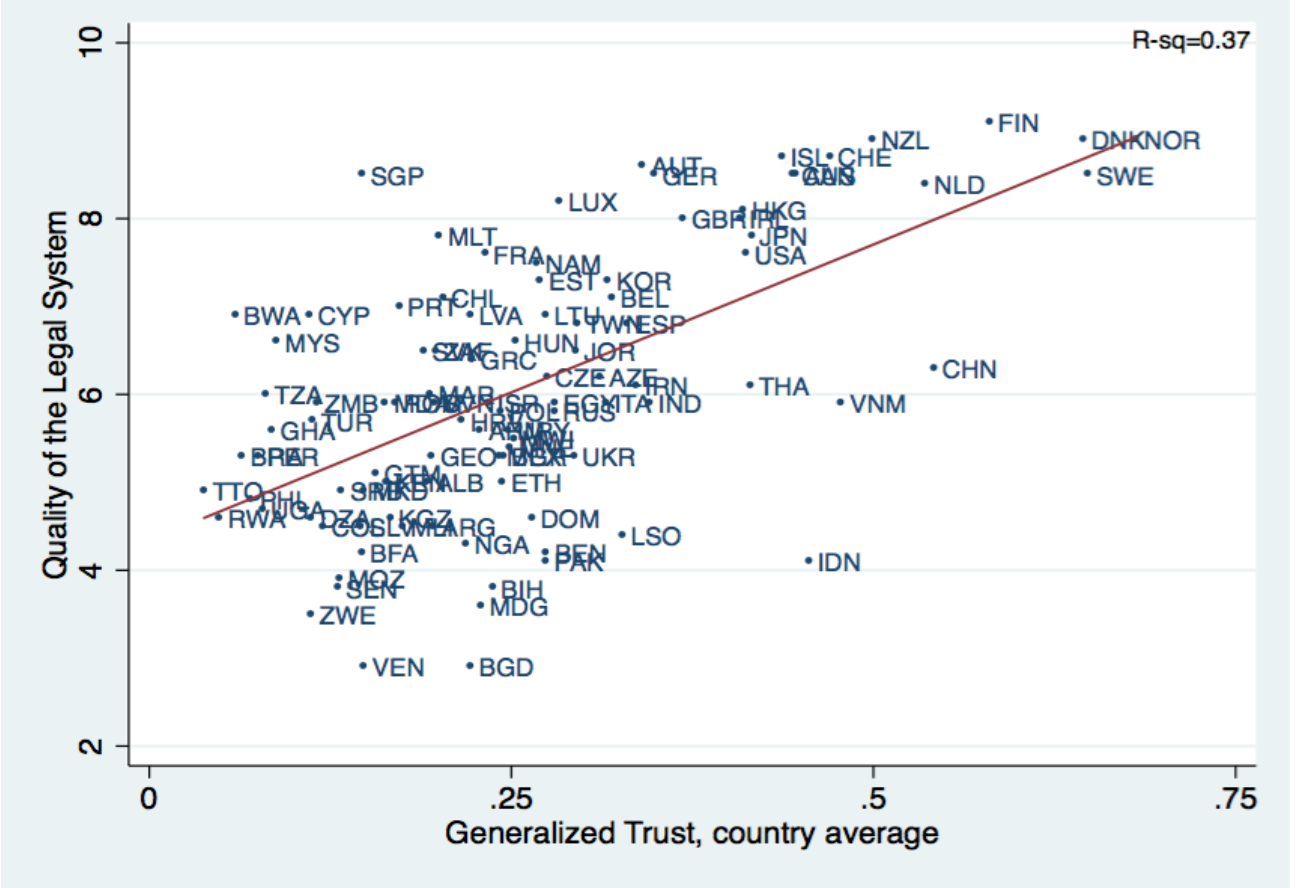

Sources: The Quality of the Legal System is taken from the Economic Freedom of the World Index (2007). Generalized trust is measured as the country average from WVS (1981-2009) and EVS (1981-2008). 
Figure 15: Quality of Governance and Generalized Trust in 163 European regions

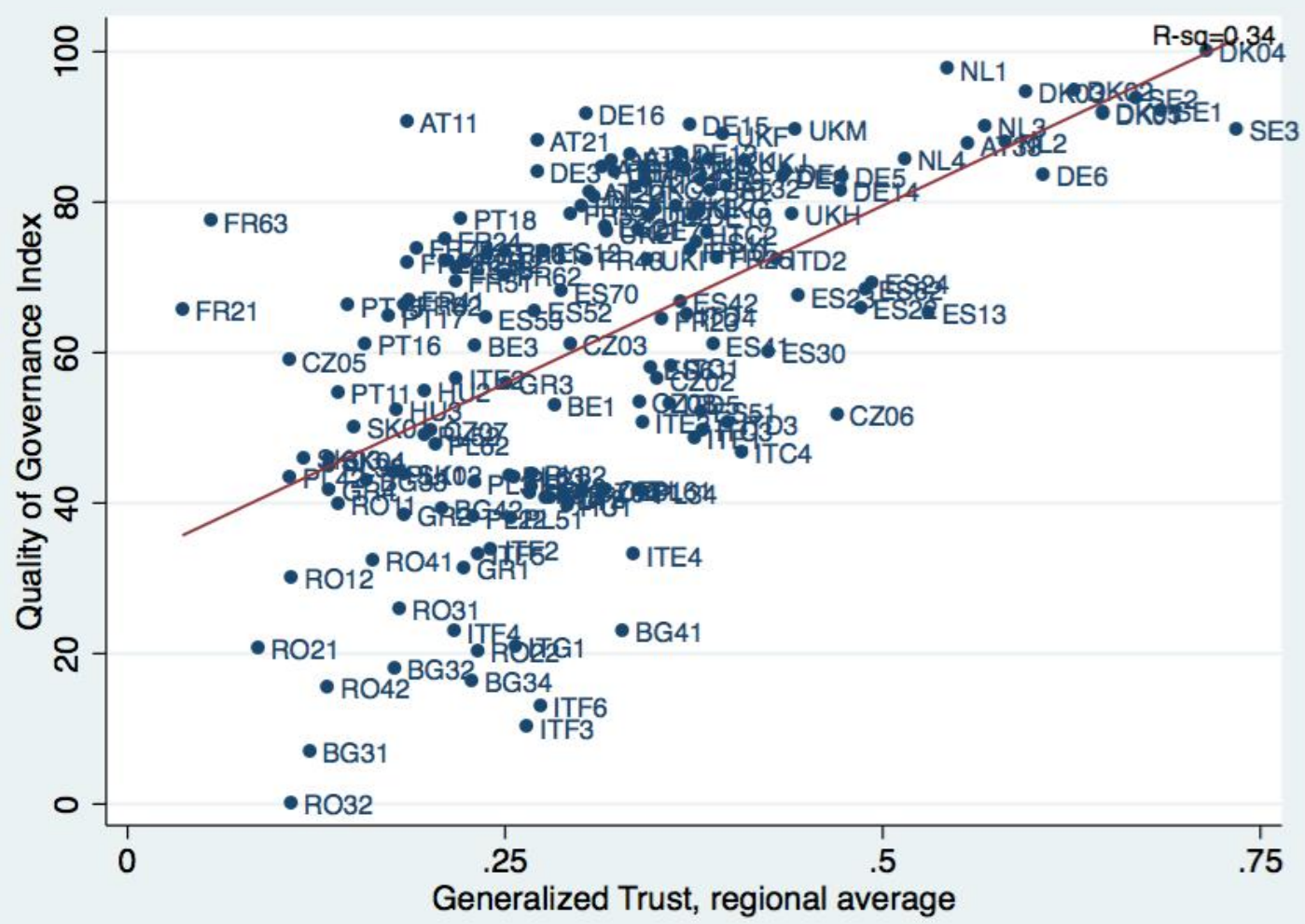

Sources: The Quality of Governance is taken from the Quality of Government Index (2010). Generalized trust is measured as the country average from the WVS (1981-2009) and EVS (1981-2008).

Figure 16: Inequality and Generalized Trust in 101 countries

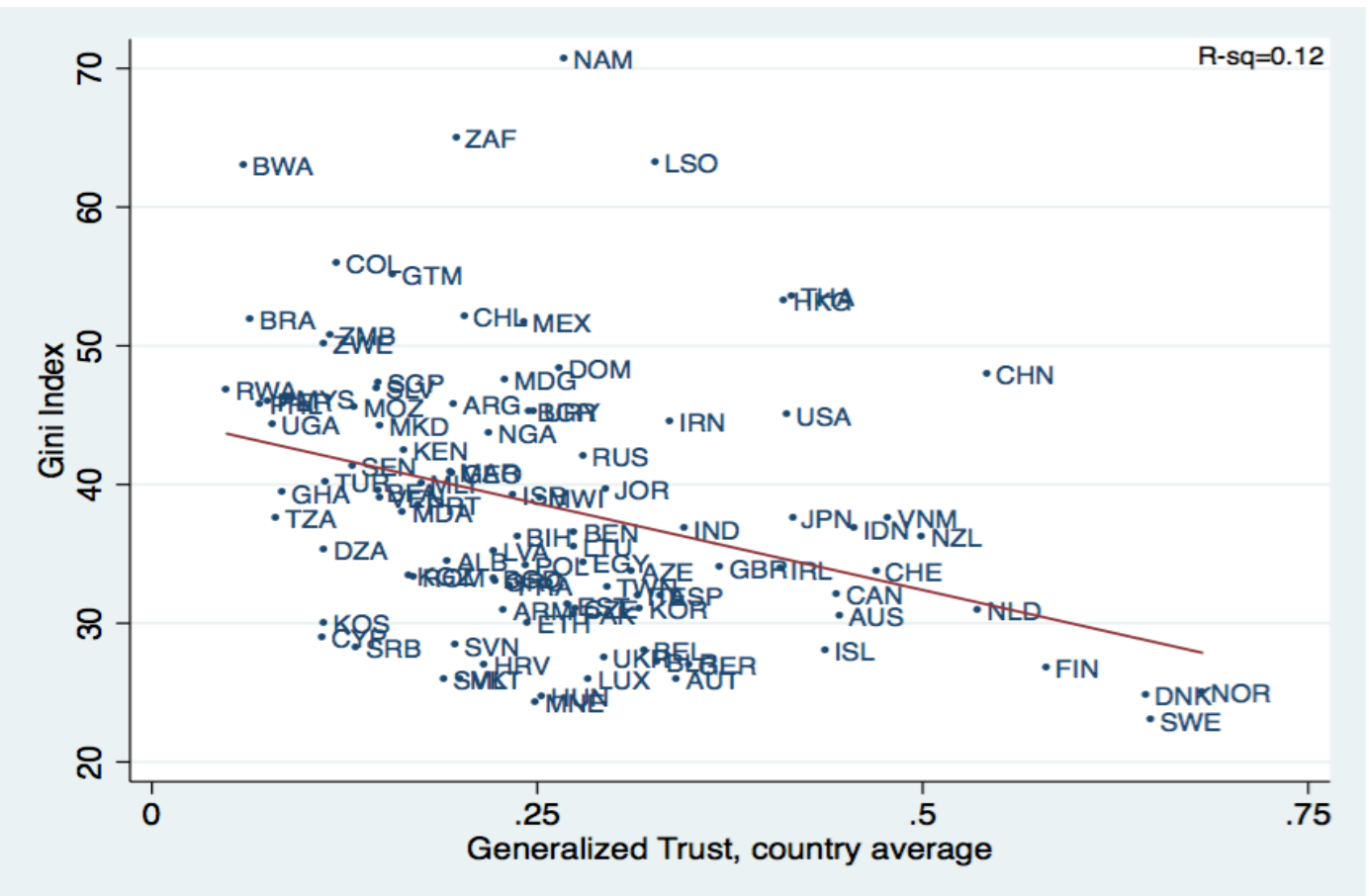

Sources: Inequality is measured by average of the Gini Index between 2005 and 2012 (World Bank). Generalized trust is measured as the country average from WVS (1981-2009) and EVS (1981-2008). 
Figure 17: Inequality and Generalized Trust in 46 US States

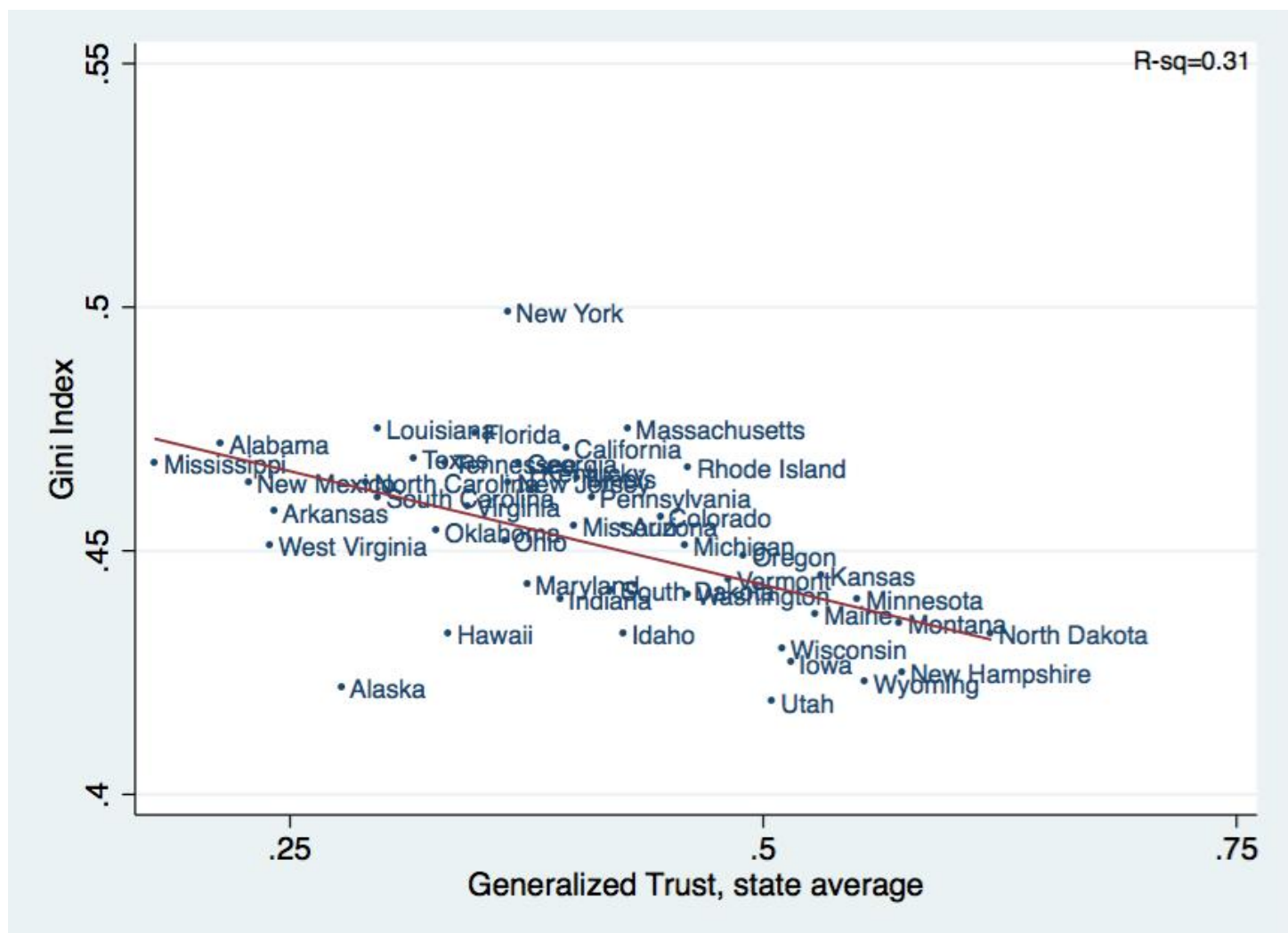

Sources: Inequality is measured by the Gini Index in 2010 (US Census Bureau). Generalized trust is taken from the General Social Survey (1973-2006) 
Figure 18: Trust and the Gap between Vertical and Horizontal Teaching

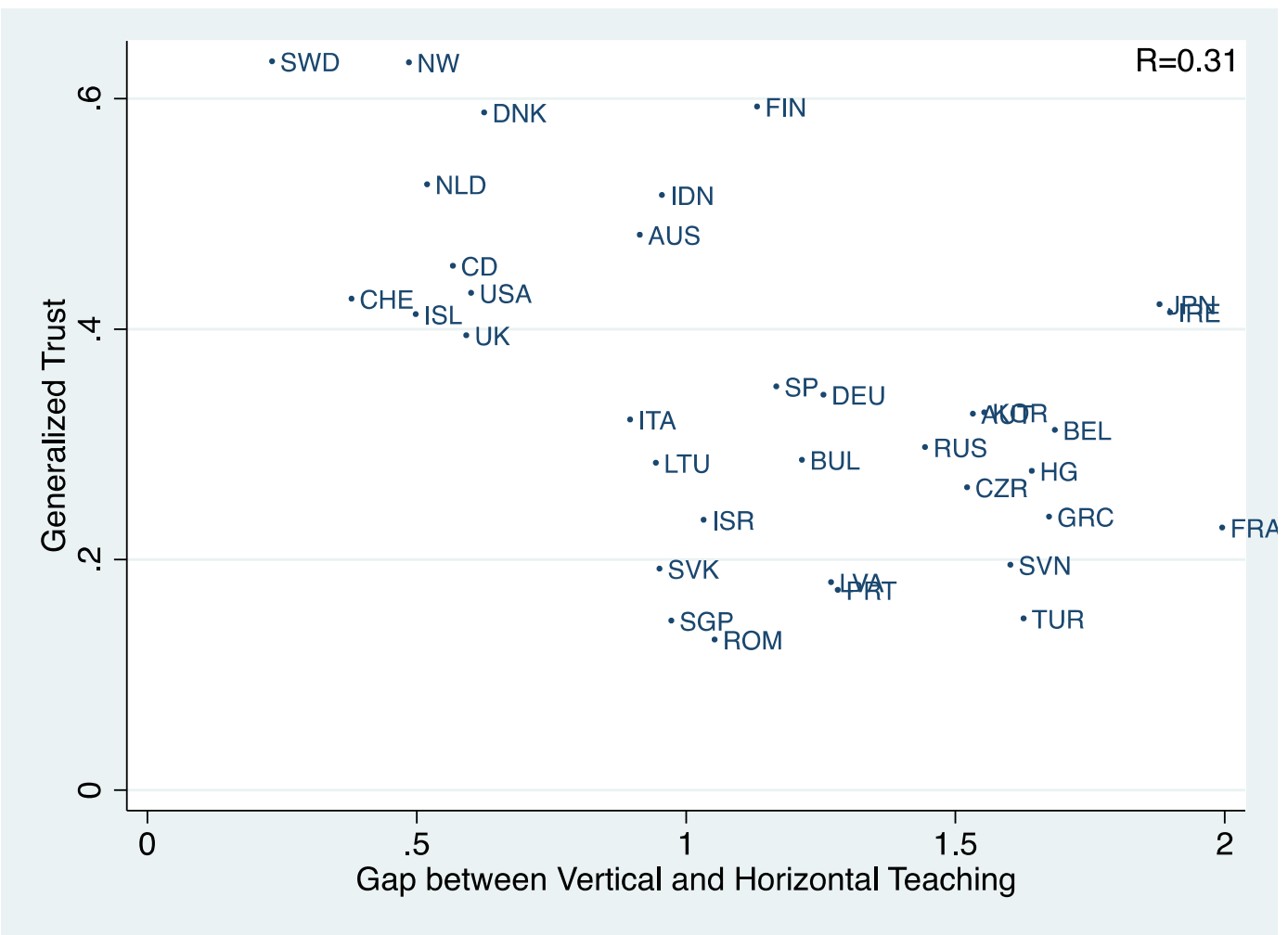

Sources: TIMSS, WVS

Figure 19: Trust and Life Satisfaction

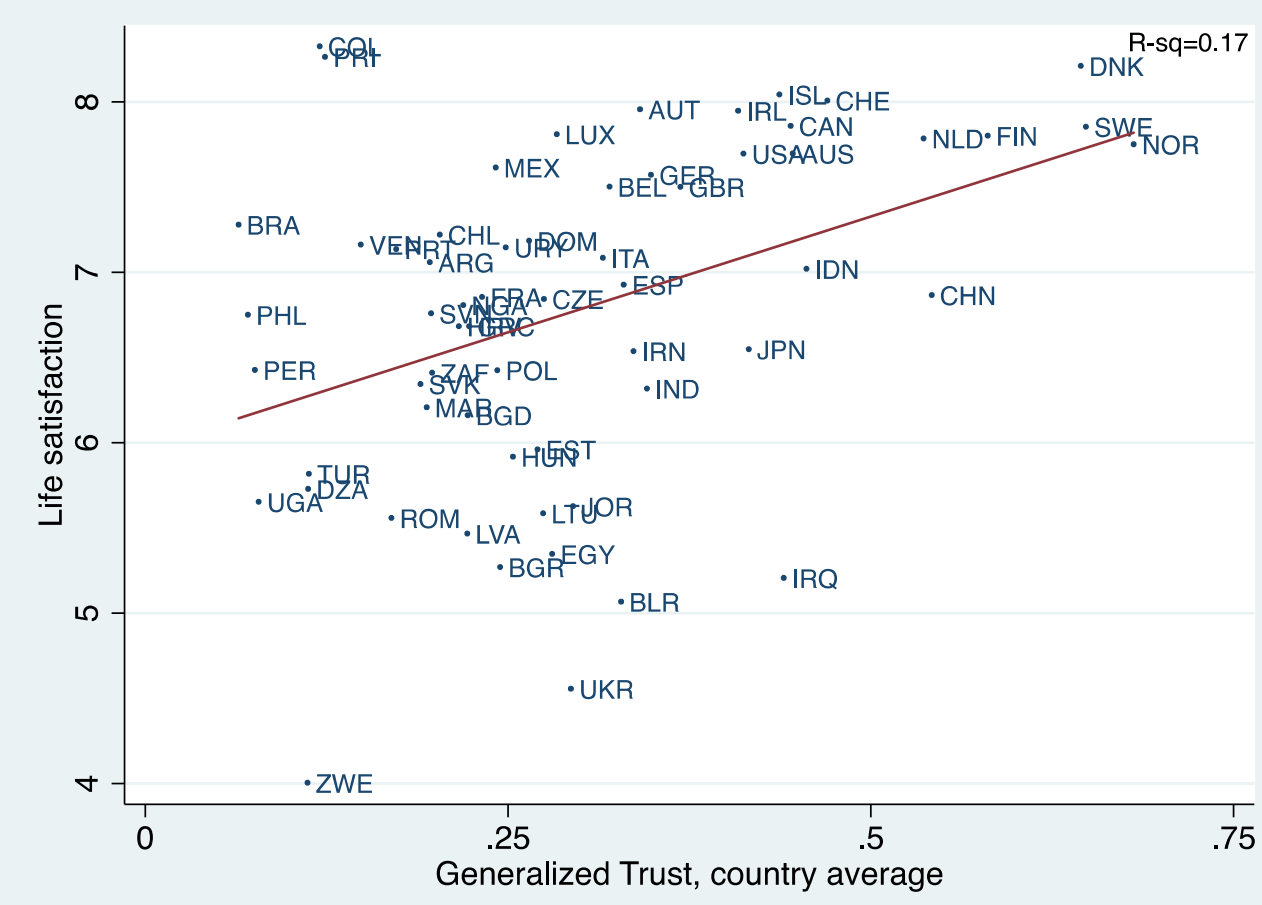

Sources: Life satisfaction (1 to 10) and generalized trust are taken from the World Values Survey (2008). 
TABLES

Table 1: Payoff Matrix

\begin{tabular}{|lll|}
$\boldsymbol{P 1} \mid \boldsymbol{P} 2$ & Cooperation & Defection \\
Cooperation & $(\mathrm{Y}, \mathrm{Y})$ & $(-\mathrm{I}, 2 \mathrm{Y}+\mathrm{I})$ \\
Defection & $(2 \mathrm{Y}+\mathrm{I},-\mathrm{I})$ & $(-\mathrm{I},-\mathrm{I})$ \\
& & \\
\hline
\end{tabular}

Notes: This table shows the payoff matrix of the prisoner's dilemma game. Player 1 chooses row strategies, Player 2 play columns. 
Table 2: Determinants of Trust: Micro Estimates

\begin{tabular}{|c|c|c|}
\hline & \multicolumn{2}{|c|}{ Trust } \\
\hline & (1) & (2) \\
\hline \multirow[t]{2}{*}{ Age } & $0.003^{* * *}$ & $0.001 * * *$ \\
\hline & $(.000)$ & $(.000)$ \\
\hline \multirow[t]{2}{*}{ Age sq. } & $-0.000 * *$ & -0.000 \\
\hline & $(.000)$ & $(.000)$ \\
\hline \multirow[t]{2}{*}{ Gender } & $0.009 * *$ & 0.004 \\
\hline & $(.003)$ & $(.003)$ \\
\hline \multirow[t]{2}{*}{ Education } & $0.019 * * *$ & $0.015^{* * *}$ \\
\hline & $(.004)$ & $(.003)$ \\
\hline \multirow[t]{2}{*}{ Protestant } & $0.165^{* * *}$ & 0.013 \\
\hline & $(.051)$ & $(.009)$ \\
\hline \multirow[t]{2}{*}{ Catholic } & -0.011 & -0.004 \\
\hline & $(.200)$ & $(.006)$ \\
\hline \multirow[t]{2}{*}{ Hindu } & $0.107 * *$ & 0.023 \\
\hline & $(.053)$ & $(.023)$ \\
\hline \multirow[t]{2}{*}{ Buddhist } & 0.057 & 0.010 \\
\hline & $(.042)$ & $(.013)$ \\
\hline \multirow[t]{2}{*}{ Muslim } & 0.034 & $0.021 *$ \\
\hline & $(.047)$ & $(.011)$ \\
\hline \multirow[t]{2}{*}{ Jew } & -0.030 & 0.045 \\
\hline & $(.018)$ & $(0.032)$ \\
\hline \multirow[t]{2}{*}{ Income level } & $0.020^{* * *}$ & $0.023^{* * *}$ \\
\hline & $(.004)$ & $(.003)$ \\
\hline Country FE & No & Yes \\
\hline Observations & 136105 & 136105 \\
\hline $\mathrm{R}^{2}$ & 0.027 & 0.123 \\
\hline
\end{tabular}

Notes: The dependent variable is Trust. It is calculated from answers to the question "Generally speaking, would you say that most people can be trusted, or that you need to be very careful in dealing with people?". Trust is equal to 1 if the respondent answers "Most people can be trusted" and 0 otherwise.

Control variables include age in years, Gender $(1=$ Male), Education (from $1=$ No elementary school to $7=$ Graduate studies), Income ( $1=$ Below national average, $2=$ Average, $3=$ Above national average $)$ and dummy variables indicating the religious denomination of the respondent.

Sources: World Values Survey (1981-2008) and European Values Survey (1981-2008).

Column (2) includes country fixed effects. OLS regressions with robust standard errors clustered at the country level in parentheses. Coefficient is statistically different from 0 at the ***.01, **.05, and * .10 levels. 
Table 3 - Trust and Income: Cross-Country Correlation

\begin{tabular}{|c|c|c|c|c|c|c|c|}
\hline & & & $\operatorname{Ln} G D P_{p}$ & er capita ( & $980-2009$ & & \\
\hline & (1) & (2) & (3) & (4) & (5) & (6) & (7) \\
\hline Generalized Trust & $\begin{array}{c}4.231^{* * *} \\
(.718)\end{array}$ & $\begin{array}{c}1.308^{* *} \\
(.617)\end{array}$ & $\begin{array}{c}1.526^{*} \\
(.849)\end{array}$ & $\begin{array}{c}1.407 * * \\
(.669)\end{array}$ & & & \\
\hline Trust in Family & & & & & $\begin{array}{l}.418 \\
(.485)\end{array}$ & & \\
\hline Trust in Neighbors & & & & & & $\begin{array}{l}.295 \\
(.311)\end{array}$ & \\
\hline Trust "People we know" & & & & & & & $\begin{array}{c}.176 \\
(.179)\end{array}$ \\
\hline Education & & $\begin{array}{c}0.294 * * * \\
(.034)\end{array}$ & $\begin{array}{c}0.302^{* * *} \\
(.040)\end{array}$ & $\begin{array}{c}0.249^{* * *} \\
(.047)\end{array}$ & $\begin{array}{c}0.307 * * * \\
(.034)\end{array}$ & $\begin{array}{c}0.348^{* * *} \\
(.034)\end{array}$ & $\begin{array}{c}0.359 * * * \\
(.033)\end{array}$ \\
\hline Ethnic Segmentation & & $\begin{array}{c}-0.911 * * \\
(.360)\end{array}$ & $\begin{array}{c}-0.802 * \\
(.404)\end{array}$ & $\begin{array}{c}-0.908^{* *} \\
(.368)\end{array}$ & $\begin{array}{c}-1.03 * * * \\
(.351)\end{array}$ & $\begin{array}{c}-0.824^{* *} \\
(.387)\end{array}$ & $\begin{array}{c}-0.786^{*} \\
(.396)\end{array}$ \\
\hline Population (ln) & & $\begin{array}{l}-0.015 \\
(.051)\end{array}$ & $\begin{array}{c}-0.024 \\
(.506)\end{array}$ & $\begin{array}{l}0.037 \\
(.058)\end{array}$ & $\begin{array}{l}0.018 \\
(.046)\end{array}$ & $\begin{array}{l}0.060 \\
(.056)\end{array}$ & $\begin{array}{l}0.057 \\
(.054)\end{array}$ \\
\hline French LO & & & $\begin{array}{l}0.275 \\
(.233)\end{array}$ & & & & \\
\hline German LO & & & $\begin{array}{l}0.100 \\
(.224)\end{array}$ & & & & \\
\hline Scandinavian LO & & & $\begin{array}{l}0.007 \\
(.367)\end{array}$ & & & & \\
\hline Political Institutions & & & & $\begin{array}{c}0.0377 \\
(.029)\end{array}$ & & & \\
\hline Observations & 106 & 93 & 93 & 89 & 61 & 56 & 56 \\
\hline $\mathrm{R}^{2}$ & 0.218 & 0.642 & 0.651 & 0.653 & 0.692 & 0.782 & 0.782 \\
\hline
\end{tabular}

Notes: The dependent variable is income per capita (In), averaged over the years 1980-2009, taken from the Penn World Tables. Generalized Trust is calculated from answers to the question "Generally speaking, would you say that most people can be trusted, or that you need to be very careful in dealing with people?". Trust is equal to 1 if the respondent answers "Most people can be trusted" and 0 otherwise. Average trust in family, neighbors, and people you know, is calculated from the question "Could you tell me for each whether you trust people from this group completely, somewhat, not very much or not at all?" and the variable takes on the value 4, if the respondent answers "Trust completely", 3 for "Somewhat", 2 for "Not very much" and 1 for "No trust at all". Sources: The trust data comes from the five waves of the World Values Survey (1981-2008), the four waves of the European Values Survey (1981-2008) and the third wave of the Afrobarometer (2005). Education measures average years of schooling between 1950 and 2010 and is taken from Barro and Lee (2010). Ethnic fractionalization measures the degree of ethnic fractionalization and is taken from Alesina et al. (2003). Population is the average population (ln) between 1980 and 2009, taken from the Penn World Tables 7.0. Legal Origins are taken from La Porta et al. (2007). Political Institutions are measured by the Polity 2 index averaged over 2000-2010, taken from the Polity IV database. OLS regressions with robust standard errors in parentheses. Coefficients are statistically different from 0 at the $* * * 1 \%, * * 5 \%$ and $* 10 \%$ level. 
Table 4 : Trust and Regional GDP per capita

\begin{tabular}{|c|c|c|c|c|c|c|}
\hline & \multicolumn{6}{|c|}{ Ln GDP per capita } \\
\hline & \multicolumn{2}{|c|}{ Full Sample } & \multicolumn{2}{|c|}{$\mathbf{E U}$} & \multicolumn{2}{|c|}{ OECD } \\
\hline & (1) & (2) & (3) & (4) & (5) & (6) \\
\hline \multirow[t]{2}{*}{ Trust } & $1.134^{* *}$ & 0.313 & $1.345^{* * *}$ & 0.616 & $1.180^{* * *}$ & 0.867 \\
\hline & $(0.497)$ & $(0.211)$ & $(0.369)$ & $(0.719)$ & $(0.341)$ & $(0.625)$ \\
\hline \multirow[t]{2}{*}{ Education } & $0.306^{* * *}$ & $0.342 * * *$ & $0.113^{* *}$ & $0.327 * * *$ & $0.080^{* *}$ & $0.277 * *$ \\
\hline & $(0.030)$ & $(0.031)$ & $(0.053)$ & $(0.106)$ & $(0.033)$ & $(0.110)$ \\
\hline Country FE & No & Yes & No & Yes & No & Yes \\
\hline Observations & 771 & 771 & 278 & 278 & 350 & 350 \\
\hline $\mathrm{R}^{2}$ & 0.603 & 0.964 & 0.321 & 0.834 & 0.298 & 0.755 \\
\hline
\end{tabular}

Notes: The dependent variable is In GDP per capita, which measures the log of regional income per capita, taken from Gennaioli et al. (2012).

Trust is calculated from answers to the question "Generally speaking, would you say that most people can be trusted or that you need to be very careful in dealing with people?" Trust is equal to 1 if the respondent answers "Most people can be trusted" and 0 otherwise.

Sources: The trust data comes from the five waves of the World Values Survey (1981-2008), the four waves of the European Values Survey (1981-2008), and all waves of the US GSS (1973-2006). Education measures the average years of schooling.

Sample: Columns (1) and (2) uses the full sample of regions, as in Gennaioli et al. (2012). Columns (3) and (4) restrict the sample to regions belonging to a country being member of the EU27 (including Norway, but excluding Malta, Cyprus and Luxembourg). Columns (5) and (6) restrict the sample to regions belonging to a country being member of the OECD.

OLS regressions with robust standard errors, clustered at the country level, in parentheses. All regressions are weighted by the number of individuals polled in each region. Coefficients are statistically different from 0 at the *** $1 \%$, ** $5 \%$ and $* 10 \%$ level. 
Table 5 : Trust and Growth: Cross-Country Correlation

\begin{tabular}{|c|c|c|c|}
\hline & \multicolumn{2}{|c|}{ Growth 1990-2009 } & \multirow[b]{2}{*}{ (3) } \\
\hline & (1) & (2) & \\
\hline \multirow[t]{2}{*}{ Trust 1980-1990 } & $0.0396^{*}$ & $0.0273^{* *}$ & $0.480 * * *$ \\
\hline & $(0.021)$ & $(0.010)$ & $(0.078)$ \\
\hline \multirow[t]{2}{*}{ Income p.c. 1990} & $-0.014 * * *$ & $-0.012 * * *$ & 0.002 \\
\hline & $(0.003)$ & $(0.002)$ & $(0.002)$ \\
\hline \multirow[t]{2}{*}{ Education 1990} & $0.002 * *$ & $0.001 *$ & $0.002^{* * *}$ \\
\hline & $(0.001)$ & $(0.001)$ & $(0.001)$ \\
\hline \multirow[t]{2}{*}{ Investment } & & $0.001 * * *$ & \\
\hline & & $(0.000)$ & \\
\hline \multirow[t]{2}{*}{ Trust x Income p.c. 1990} & & & $-0.048^{* * *}$ \\
\hline & & & $(0.008)$ \\
\hline Observations & 52 & 52 & 52 \\
\hline $\mathrm{R}^{2}$ & 0.491 & 0.658 & 0.706 \\
\hline
\end{tabular}

Notes: The dependent variable measures average GDP per capita growth between 1990-2009, computed from Penn World Tables 7.0.

Trust is calculated from answers to the question "Generally speaking, would you say that most people can be trusted or that you need to be very careful in dealing with people?" Trust is equal to 1 if the respondent answers "Most people can be trusted" and 0 otherwise.

Sources: The trust data comes from the waves 1-3 of the World Values Survey (1981-1995). Additional Controls: Income p.c. 1990 measures income per capita in 1990 (ln), Penn World Tables 7.0. Education 1990 measures average years of schooling in 1990, taken from Barro and Lee (2010).

OLS regressions with robust standard errors in parentheses. Coefficients are statistically different from 0 at the *** $1 \%$, ** $5 \%$ and $* 10 \%$ level. 
Table 6: Trust and Institutions

a) Cross-Country Correlation

\begin{tabular}{lcccc}
\hline & Quality of Legal System & Rule of Law & Property Rights & $\begin{array}{c}\text { Enforcement of } \\
\text { Contracts }\end{array}$ \\
& $(\mathbf{1})$ & $\mathbf{( 2 )}$ & $\mathbf{( 3 )}$ & $\mathbf{( 4 )}$ \\
Trust & $3.942^{* * *}$ & $1.271^{* *}$ & $1.604^{* * *}$ & $2.864^{* * *}$ \\
& $(0.719)$ & $(0.484)$ & $(0.602)$ & $(0.674)$ \\
Income per Capita & $0.646^{* * *}$ & $0.420^{* * *}$ & $0.531^{* * *}$ & $0.930^{* * *}$ \\
& $(0.126)$ & $(0.0891)$ & $(0.101)$ & $(0.250)$ \\
Population & $-0.167 * * *$ & $-0.109 * * *$ & $-0.195 * * *$ & -0.0284 \\
Education & $(0.055)$ & $(0.035)$ & $(0.050)$ & $(0.092)$ \\
& 0.0146 & 0.0558 & 0.0120 & $0.178^{* *}$ \\
Ethnic segmentation & $(0.053)$ & $(0.047)$ & $(0.052)$ & $(0.087)$ \\
& 0.152 & -0.242 & 0.0572 & $1.614^{* * *}$ \\
$\mathrm{R}^{2}$ & $(0.440)$ & $(0.251)$ & $(0.377)$ & $(0.535)$ \\
\hline
\end{tabular}

Notes: Dependent variables: (1) Quality of Legal System measures the overall quality of the legal system, taken from Economic Freedom of the World Index, 2007. (2) Rule of Law gives the average rule of law between 1996-2010, taken from Kaufman et al. (2010). (3) Property Rights are a measure of property rights taken from the Heritage Foundation, 2 004. (4) Enforcement measures enforceability of contracts, taken from Djankov et al. (2003).

Trust is measured from the answer to the question "Generally speaking, would you say that most people can be trusted or that you need to be very careful in dealing with people?" Trust is equal to 1 if the respondent answers "Most people can be trusted" and 0 otherwise.

Sources: The trust data comes from the five wave of the World Values Survey (1981-2008), the four waves of the European Values Survey (1981-2008) and the third wave of the Afrobarometer (2005). Additional Controls: Investment Share measures Investment \% of GDP 1980-2009, Penn World Tables 7.0. Income per capita measures GDP per capita (ln), const. prices, averaged for the years 1980-2009, taken from the Penn World Tables 7.0. Population measures population (ln), averaged between 1980-2009, Penn World Tables 7.0

OLS regressions with robust standard errors in parentheses. Coefficients are statistically different from 0 at the $* * *$ $1 \%, * * 5 \%$ and $* 10 \%$ level. 
b) Cross-Regional Correlation

\begin{tabular}{lccccc}
\hline & Quality of Governance & Quality of Governance & Rule of Law & Effectivity & Accountability \\
& $(\mathbf{1})$ & $\mathbf{( 2 )}$ & $\mathbf{( 3 )}$ & $\mathbf{( 4 )}$ & $\mathbf{( 5 )}$ \\
\hline \multirow{3}{*}{ Trust } & & & & & \\
& $4.376^{* * *}$ & $1.291^{* *}$ & $3.285^{* * *}$ & $5.423^{* * *}$ & $2.463^{*}$ \\
Population & $(0.924)$ & $(0.559)$ & $(0.736)$ & $(1.356)$ & $(1.222)$ \\
& & $-0.263^{*}$ & 0.05 & -0.253 & -0.160 \\
Ln GDP p.c. & $(0.147)$ & $(0.120)$ & $(0.270)$ & $(0.103)$ \\
& & $0.932^{* * *}$ & $0.487^{* *}$ & 0.684 & $1.039^{* * *}$ \\
Education & $(0.191)$ & $(0.222)$ & $(0.583)$ & $(0.220)$ \\
& & 0.03 & $-0.029^{* *}$ & 0.0246 & -0.0127 \\
Autonomous & $(0.027)$ & $(0.011)$ & $(0.043)$ & $(0.021)$ \\
& & -0.267 & $0.275^{* *}$ & 0.0685 & $0.477 * * *$ \\
Bilingual & $(0.164)$ & $(0.105)$ & $(0.334)$ & $(0.147)$ \\
& & -0.0513 & 0.0791 & $1.207 * *$ & -0.32 \\
Area & $(0.198)$ & $(0.199)$ & $(0.556)$ & $(0.184)$ \\
& & $-0.216 * *$ & 0.0351 & 0.134 & 0.227 \\
& & $(0.087)$ & $(0.073)$ & $(0.187)$ & $(0.131)$ \\
Observations & 163 & & & & \\
$\mathrm{R}^{2}$ & 0.342 & 163 & 163 & 163 & 163 \\
\hline
\end{tabular}

Notes: Dependent variables: Columns (1) and (2): Quality of Governance index measures the overall quality of regional institutions, taken from the Quality of Governance Institute, 2010. (3) Rule of Law measures the quality of the rule of law, taken from the Quality of Governance Institute, 2010. (4) Effectivity measures the governance effectivity, taken from the Quality of Governance Institute, 2010. 4) Accountability measures the quality of media and elections, taken from the Quality of Governance Institute, 2010.

Trust is measured from the answer to the question "Generally speaking, would you say that most people can be trusted or that you need to be very careful in dealing with people?" Trust is equal to 1 if the respondent answers "Most people can be trusted" and 0 otherwise.

Sources: The trust data is taken from the four waves of the European Values Survey (1981-2008. Population measures the $\log$ of the average number of inhabitants 2007 to 2009 per region, taken from Eurostat. GDP p.c. gives the log of the regional average GDP per capita between 2007 and 2009, taken from Eurostat. Education gives the percentage of population with some type of tertiary degree in 2006, taken from Eurostat. Bilingual equals to 1 if more than one official languages exists in the region. Autonomous equals 1 if the region is an autonomous region. Logarea gives the log value of the region's area.

OLS regressions with robust standard errors, clustered at the country level, in parentheses. Coefficients are statistically different from 0 at the $* * * 1 \%, * * 5 \%$ and $* 10 \%$ level. 
Table 7: Trust and Inequality

\begin{tabular}{|c|c|c|c|c|}
\hline & \multicolumn{4}{|c|}{ Inequality } \\
\hline & \multicolumn{2}{|c|}{ Cross Country } & \multicolumn{2}{|c|}{ US States } \\
\hline & (1) & $(2)$ & (3) & (4) \\
\hline \multirow[t]{2}{*}{ Trust } & $-24.96 * * *$ & $-12.63^{*}$ & $-0.093^{* * *}$ & $-0.064 * * *$ \\
\hline & $(5.600)$ & $(7.451)$ & $(0.017)$ & $(0.016)$ \\
\hline \multirow[t]{2}{*}{ Income per capita } & & 0.0954 & & -0.01 \\
\hline & & $(1.240)$ & & $(0.022)$ \\
\hline \multirow[t]{2}{*}{ Population } & & 0.324 & & $0.007 * * *$ \\
\hline & & $(0.791)$ & & $(0.002)$ \\
\hline \multirow[t]{2}{*}{ Education } & & $-1.116^{* *}$ & & 0.002 \\
\hline & & $(0.542)$ & & $(0.001)$ \\
\hline \multirow[t]{2}{*}{ Ethnic segmentation } & & 7.385 & & \\
\hline & & $(5.003)$ & & \\
\hline \multirow[t]{2}{*}{ Latitude } & & & & $-0.0004^{*}$ \\
\hline & & & & $(0.0002)$ \\
\hline \multirow[t]{2}{*}{ Longitude } & & & & $0.0002^{* *}$ \\
\hline & & & & $(0.0001)$ \\
\hline Observations & 101 & 89 & 46 & 46 \\
\hline $\mathrm{R}^{2}$ & 0.122 & 0.276 & 0.314 & 0.680 \\
\hline
\end{tabular}

Notes: The dependent variable Inequality measures income inequality as given by the Gini Index.

Trust is measured from the answer to the question "Generally speaking, would you say that most people can be trusted or that you need to be very careful in dealing with people?" Trust is equal to 1 if the respondent answers "Most people can be trusted" and 0 otherwise.

Sources: Trust data used in regressions in columns (1) and (2) comes from the five waves of the World Values Survey (1981-2008), and the four waves of the European Values Survey (1981-2008), for regressions in columns (3) and (4) from the US GSS (1973-2006). Income per capita measures the regions average log income per capita. Population gives the log of the total population living in the region. Education in column (2) measures average years of schooling between 1950 and 2010 and is taken from Barro and Lee (2010), in column (4) the fraction of population having an advanced degree. Ethnic fractionalization measures the degree of ethnic fractionalization and is taken from Alesina et al. (2003). Latitude and longitude refer to the region's geographic position.

OLS regressions with robust standard errors in parentheses. Coefficients are statistically different from 0 at the $* * *$ $1 \%$, ** $5 \%$ and $* 10 \%$ level. 


\section{DATA SAMPLES}

Sample Table 2 (79 countries): Albania, Algeria, Argentina, Armenia, Austria, Azerbaijan, Bangladesh, Belarus, Belgium, Bosnia and Herzegovina, Bulgaria, Canada, Chile, China, Croatia, Cyprus, Czech Republic, Denmark, Egypt, Estonia, Finland, France, Georgia, Germany, Great Britain, Greece, Hungary, Iceland, India, Indonesia, Iran, Iraq, Ireland, Israel, Italy, Japan, Jordan, Kosovo, Kyrgysstan, Latvia, Lithuania, Luxembourg, Macedonia, Malta, Mexico, Moldova, Montenegro, Morocco, Netherlands, Nigeria, Northern Cyprus, Northern Ireland, Norway, Pakistan, Peru, Philippines, Poland, Portugal, Puerto Rico, Romania, Russian Federation, Saudi Arabia, Serbia, Singapore, Slovakia, Slovenia, South Africa, South Korea, Spain, Sweden, Switzerland, Tanzania, Turkey, Uganda, Ukraine, United States, Venęuela, Vietnam, Zimbabwe.

Sample Table 3 (106 countries): Albania, Algeria, Argentina, Armenia, Australia, Austria, Azerbaijan, Bangladesh, Belarus, Belgium, Benin, Bosnia and Herzegovina, Botswana, Brazil, Bulgaria, Burkina Faso, Canada, Cape Verde, Chile, China, Colombia, Croatia, Cyprus, Czech Republic, Denmark, Dominican Republic, Egypt, El Salvador, Estonia, Ethiopia, Finland, France, Georgia, Germany, Ghana, Great Britain, Greece, Guatemala, Hong Kong, Hungary, Iceland, India, Indonesia, Iran, Iraq, Ireland, Israel, Italy, Japan, Jordan, Kenya, Kyrgyzstan, Latvia, Lesotho, Liberia, Lithuania, Luxembourg, Macedonia, Madagascar, Malawi, Malaysia, Mali, Malta, Mexico, Moldova, Montenegro, Morocco, Mozambique, Namibia, Netherlands, New Zealand, Nigeria, Norway, Pakistan, Peru, Pbilippines, Poland, Portugal, Puerto Rico, Romania, Russian Federation, Rwanda, Saudi Arabia, Senegal, Serbia, Singapore, Slovakia, Slovenia, South Africa, South Korea, Spain, Sweden, Switzerland, Taiwan, Tanzania, Thailand, Trinidad and Tobago, Turkey, Uganda, Ukraine, United States, Uruguay, Venezuela, Vietnam, Zambia, Zimbabwe.

Sample Table 5 (52 countries): Albania, Argentina, Australia, Austria, Bangladesh, Belgium, Brazil, Bulgaria, Canada, Chile, China, Colombia, Croatia, Czech Republic, Denmark, Dominican Republic, El Salvador, Estonia, Finland, France, Germany, Great Britain, Hungary, Iceland, India, Ireland, Italy, Japan, Malta, Mexico, Netherlands, New Zealand, Norway, Pakistan, Peru, Philippines, Poland, Portugal, Romania, Russian Federation, Slovakia, Slovenia, South Africa, South Korea, Spain, Sweden, Switzerland, Taiwan, Turkey, United States, Uruguay, Venezuela.

Sample Table 6a (93 countries): Albania, Algeria, Argentina, Australia, Austria, Bangladesh, Belgium, Benin, Botswana, Brazil, Bulgaria, Canada, Chile, China, Colombia, Croatia, Cyprus, Czzech Republic, Denmark, Dominican Republic, Egypt, El Salvador, Estonia, Finland, France, Germany, Ghana, Great Britain, Greece, Guatemala, Hong Kong, Iceland, India, Indonesia, Iran, Iraq, Ireland, Israel, Italy, Japan, Jordan, Kenya, Kyrgyzstan, Latvia, Lesotho, Liberia, Lithuania, Luxembourg, Malawi, Malaysia, Mali, Malta, Mexico, Moldova, Morocco, Mozambique, Namibia, Netherlands, New Zealand, Norway, Pakistan, Peru, Philippines, Poland, Portugal, Romania, Russian Federation, Rwanda, Saudi Arabia, Senegal, Singapore, Slovakia, Slovenia, South Africa, South Korea, Spain, Sweden, Switzerland, Taiwan, Tanzania, Thailand, Trinidad and Tobago, Turkey, Uganda, Ukraine, United States, Uruguay, Venezuela, Vietnam, Zambia, Zimbabwe.

Sample Table 6b (163 regions): 163 European regions in the following countries: Austria, Belgium, Bulgaria, Crech Republic, Denmark, France, Germany, Greece, Hungary, Italy, Netherlands, Poland, Portugal, Romania, Slovakia, Spain, Sweden, United Kingdom.

Sample Table 7 (101 countries): Albania, Algeria, Argentina, Armenia, Australia, Austria, Azerbaijan, Bangladesh, Belarus, Belgium, Benin, Bosnia and Herzegovina, Botswana, Brazil, Bulgaria, Burkina Faso, Canada, Chile, China, Colombia, Croatia, Cyprus, Czech Republic, Denmark, Dominican Republic, Egypt, El Salvador, Estonia, Ethiopia, Finland, France, Georgia, Germany, Ghana, Great Britain, Greece, Guatemala, Hong Kong, Hungary, Iceland, India, Indonesia, Iran, Ireland, Israel, Italy, Japan, Jordan, Kenya, Korea, South, Kosovo, Kyrgyzstan, Latvia, Lesotho, Lithuania, Luxembourg, Macedonia, Madagascar, Malawi, Malaysia, Mali, Malta, Mexico, Moldova, Montenegro, Morocco, Mozambique, Namibia, Netherlands, New Zealand, Nigeria, Norway, Pakistan, Peru, Pbilippines, Poland, Portugal, Romania, Russian Federation, Rwanda, Senegal, Serbia, Singapore, Slovakia, Slovenia, South Africa, Spain, Sweden, Switzerland, Taiwan, Tanzania, Thailand, Turkey, Uganda, Ukraine, United States, Uruguay, Venezuela, Vietnam, Zambia, Zimbabwe. 